by

Aleksandra Usyatynsky, Bachelor of Science (Honours), Queen's University, 2016

\author{
A thesis \\ presented to Ryerson University \\ in partial fulfillment of the \\ requirements for the degree of \\ Master of Arts \\ in the program of \\ Psychology
}

Toronto, Ontario, Canada, 2018

(C) Aleksandra Usyatynsky, 2018 


\section{ROLE OF COGNITIVE BIAS IN EMOTION REGULATION}

\section{AUTHOR'S DECLARATION FOR ELECTRONIC SUBMISSION OF A THESIS}

I hereby declare that I am the sole author of this thesis. This is a true copy of the thesis, including any required final revisions, as accepted by my examiners.

I authorize Ryerson University to lend this thesis to other institutions or individuals for the purpose of scholarly research.

I further authorize Ryerson University to reproduce this thesis by photocopying or by other means, in total or in part, at the request of other institutions or individuals for the purpose of scholarly research.

I understand that my thesis may be made electronically available to the public. 


\title{
ROLE OF COGNITIVE BIAS IN EMOTION REGULATION
}

\section{Examining the Role of Cognitive Bias in Emotion Regulation}

Master of Arts, 2018

Aleksandra Usyatynsky

Psychology

Ryerson University

\begin{abstract}
Individuals experiencing depressive symptoms interpret ambiguous situations negatively and use helpful emotion regulation strategies less often than those without symptoms. Theory suggests these strategies are used less due to interference from negatively biased interpretations. This study examined whether interpretation bias interferes with emotion regulation by experimentally manipulating interpretations in a positive or negative direction. Method: Undergraduate students were randomly assigned to positive and negative bias training groups. Interpretation bias and emotion regulation questionnaires were completed before and after training. Results: The training succeeded in inducing bias change only for the positive group, and emotion regulation strategy use did not change in either group. Discussion: Interpretation bias was not found to affect emotion regulation. Possible explanations include: bias change in the positive group was not large enough to alter emotion regulation; the task eliciting emotion regulation was ill-suited for this study; and interpretation bias and emotion regulation are unrelated.
\end{abstract}




\section{ROLE OF COGNITIVE BIAS IN EMOTION REGULATION}

\section{Acknowledgements}

First and foremost, I would like express my deepest gratitude to my graduate supervisor, Dr. Colleen Carney, who I have the utmost respect for as a clinician, researcher, and most of all mentor. Her passion for research and continued support since our very first meeting has cultivated my confidence and allowed me to grow immeasurably. She has always been a fierce advocate for me, allowed me to develop my own ideas, and encouraged me when I made mistakes so that I could correct them and truly learn. Her tutelage has taken both my writing and research abilities to a level I am proud of. I am happy to continue building upon these skills in the years to come under her guidance. I do not have the words to fully express the positive impact she has had on my life.

I would like to thank my committee members, Dr. Naomi Koerner and Dr. Janice Kuo, for taking the time to evaluate my work. Dr. Koerner's ongoing direction and thoughtful feedback has elevated the quality of my thesis and ensured I produced my absolute best product.

Thank you to the members of the Sleep and Depression Lab, including Kristin Maich and Olya Bogouslavsky, for sharing their experience and their willingness to help. Further, thank you to David Sumantry for his guidance on statistical analyses. Finally, it was with the help of research assistants Scarlett Lavan and Tristan D'Cruz that I was able to complete my research in a timely manner.

I also thank Dr. Simon Blackwell of the Department of Psychology at Ruhr-Universität Bochum for generously allowing me to use his materials, which are central to this research. I gratefully acknowledge financial support from the Social Sciences and Humanities Research Council (SSHRC) of Canada, the Ontario Graduate Scholarship (OGS) program, and the Yeates School of Graduate Studies (YSGS) at Ryerson University. 


\section{ROLE OF COGNITIVE BIAS IN EMOTION REGULATION}

Finally, I must express my profound gratitude to my parents, for encouraging me to pursue academia and reveling in my accomplishments; my best friend, Rachel Chan, for always pushing me to be better and taking the time to read over my work even when spending 13 hour

days at the law library; my partner, for his unfailing support and patience even when I promised to spend time together and then proceeded to edit my thesis for several hours; and my cohort, Katie Stewart, Ari Lenton-Brym, Arielle Dryer, Shira Segal, Bev Fredborg, Iris Sjercic, Tori Ingram, and Vincent Santiago, for being more supportive than I could ever have hoped for. This endeavour would not have been possible without you. Thank you. 


\section{Table of Contents}

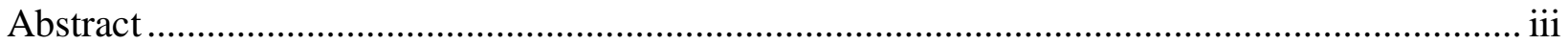

List of Tables ................................................................................................................. viii

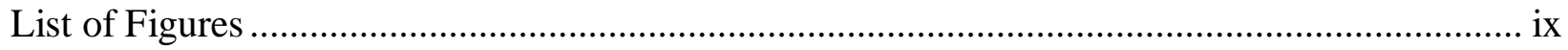

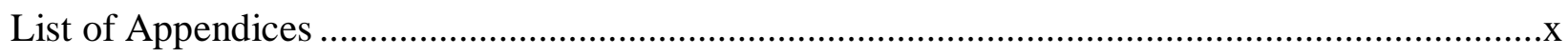

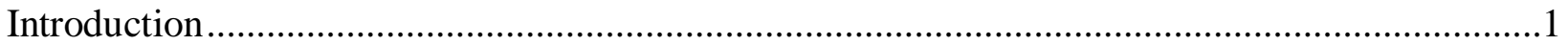

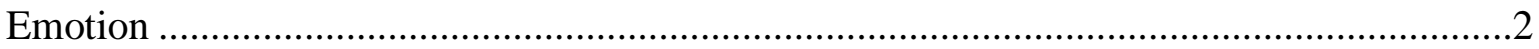

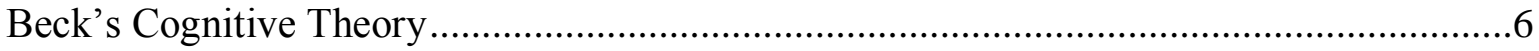

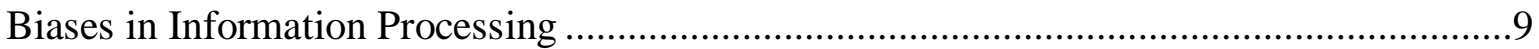

Integrating Interpretation Bias and Emotion Regulation Strategies ................................14

The Current Study ........................................................................................... 18

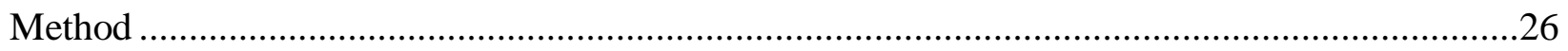

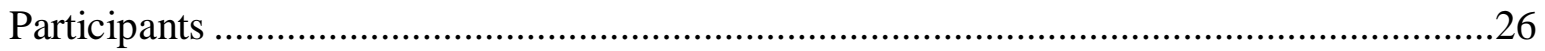

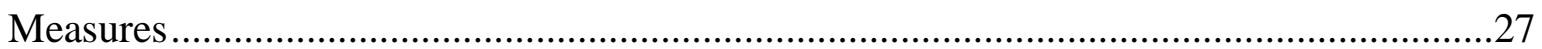

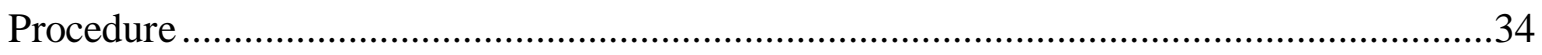

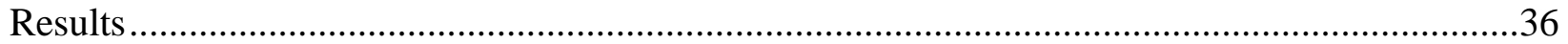

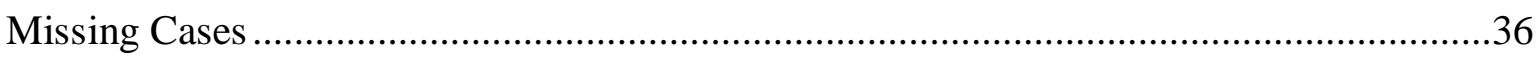

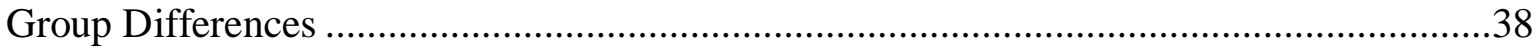

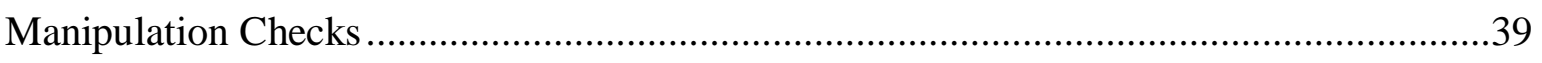

Psychometric Properties of AST-D and SERQ-M ..............................................48

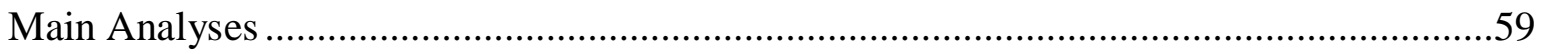

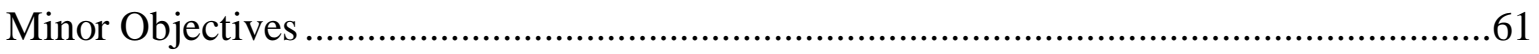

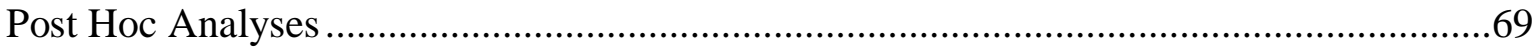




\section{ROLE OF COGNITIVE BIAS IN EMOTION REGULATION}

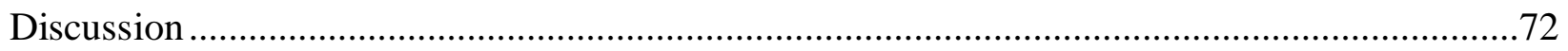

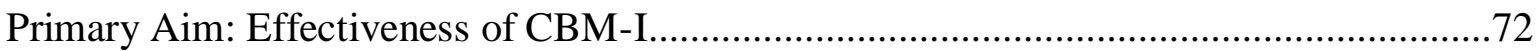

Secondary Aims: Mediation and Moderation Effects ..................................................76

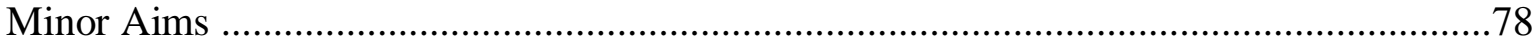

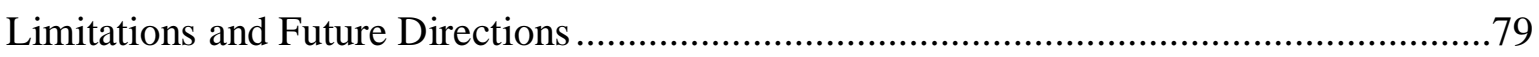

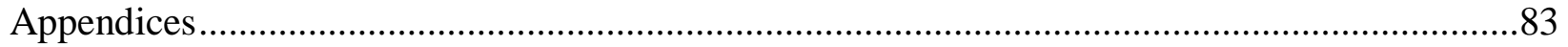

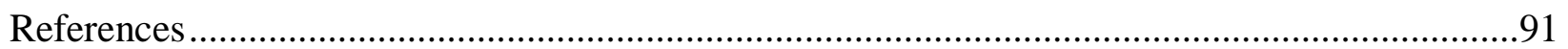


ROLE OF COGNITIVE BIAS IN EMOTION REGULATION

\section{List of Tables}

Table 1. Pretraining group differences.............................................................................40

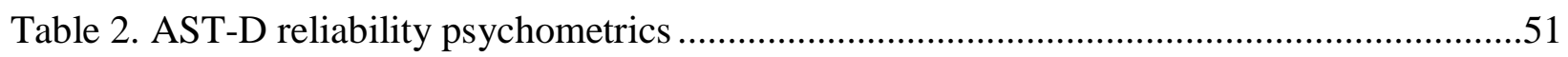

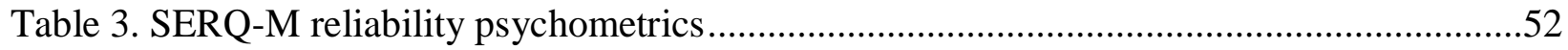

Table 4. Correlations between SERQ and SDERS subscales .............................................53

Table 5. Correlations between AST-D and other measures....................................................54

Table 6. Results of moderated mediation model for reappraisal change ..................................62

Table 7. Results of moderated mediation model for rumination change .................................63

Table 8. Results of moderated mediation model for interpretation bias change........................67 


\section{ROLE OF COGNITIVE BIAS IN EMOTION REGULATION}

\section{List of Figures}

Figure 1. Group by time interaction for interpretation bias

Figure 2. Moderation of relationship between group and interpretation bias change by depressive symptoms

Figure 3. Moderation of relationship between group and reappraisal change by depressive symptoms .23

Figure 4. Moderation of relationship between group and rumination change by depressive

symptoms

Figure 5. Moderation of relationship between group and suppression change by depressive

symptoms

Figure 6. Outline of procedure design

Figure 7. First emotion induction.

Figure 8. Second emotion induction

Figure 9. Emotion change throughout CBM-I training

Figure 10. Structural equation model for AST-D form A ..............................................56

Figure 11. Structural equation model for AST-D form B .................................................57

Figure 12. Structural equation model for SERQ pretraining ............................................58

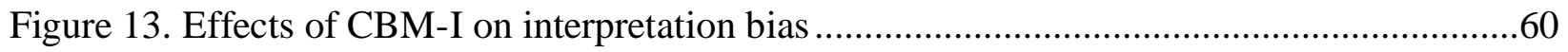

Figure 14. Example moderated mediation model ..........................................................64

Figure 15. Moderated mediation model for suppression ................................................65

Figure 16. Moderating effect of attentional control on interpretation bias change .....................68

Figure 17. Moderated regression model for interpretation bias change and ACS .....................70

Figure 18. Moderated regression model for interpretation bias change and attentional shifting...71 


\section{ROLE OF COGNITIVE BIAS IN EMOTION REGULATION}

\section{List of Appendices}

Appendix A. Attentional Control Scale

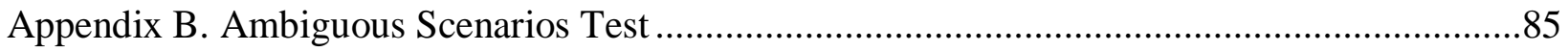

Appendix C. State Emotion Regulation Questionnaire ....................................................8

Appendix D. Manipulation Check Questionnaire ............................................................89 


\section{ROLE OF COGNITIVE BIAS IN EMOTION REGULATION}

\section{Examining the Role of Cognitive Bias in Emotion Regulation}

Emotion is a quintessential human experience, although it can be difficult to define.

Emotions are reactions to interactions between an individual and their environment based on how the situation is interpreted. There are changes seen in three different domains: 1) the subjective experience of feelings such as anger or happiness, 2) physiological changes in the body, and 3) behavioural reactions (Mauss, Levenson, McCarter, Wilhelm, \& Gross, 2005). The changes in these domains in response to some event is termed emotion generation (Gross, 2010). However, the initial response that arises may not be the reaction one wishes to experience or display, making the ability to regulate emotions integral to everyday functioning. Emotion regulation is the process of altering the magnitude or trajectory of an initial physiological, experiential, or behavioural emotional response (Gross, 2010). This encompasses everything from breathing deeply to calm a racing heart before a first date, deciding a test was not important to negate disappointment about a bad grade, or suppressing disgust to spare someone's feelings. While all people engage in these processes, those experiencing depressive symptoms can find it particularly difficult to regulate emotions when faced with a stressor.

The presence of depressive symptoms is associated with difficulties in both emotion generation and emotion regulation. Research shows that depressed mood is initiated and maintained in part by interacting biases in information processing (Joormann \& Stanton, 2016). These biases include difficulty disengaging attention from negative stimuli, selective memory for negative material, and a habitual tendency to interpret ambiguous situations in a negative manner. Such difficulties are considered biases because they describe the preferential processing of negative material, lead to negative emotion generation, and perpetuate a more pervasive low mood and symptoms of depression (Gotlib \& Joormann, 2010; Joormann \& Siemer, 2011). 


\section{ROLE OF COGNITIVE BIAS IN EMOTION REGULATION}

Moreover, these biases are seen transdiagnostically in a spectrum of individuals with mood problems. These difficulties are found in people with dysphoria, subclinical depressive symptoms accompanied by a persistent low mood, but also in individuals with anxiety disorders and major depressive disorder (Joormann \& Stanton, 2016). Individuals experiencing depressive symptoms also show differing habitual patterns of emotion regulation strategy use in comparison to healthy individuals, as individuals with depressed mood are more likely to use unhelpful strategies (Joormann \& Stanton, 2016). Given that dysphoria is associated with both negative emotion generation and difficulties regulating emotions, it has been hypothesized that biases in attention, memory, and interpretation may interfere with use of certain regulation strategies (Joormann \& Stanton, 2016). It is possible that cognitive biases that lead to negative interpretations of situations are automatic, thus making it difficult for dysphoric individuals to use certain emotion regulation strategies to alter their resulting negative emotions (Joormann \& Siemer, 2011). However, whether the presence of a negatively biased interpretation style interferes with the use of certain emotion regulation strategies has not been tested directly. The current study examines whether a negative bias in the appraisal of ambiguous situations interferes with the use of specific emotion regulation strategies, and whether depressive symptoms moderate this relationship. Relevant theories of emotion and cognition are reviewed, followed by an integration of these key models; finally, the current study to test the integrative model is described.

\section{Emotion}

The emotion-focused literature is vast and terms such as emotions, feelings, affect, and mood are often used interchangeably. However, the distinction between the concepts of emotion and mood is critical to the present study. For the purposes of this paper emotion is a short term 


\section{ROLE OF COGNITIVE BIAS IN EMOTION REGULATION}

reaction (e.g. sadness, anger, happiness); the experience of an emotion is a temporary state of being, dependent on the situation. Conversely, mood refers to a more pervasive (i.e., lasting hours to days), less specific feeling that is generally positive or negative (Hume, 2008).

Emotions can arise from interactions between an individual and their environment; however, individuals react to situations differently as a result of the meanings they assign to the situation based on a variety of factors, including past experiences, culture, and their current mood (Scherer, Shorr, \& Johnstone, 2001). Lazarus (1966) posited that a cognitive appraisal of a situation is made before an emotion occurs, which determines whether the situation is significant enough to warrant an emotional response and whether the evoked emotion is negative or positive (Power \& Dalgleish, 2016). The question of whether emotions or cognitions come first has been debated by theorists like Lazarus and Zajonc over the last century (Power \& Dalgleish, 2016). Despite the ongoing debate, it is generally accepted that: 1) cognitive appraisals of situations are a part of the emotion generation process as mechanisms that determine which emotions will be generated (e.g. anger or sadness) and how mild or strong the response will be; and 2) emotion generation is an ongoing process whereby generated emotions feedback to influence new appraisals (Power \& Dalgleish, 2016).

Gross' modal model of emotion (Gross \& Thompson, 2007) brings together key aspects of emotion theories, including appraisal theory, in a comprehensive outline of the emotional process. The model proposes that the emotion generation process involves a situation, attention, appraisal, and a response. An individual must first attend to a situation and then appraise it for personal meaning. Based on the appraisal, there is a subjective experiential, behavioural, and/or physiological emotional response (Gross, 2010). In this way, Gross highlights that emotion involves attention, has multiple domains of responding, and is malleable to allow for emotion 


\section{ROLE OF COGNITIVE BIAS IN EMOTION REGULATION}

regulation (Gross, 2010). This conceptualization of emotion generation is key to understanding emotion regulation and the role that certain regulation strategies play in those with depressive symptoms.

\section{Emotion Regulation and Depressive Symptoms}

As stated, a characteristic feature of dysphoria is difficulty with emotion regulation. Based on his modal model of emotion, Gross (2010) suggests that emotion regulation strategies consist of: 1) antecedent-focused strategies which occur before appraisals are made that give rise to a full emotional response, and 2) response-focused strategies which occur after the experiential, behavioural, and physiological responses are generated. According to Gross's process model of emotion regulation, there are strategies that can be used at each stage of the model. The first strategy that can help an individual manage their emotions is situation selection. Simply put, if a situation in the environment is not encountered, then there is no precipitant to elicit an emotional response. Once an individual is presented with a situation, then situation modification can be implemented, whereby the situation itself can be altered. Attentional deployment is the process of redirecting attention to certain aspects of the situation. Distraction and concentration are both forms of attentional deployment. In distraction, attention is willfully drawn away from an emotional component of the situation or towards another stimulus. In contrast, concentration draws attention towards emotional features of a situation (Gross \& Thompson, 2007). In more recent literature, Gross (2010) has termed this strategy rumination, which refers to the repetitive concentration toward internal feelings and consequences associated with an event. Cognitive change is employed at the time of the appraisal; it is the process of changing initial or automatic appraisals to alter the situation's significance before the emotional response has occurred (Gross, 2010). Reappraisal is a cognitive change strategy involving 


\section{ROLE OF COGNITIVE BIAS IN EMOTION REGULATION}

changing how one thinks about the situation itself or one's capacity to manage it. Richards and Gross (2000) hypothesized that reappraisal is the singular act of reconstructing one's perception of an event, akin to turning on a switch rather than an ongoing process. Finally, response modulation refers to attempts to alter a generated emotional response, and includes relaxation and expressive suppression. Relaxation is one strategy to down-regulate physiological sensations like a racing heart. Expressive suppression is the attempt to decrease expressive behaviours and to not show the emotions one is feeling (i.e., "putting on a brave face").

Reappraisal has been found to be an effective and adaptive way of down-regulating negative emotions, without depleting cognitive resources (Joormann \& D’Avanzato, 2010). Conversely, ruminating on negative events increases both intensity and duration of negative emotion (Nolen-Hoeksema, Wisco, \& Lyubomisky, 2008), and suppression is cognitively effortful (Richards \& Gross, 2000). In fact, rumination and suppression are consistently found to be ineffective in decreasing experiential and physiological emotional responses. When compared to reappraisal, rumination about a past anger-eliciting event led to both greater self-reported anger and greater sympathetic nervous system activation (Ray, Wilhelm, \& Gross, 2008). Likewise, in a study examining spontaneous emotion regulation strategy use-in which participants had several minutes to prepare and present a speech on an assigned topic- — while suppression was associated with less outwardly visible anxiety, it was associated with greater physiological responding and less memory for the details provided on the topic: all while having no beneficial impact on self-reported negative emotions (Egloff, Shcmukle, Burns, \& Schwedrtfeger, 2006).

Emotion regulation strategy research has found that certain strategies perpetuate depressed mood, and healthy individuals differ from those with depressive symptoms in their use 


\section{ROLE OF COGNITIVE BIAS IN EMOTION REGULATION}

of emotion regulation strategies. The habitual use of both suppression and rumination has been shown to maintain depression in the long term (Joormann \& D'Avanzato, 2010; NolenHoeksema et al., 2008). Furthermore, individuals with depression and dysphoria tend to use suppression and rumination more than reappraisal, more often than non-depressed individuals (Joormann \& Stanton, 2016). Interestingly, when instructed to use reappraisal participants who had depression in the past did not differ in their ability to do so from participants who had never had depression (Ehring, Tuschen-Caffier, Schnülle, Fischer, \& Gross, 2010); suggesting the issue may be using reappraisal less often, rather than an inability to reappraise. Taken together, this means individuals with depression habitually engage in unhelpful ways of dealing with emotions when faced with potentially emotionally-eliciting situations. The strategies people with depression tend to use perpetuate and worsen negative emotions, likely contributing to the overarching and persistent low mood characteristic of the disorder. Indeed, it is both the more frequent use of rumination and suppression combined with the less frequent use of reappraisal that have been associated with higher depressive symptoms (Joormann \& Stanton, 2016). Given that appraisals are a key component in both emotion generation and regulation, it is possible this emotion regulation difference between healthy and dysphoric individuals is related to the aforementioned biases in information processing also seen in those with depressive symptoms. The next sections will provide an overview of cognitive theories of depression and review evidence for specific information processing biases. Understanding these cognitive processes can help elucidate how information processing biases and emotion regulation may relate.

\section{Beck's Cognitive Theory of Depression}

Beck's cognitive theory of depression (1967) suggested that individuals who are depressed experience distorted cognitions. Beck (1963) was the first to suggest negative thinking 


\section{ROLE OF COGNITIVE BIAS IN EMOTION REGULATION}

precedes depression, rather than being a symptom. This early theory led to subsequent research to identify specific cognitive biases that lead to the development of depression. This section will outline three interacting mechanisms Beck believed to be responsible for the disorder, as it is the basis for the conceptualization of cognitive biases in information processing.

The first of these mechanisms is the cognitive triad (Beck, Rush, Shaw, \& Emery, 1979). The cognitive triad refers to set negative beliefs about the self, the world, and the future that have formed from early life experiences. These learned ways of viewing reality permeate every aspect of the individual's life, such that they expect to fail tasks in their immediate future and assume they will always face such hardships because they are worthless. Depressed mood is a consequence of the repeated activation of these negative thinking patterns and beliefs, as expecting negativity in one's life will create lasting feelings of hopelessness and sadness.

The second component of Beck's theory is the concept of schemas (Beck, 1964).

Schemas form over time based on ongoing experiences and are representations of prototypical situations in one's memory to help understand new situations. People form mental conceptualizations of situations, and schemas are the cognitive molds within which to fit incoming information (Beck et al., 1979). When an individual attends to details of a situation, an existing related schema is activated so that the new information may be understood based on already developed assumptions. The cognitive triad leads those with depression to form dysfunctional schemas that are consistent with their negative worldview. As such, incoming information about new situations becomes negatively distorted. The more these dysfunctional schemas are activated, the faster their activation becomes - eventually becoming automatic and interfering with activation of other appropriate schemas. 


\section{ROLE OF COGNITIVE BIAS IN EMOTION REGULATION}

The final piece of Beck's theory is cognitive errors, or faulty information processing (Beck et al., 1979). Such errors include response sets, or set ways of reacting to situations. An example is selective abstraction, or the conceptualization of situations based on attention to one detail without the context. These systematic errors in thinking, as a result of continued automatic activation of dysfunctional schemas, perpetuate the person's beliefs that their negative thoughts are valid despite evidence to suggest otherwise.

Thus, certain individuals are predisposed to develop depression when dysfunctional beliefs develop from early negative experiences and lead to the formation of dysfunctional assumptions about types of situations. Incoming information is then distorted and conceptualized in a way compatible with the negative worldview, and the negative worldview is maintained by the oversimplification and overgeneralization of cognitive errors (Beck et al., 1979). Whereas Beck's theory explains the negative cognitions that may cause the onset of low mood and lead to the development of depressive symptoms, it is not a theory of emotion and as such, augmentation via Gross’ perspective may provide a more contemporary understanding of cognitive-emotional processes in depression and dysphoria. Incorporating the modal model of emotion (Gross, 2010), the activation of negative schemas leads to negatively distorted appraisals of situations, thus causing the generation of negative emotions. Faulty information processing maintains this cycle through concentration, or what Beck would term rumination, on details of situations that confirm this negative thinking. When negative emotions are continually generated in this way, it leads to a more pervasive negative mood, and a depressive episode may result (Power \& Dalgleish, 2016). Beck's theory was the foundation for subsequent information-processing theories of depression. The ensuing research has led to the identification of three cognitive biases in 


\section{ROLE OF COGNITIVE BIAS IN EMOTION REGULATION}

memory, attention, and interpretation that act together to result in continued negative appraisals that maintain depressive symptoms and low mood.

\section{Biases in Information Processing}

Building on Beck’s 1967 cognitive conceptualization of depression, Williams and colleagues (1988) reviewed research on cognitive biases and deficits in depression within an information-processing paradigm: differentiating between low and high level cognitive processes (where low level processes operate automatically and higher level processes are elaborative and conscious). They identified attention, memory, and judgement biases as consistently accompanying mood disorders and argued these biases do not occur at the automatic level but are a result of more elaborative, conscious processes. Recent research supports many of their hypotheses. For one, attention bias has been found to consistently accompany depression. Individuals with depressive symptoms have more difficulty disengaging from negative stimuli once they have attended to it, and their attention is more likely to continually return back to the negative stimuli (Wisco, 2009). Mood congruent memory effects in encoding and recall (that cause individuals with depression to encode more negative aspects of situations in memory and recall negative aspects easier) are also robust in depression (Wisco, 2009). Finally, Williams and colleagues (1988) reported those high in depression and anxiety tend to judge their performances more negatively, feel less in control of their success, anticipate future events to be unpleasant, and interpret ambiguous events negatively. More recent research has focused specifically on the

tendency to interpret ambiguous events negatively and this phenomenon has been called interpretation bias (Wisco, 2009).

All three biases lead to negatively distorted information processing and result in negative emotional reactions, thus contributing to the development and maintenance of low mood and 


\section{ROLE OF COGNITIVE BIAS IN EMOTION REGULATION}

subsequent depression. A proof of principle test of the combined cognitive bias hypothesis showed these biases do not exist in a vacuum but rather influence each other to maintain depressed mood (Everaert et al., 2014). It stands to reason that altering one bias will lead to improvements in the others by disrupting the recursive process through which they interact. While there has been a considerable research focus on attention and memory biases in mood disorders (for a review see Gotlib and Joormann, 2010), issues with studying interpretation bias have only recently been addressed. For example, researchers have only recently recognized that a lack of significant findings in the past may have been due to the fact that older studies did not take self-relevance of the situation into account, which research now shows is a key factor in interpretation bias (Hertel \& El-Messidi, 2006). As interpretation bias has only been reliably studied in more recent years, there is a dearth of research in the area compared to the other information-processing biases. As such, the present study focuses specifically on interpretation bias and its possible relation to emotion regulation differences in individuals with depressive symptoms. The subsequent section reviews recent findings on interpretation bias in order to propose how it relates to emotion regulation.

\section{Interpretation Bias}

Interpretation bias is the tendency to make negative appraisals about ambiguous situations more often than neutral or positive appraisals, and is seen in individuals with depressive symptoms (Gotlib \& Joormann, 2010). Beck (1964) hypothesized those with depression have developed dysfunctional negative schemas, or assumptions, about types of situations. Williams and colleagues (1988) proposed that the distorted processing of incoming information within these negative schemas leads individuals with mood disorders to judge situations in an overly negative way. Beck and colleagues (1979) also argued negative appraisals 


\section{ROLE OF COGNITIVE BIAS IN EMOTION REGULATION}

become automatic over time, due to continued activation of negative schemas. Thus, Beck's theory suggests interpretation bias is the observable result of the automatic activation of negatively distorted schemas. As such, if interpretation bias is an indicator of underlying negative schemas, Beck's theory suggests it should precede and maintain depression, and should be an automatic process (Beck et al., 1979).

Research over the years has examined when interpretation bias is present (Gotlib \& Joormann, 2010). Given the self-focus that accompanies depression, interpretation bias has been suggested to be self-relevant (Wisco, 2009). Dysphoric individuals show a negative interpretation bias when they are primed to think about themselves, but not when they are primed to think about others; thus interpretation bias is activated when one is presented with selfreferent material (Hertel \& El-Messidi, 2006; Wisco \& Nolen-Hoeksema, 2010). In relation to the timeline of depression, the presence of a negative interpretation bias is both a vulnerability for depression and a predictor of recurrence; interpretation bias in undergraduate students predicts subsequent increases in depressive symptoms over and above current and past depressive symptoms (Rude, Wenzlaff, Gibbs, Vane, \& Whitney, 2002). Interpretation bias also exists in those currently depressed, as found through self-reported rankings of possible interpretations of ambiguous scenarios, more negative solutions for unscrambling sentences, and implicit measures such as startle magnitude (Butler \& Mathews, 1983; Hedlund \& Rude, 1995, Lawson, MacLeod, \& Hammond, 2002). Moreover, comparing individuals with past depression to those never depressed revealed that participants with former depression showed significantly more interpretation bias on the Scrambled Sentences Task, that allows for a positive or negative solution of a scrambled sentence: suggesting the bias remains despite remission from a depressive state and acts as a risk factor for recurrence (Hedlund \& Rude, 1995). Finally, in 


\section{ROLE OF COGNITIVE BIAS IN EMOTION REGULATION}

order to test whether interpretation bias is an automatic process, Cowden Hindash and Rottenberg (2017) developed a semantic association task to restrict elaboration of material, by minimizing the length of time sentences were presented to $1000 \mathrm{~ms}$. They found that dysphoric individuals not only endorsed negative interpretations more often, but they were also faster to endorse negative words as being related to an ambiguous sentence: concluding that both automatic and elaborative interpretation biases are associated with dysphoria. To summarize, evidence shows that interpretation bias is a vulnerability for the development and recurrence of depression and has been shown to be automatic. This supports the notion that interpretation bias reflects underlying negative schemas and is consistent with Beck and colleagues' model (1979) that the automatic activation of these distorted schemas predisposes individuals to develop depression, maintains depressive symptoms, and is a risk factor for recurrent episodes. While self-report measures do not allow for the direct assessment of automatic cognitive processes, given this evidence that interpretation bias is the observable result of the automatic activation of negative schemas, its presence can be used to infer the underlying automatic cognitive process.

Since interpretation bias is a vulnerability for developing depression and also maintains depressed mood, it is important to determine if interpretation biases can be modified. Mathews and Mackintosh (2000) tested whether interpretation bias in anxiety could be altered through an interpretation bias modification training. Participants are trained to adopt a positive or more benign interpretation bias by being continually presented with scenarios that begin ambiguously but resolve in a positive manner. Recent studies have adapted the Mathews and Mackintosh (2000) interpretation bias training to optimize the training and examine it as a potential intervention for depression. There is evidence that suggests that cognitive bias modification for interpretation bias (CBM-I) is effective in correcting the negative interpretation bias seen in 


\section{ROLE OF COGNITIVE BIAS IN EMOTION REGULATION}

depression (Bowler, Mackintosh, Dunn, Mathews, Dalgeish, \& Hoppitt, 2012; Koster \& Hoorelbeke, 2015; Möbius, Tendolkar, Lohner, Baltussen, \& Becker, 2015), particularly when presented through imagery-based as opposed to verbal processing (Holmes, Mathews, Dalgleish, \& Mackintosh, 2006). Recent versions of the CBM-I paradigm more readily allow for imagery use by participants through auditory presentation of scenarios that begin ambiguously and resolve in a positive manner at the end of the sentence, with instructions to imagine oneself in the scenario (Blackwell \& Holmes, 2010). Williams, Blackwell, Mackenzie, Holmes, and Andrews (2013) even found that following seven daily imagery-based bias training sessions, there was a significant decrease in depressive symptoms that was partially mediated by change in interpretation bias, even before a subsequent 10 weeks of internet-based cognitive behavioural therapy. Finally, Yiend, Mackintosh, and Andrews (2005) examined positive and negative bias training for healthy individuals and found a trend that greater trait anxiety was associated with higher emotion congruent training effects, and that this correlation was significant in the positive training group. They suggested that those with higher trait anxiety at the outset of the study may be more susceptible to emotion change induced by the training. It is also possible that there may be a similar effect with depressive symptoms, and given the relation between depression and interpretation bias, level of depressive symptoms prior to training may influence the amount of change in interpretation bias that CBM-I training can produce.

Therefore, research shows interpretation bias precedes and accompanies depressed mood, can be modified through training, and partially mediates decreases in depressive symptoms. However, the way in which emotion regulation is affected by interpretation bias has yet to be examined. According to Gross (2010), reappraisal is a strategy that must be employed shortly following the initial appraisal of a situation in order to curtail the generation of negative 


\section{ROLE OF COGNITIVE BIAS IN EMOTION REGULATION}

emotional responses. If negative appraisals are automatically triggered through activation of negatively distorted schemas, it becomes hard to override such automatic processes. Automatic processes are fast and occur without conscious effort, whereas controlled processes are slower, voluntary, and require concentration (Schneider \& Chein, 2003). For example, reading words is an automatic process for adults, but naming the colors of those words is a controlled process. As the Stroop Task shows, the problem arises because automatic processes are difficult to control and thus conflict with controlled processes, slowing them down (Schneider \& Chein, 2003). Beck and colleagues similarly argued that the automatic activation of negative schemas interferes with activation of more helpful schemas (1979). In this way, the automatic interpretation bias may be conflicting with the more controlled reappraisal. To date, few studies have attempted to directly link cognitive biases to emotion regulation. The next section integrates the theories presented thus far to lay the foundation for the current study.

\section{Integrating Interpretation Bias and Emotion Regulation Strategies}

Beck and colleagues' cognitive model (1979) can explain how a negative interpretation bias forms over time and then acts in the development and maintenance of low mood - and even depression - on the basis of schemas. However, Beck's model lacks an explanation for the differential use of emotion regulation strategies seen between healthy individuals and those depressive symptoms. Joormann and D'Avanzato (2010) propose that the differential use of emotion regulation strategies occurs largely due to the interference of cognitive biases. They propose biases in attention, memory, and interpretation sustain negative mood by leading to greater use of unhelpful strategies through interference with adaptive strategies. One of their hypotheses is that effective reappraisal depends on individual differences in cognitive control. Cognitive control is the ability to select and monitor behaviour to attain specific goals, and it 


\section{ROLE OF COGNITIVE BIAS IN EMOTION REGULATION}

requires inhibition of dominant responses that compete with goal-directed actions. As such, Joormann and D'Avanzato (2010) hypothesize that cognitive control relates to one's ability to override an automatic interpretation bias and to then successfully engage in more goal-directed reappraisal. Cognitive control is affected by stress, sadness, loneliness, and sleep deprivation, all of which are associated with depression (Diamond, 2013). Indeed, a review of the literature shows that those with depression have difficulties with many aspects of cognitive control (Gotlib \& Joormann, 2010). Thus, a more adaptive reappraisal of the situation would have to first be generated and then override the initial negatively biased interpretation, which may be difficult for individuals with issues in cognitive control, including those with depressive symptoms.

Cowden Hindash and Rottenberg (2017) similarly suggest that the interplay of reappraisal and interpretation bias can be understood on a mechanistic level on the basis of the dual process model of vulnerability to depression, which posits that vulnerability to depression begins with negatively biased self-referential associative processing (Beevers, 2005). According to Beevers (2005), associative processing is nonconscious, effortless, and quick information processing that triggers the recollection of information or an emotional response based on associations made between the current experience with stimuli and past interactions. In this way, activation of schemas is associative processing, and an automatic negative interpretation bias is the result of such processing in the presence of negatively distorted beliefs. Contrasting associative processing is reflective processing, which is effortful, involves intent, and occurs at a conscious level. Thus, an individual could deliberately derive a rule to explain a particular phenomenon and direct processing of information (Beevers, 2005). Such reflective processing explains the effortful reinterpretation of an initial automatic appraisal of a situation, or cognitive reappraisal. The dual process model suggests that the automatic retrieval of negative cognitions 


\section{ROLE OF COGNITIVE BIAS IN EMOTION REGULATION}

is associated with a corresponding negative shift in emotion and must be corrected by effortful reflective processing (Beevers, 2005). This is consistent with how Gross (2010) models emotion generation: negative appraisals lead to negative emotional responses and in order to mitigate the original trajectory of the emotional response, emotion regulation strategies must be deployed. Phrased another way, a negative interpretation bias will induce and maintain negative emotions unless corrected through reappraisal. In turn, the dysphoric mood itself will lead to limited cognitive resources by bringing to mind task irrelevant intrusive thoughts that will interfere with reflective processing (Beevers, 2005). Indeed, findings show that anhedonic depression (symptoms of depression that do not overlap with anxiety and other distress, specifically a persistent depressed mood) has similar effects on cognition to multi-tasking (Bredemeier, Berenbaum, Brockmole, Boot, Simons, \& Most, 2012) as well as other cognitive resourcedepleting effects (Ellis, Ottaway, Varner, Becker, \& Moore, 1997). This explains how dysphoria overwhelms cognitive control. The dual process model posits that a feedback loop develops between these negative cognitions and the dysphoria itself, which perpetuates depressed mood and makes it difficult to resist automatic negative interpretations (Beevers, 2005). According to Beevers (2005), the way to stop this pattern is by introducing deliberate reflective processing to correct these biases. Beevers (2005) posits that problems arise when dysphoric mood and depressive symptoms deplete cognitive resources that are required to engage deliberate processes, like reappraisal. This is consistent with the findings of Rude, Valdez, Odom, and Ebrahimi (2003) that interpretation biases become evident when tested under a cognitive load (i.e. when cognitive control is overwhelmed and cognitive resources are limited), suggesting that individuals are relatively able to suppress their interpretation bias when their cognitive resources are free in the absence of stressors. To minimize cognitive effort, associative processing 


\section{ROLE OF COGNITIVE BIAS IN EMOTION REGULATION}

dominates until expectations are violated, at which point reflective processing takes over (Beevers, 2005). That is, if the automatic interpretations are consistent with what the person expects of a situation, the individual will continue to rely on them. Due to the cognitive triad, individuals with depression have dysfunctional negative expectations of the world, themselves, and their future: thus the automatic interpretations would not violate these expectations. This would explain why individuals with depression are able to reappraise when instructed to do so, yet still use it less often than do healthy controls (Ehring et al., 2010). Therefore, the Beevers (2005) model provides two explanations for why reappraisal is underutilized by those with depressive symptoms. First, when the negative appraisals of situations that result from interpretation bias are consistent with the core beliefs held by those with depression, there would be no need to correct them and reappraisal would not be engaged in at all. Second, given the automaticity of the bias, it is difficult to correct with effortful reflective processes like cognitive reappraisal. Due to depleted cognitive resources that accompany depression, the individual may then forego effortful processing in lieu of other strategies.

This model can also explain how CBM-I works to train a more benign interpretation bias due to changes in memory associations formed from repeated experience. Beevers explains this through the idea of consolidation, or repeated experience with a particular association that eventually becomes integrated into the associative system (2005). Thus, the associative processing mode, which is an automatic mode of information processing, attends to similarities that have been presented repeatedly by the training procedure and begins to retrieve more positive or benign interpretations in response to ambiguous scenarios. This is consistent with Beck's framework (1979), whereby appropriate schemas are being continually activated, thus making dysfunctional schemas less likely to be activated and less automatic. 


\section{ROLE OF COGNITIVE BIAS IN EMOTION REGULATION}

More recently, research has attempted to directly link cognitive biases and emotion regulation. Sanchez, Everaert, and Koster (2016) found that attention bias training resulted in a decrease in attention bias which resulted in more successful reappraisal. Building off these findings, Everaert, Grahek, Duyck, Buelens, Van den Bergh, and Koster (2017) suggested that the effect of attentional bias on ability to reappraise may be explained by changes in interpretation bias. Their cross-sectional path analysis revealed that attention bias predicted an interpretation bias, which in turn was related to low habitual reappraisal and high ruminative brooding. Thus, their study was the first step in tying interpretation bias to reappraisal. However, as there was no direct manipulation, causal conclusions about the relationship between interpretation bias and emotion regulation strategies cannot be made. As such, the present study employs an experimental design to determine whether induced negative and positive interpretation biases result in changes in emotion regulation strategy use.

\section{The Current Study}

It is proposed that the presence of interpretation bias interferes with the use of reappraisal and that those with difficulties in cognitive control, particularly individuals with depressive symptoms, lack the ability to effortfully override their negative interpretation bias. This makes it especially difficult for dysphoric individuals to engage in reappraisal, resulting in its habitual disuse in favor of suppression and rumination. This study examined whether a negative interpretation bias leads to decreased spontaneous use of reappraisal during a negative emotion induction. The current study compared two groups of undergraduate students receiving imagerybased bias training (Blackwell et al., 2015) to induce a more negative bias in one group and a more positive bias in the other, in order to identify changes in emotion regulation strategy use from pre- to posttraining. The comparison between positive and negative bias training, rather 


\section{ROLE OF COGNITIVE BIAS IN EMOTION REGULATION}

than a neutral control, allows for the clearest separation between the two conditions to determine the causal role of interpretation bias on the use of emotion regulation strategies (MacLeod \& Grafton, 2016). Interpretation bias was assessed as a possible mediator of change in emotion regulation strategies, and depressive symptoms were assessed as a moderator of this relationship. As such, the present study was a mixed-model design with both within (pre- and posttraining) and between (positive and negative training) group factors. Therefore, data analyses included a mixed-model analysis of variance as well as regression analyses of a moderated mediation model.

\section{Objectives}

Aim 1. Test whether a single session of CBM-I training leads to changes in interpretation bias.

Hypothesis 1. There will be a significant time by group interaction and follow up tests will reveal interpretation bias became more positive in those who underwent positive bias training, and more negative in those who underwent negative bias training (see Figure 1 for graphical representation).

Aim 2. Test whether changes in interpretation bias lead to changes in emotion regulation strategy use during a negative emotion induction.

Hypothesis 2. Interpretation bias change ( $\Delta \mathrm{IB}=$ scores posttraining - scores pretraining) will partially or fully mediate the relationship between group (positive and negative training) and reappraisal change $(\Delta \mathrm{RE}=$ scores posttraining - scores pretraining $)$, suppression change $(\Delta \mathrm{SU}$ $=$ sores posttraining - scores pretraining $)$, and rumination change $(\Delta \mathrm{RU}=$ scores posttraining scores pretraining). 
Group by Time Interaction for Interpretation Bias

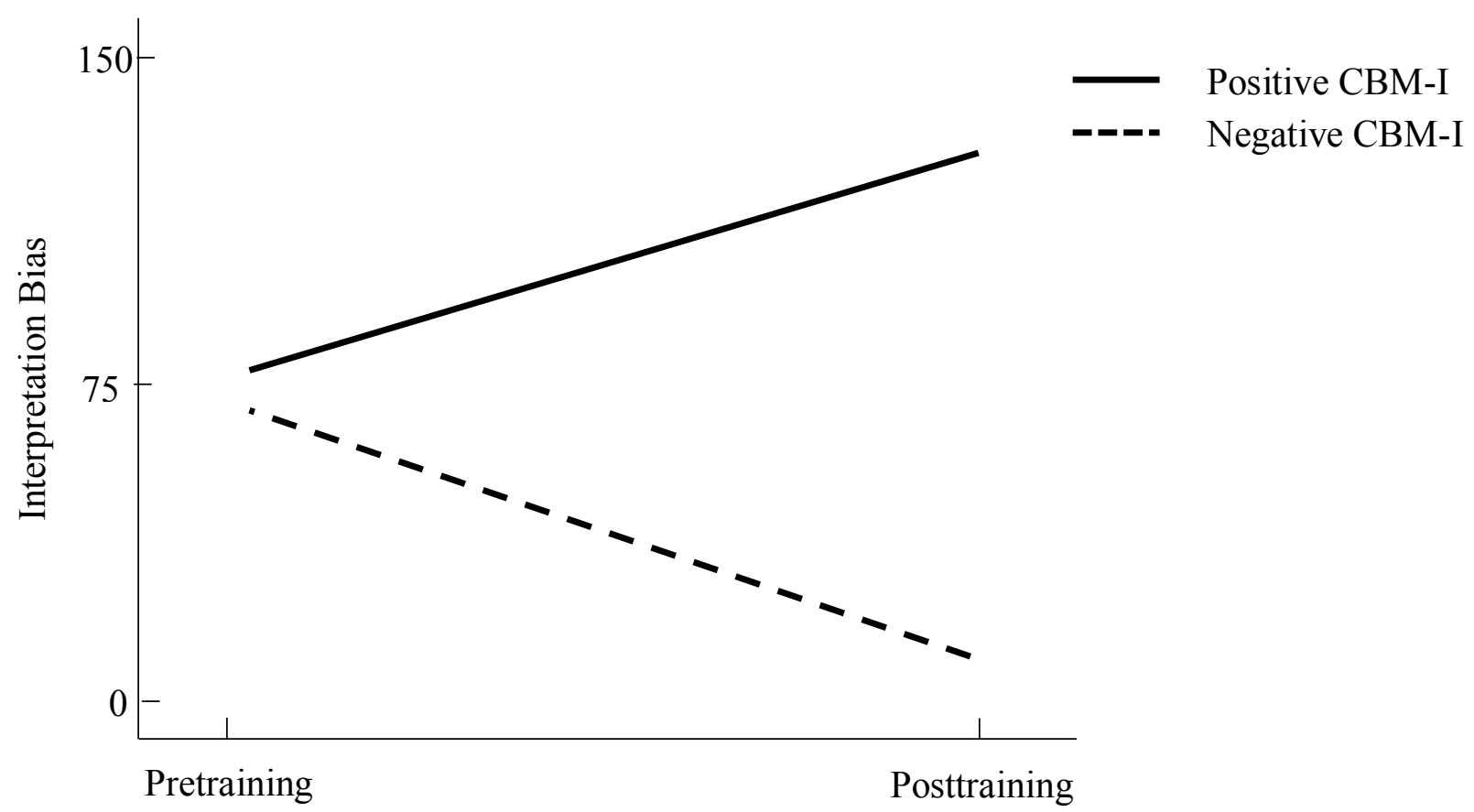

Figure 1. The hypothesized group (positive and negative CBM-I training) by time (pre- to posttraining) interaction for interpretation bias (scores on the AST-D). A score of 0 on the AST$\mathrm{D}$ indicates a very negative interpretation bias, a score of 150 indicates a very positive interpretation bias, and a score of 75 indicates no bias; therefore, higher scores on the AST-D indicate a decrease in negative interpretation bias. 


\section{ROLE OF COGNITIVE BIAS IN EMOTION REGULATION}

Aim 3. Determine whether depressive symptoms moderate the relationship between training group and interpretation bias change.

Hypothesis 3. Depressive symptoms will be a significant moderator and follow up tests will reveal that in the positive bias training group, those with more depressive symptoms (higher DASS-D scores) will experience more interpretation bias change (more positive $\Delta$ IB scores); while in the negative CBM-I training group, those with less depressive symptoms (lower DASSD scores) will experience more interpretation bias change (more negative $\Delta$ IB scores; see Figure 2 for graphical representation).

Aim 4. Determine whether depressive symptoms moderate the relationship between training group and emotion regulation strategy change ( $\Delta \mathrm{RE}, \Delta \mathrm{RU}, \Delta \mathrm{SU})$.

Hypothesis 4. Depressive symptoms will be a significant moderator and follow up tests will reveal that in the positive bias training group, those with more severe depressive symptoms (higher DASS-D scores) will experience more reappraisal change (more positive $\Delta$ RE scores), more rumination change (more negative $\Delta \mathrm{RU}$ scores), and more suppression change (more negative $\Delta \mathrm{SU}$ scores); while in the negative bias training group, those with less depressive symptoms (lower DASS-D scores) will experience more reappraisal change (more negative $\Delta$ RE scores), more rumination change (more positive $\Delta \mathrm{RU}$ scores), and more suppression change (more positive $\Delta$ SU scores; see Figures 3, 4, and 5 for graphical representations).

Minor Objectives. Minor objectives are as follows: (a) replicate past findings that depressive symptoms are positively correlated with rumination and suppression, and negatively correlated with reappraisal, (b) replicate and expand past findings that one session of imagery CBM-I training is effective in altering interpretation bias in a Canadian undergraduate population, (c) evaluate psychometric properties of the measure of interpretation bias and 

Moderation of Relationship Between Group and Interpretation Bias Change by Depressive
Symptoms

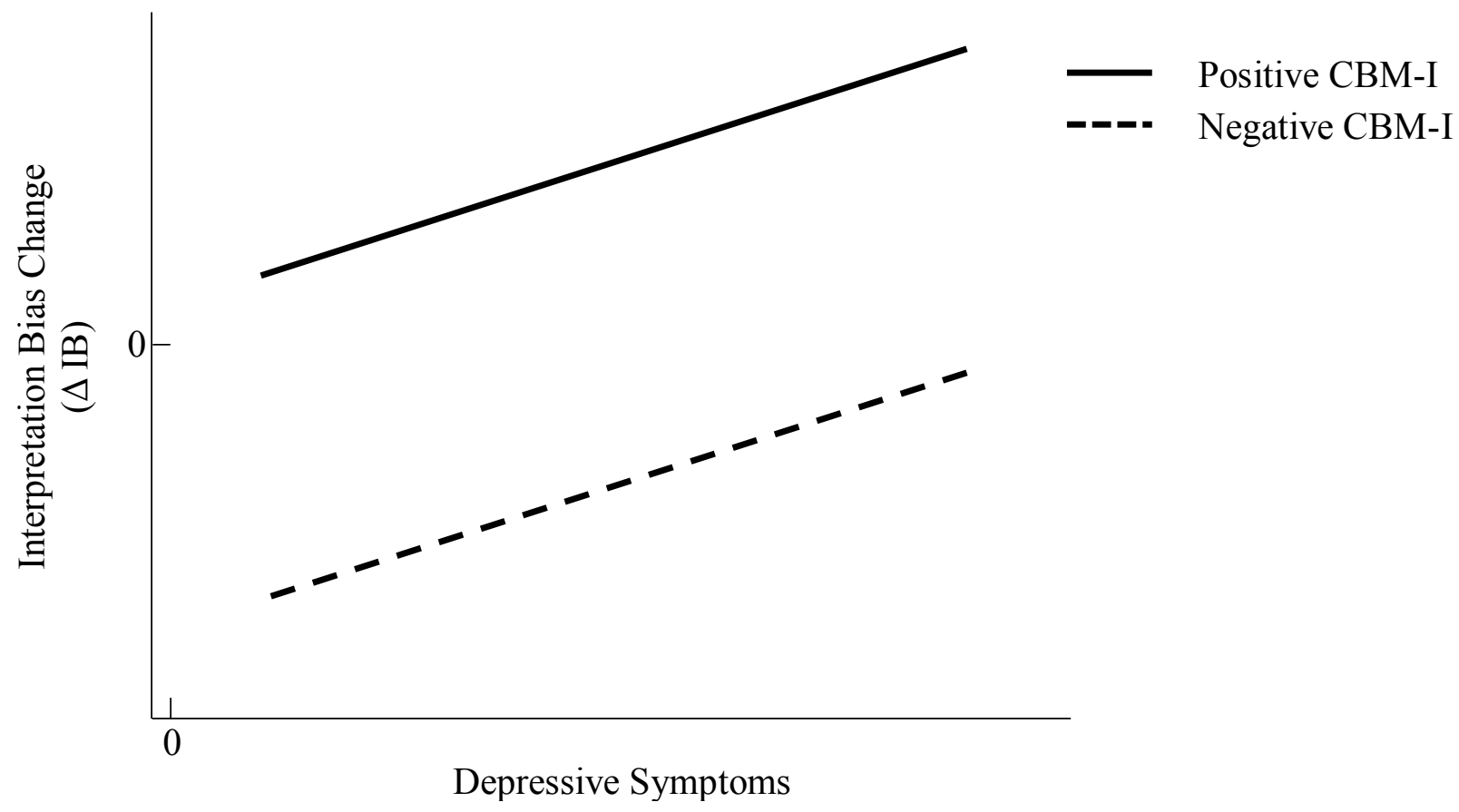

Figure 2. Depressive symptoms (DASS-D) moderate the relationship between CBM-I training group and interpretation bias change (AST-D scores posttraining - scores pretraining). $\Delta$ IB scores closer to 0 indicate less change; positive $\Delta$ IB scores indicate a decrease occurred in negative interpretation bias, while negative $\Delta$ IB scores indicate an increase occurred in negative interpretation bias. 
Moderation of Relationship Between Group and Reappraisal Change by Depressive Symptoms

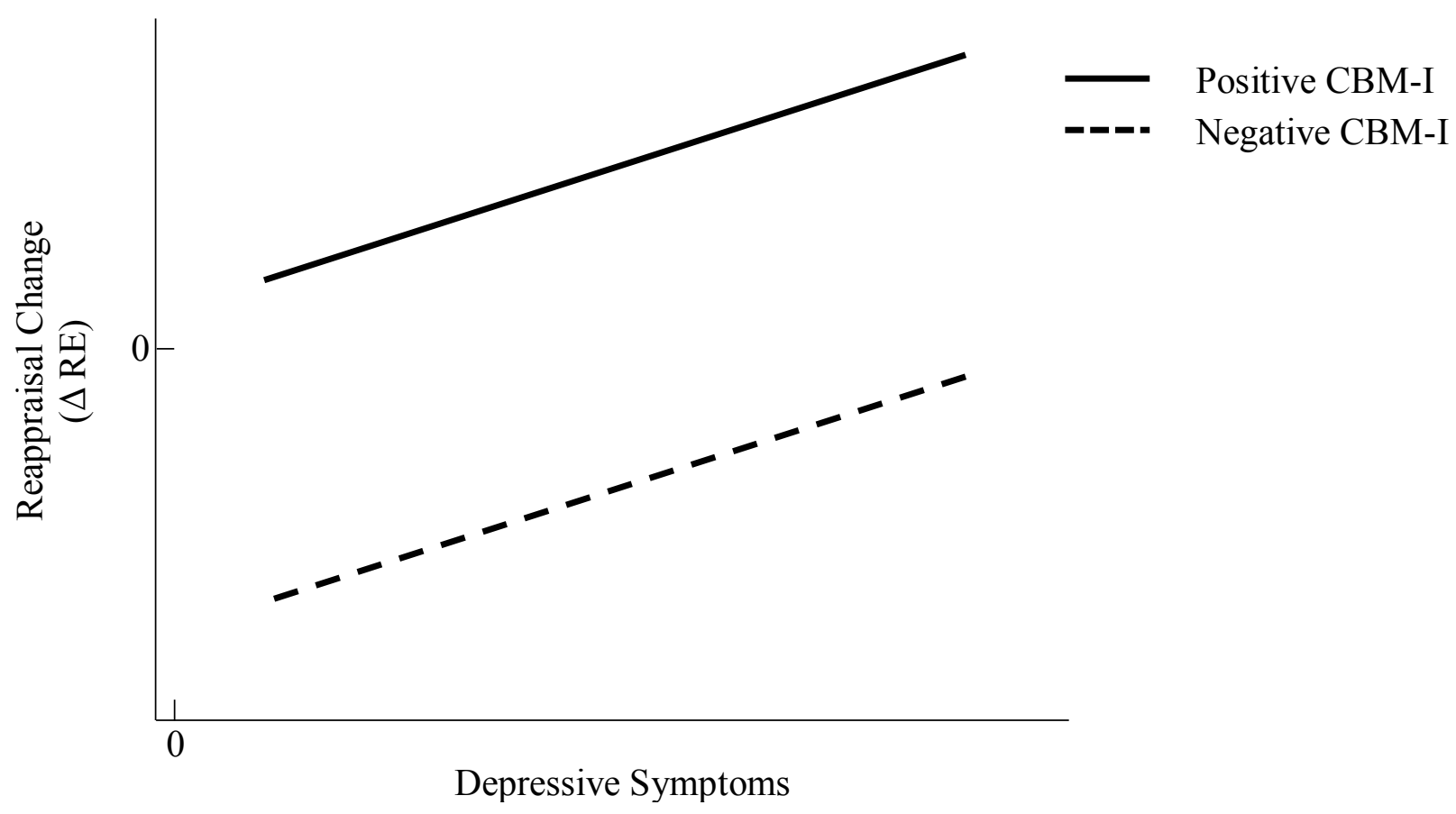

Figure 3. Depressive symptoms (DASS-D) moderate the relationship between CBM-I training group and reappraisal change (SERQ-M-RE scores posttraining - scores pretraining). $\Delta \mathrm{RE}$ scores closer to 0 indicate less change; positive $\Delta \mathrm{RE}$ scores indicate an increase occurred in reappraisal use, while negative $\Delta \mathrm{RE}$ scores indicate a decrease occurred in reappraisal use. 
Moderation of Relationship Between Group and

Rumination Change by Depressive Symptoms

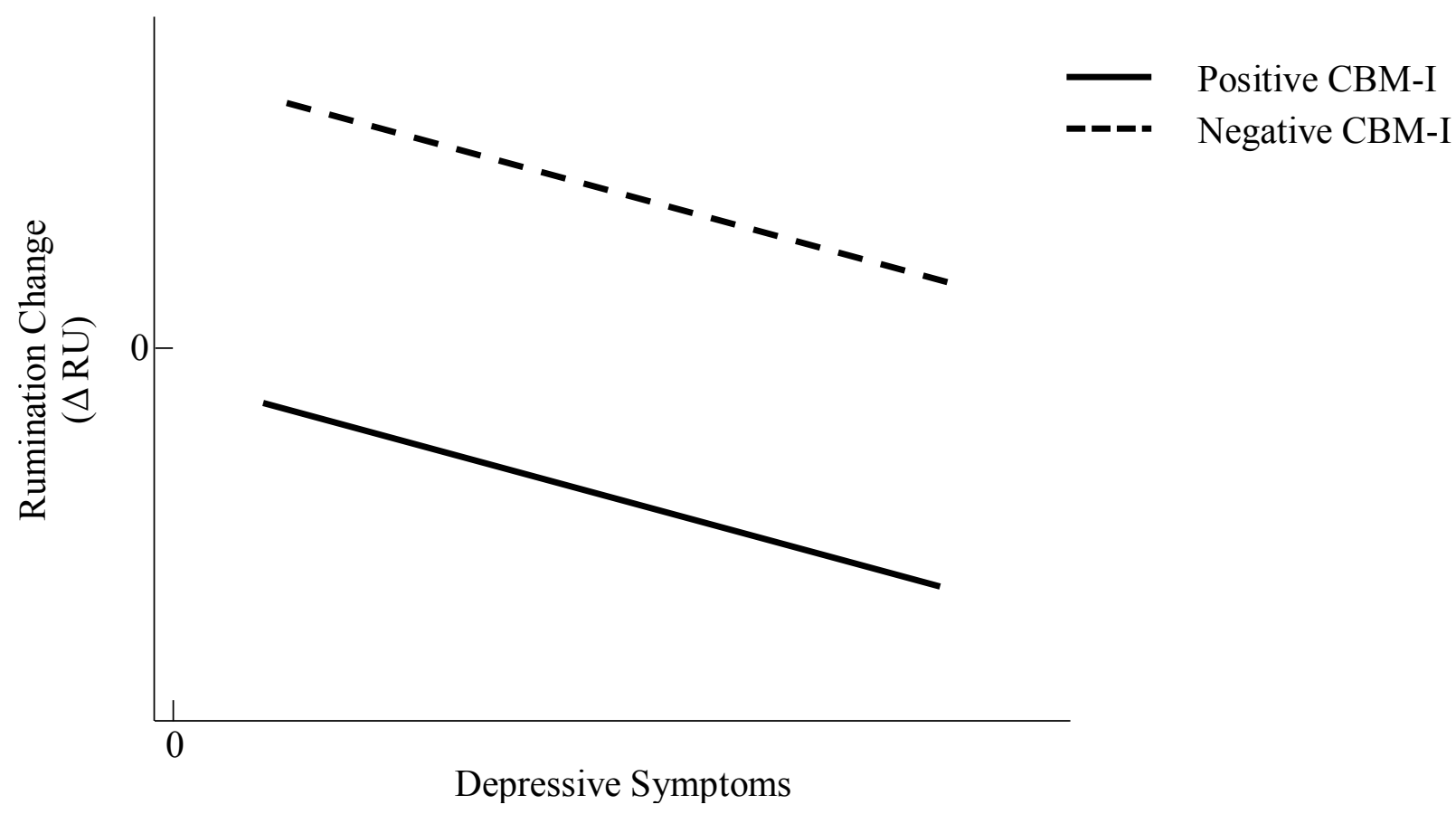

Figure 4. Depressive symptoms (DASS-D) moderate the relationship between CBM-I training group and rumination change (SERQ-M-RU scores posttraining - scores pretraining). $\Delta \mathrm{RU}$ scores closer to 0 indicate less change; positive $\Delta \mathrm{RU}$ scores indicate an increase occurred in rumination use, while negative $\Delta \mathrm{RE}$ scores indicate a decrease occurred in rumination use. 
Moderation of Relationship Between Group and Suppression Change by Depressive Symptoms

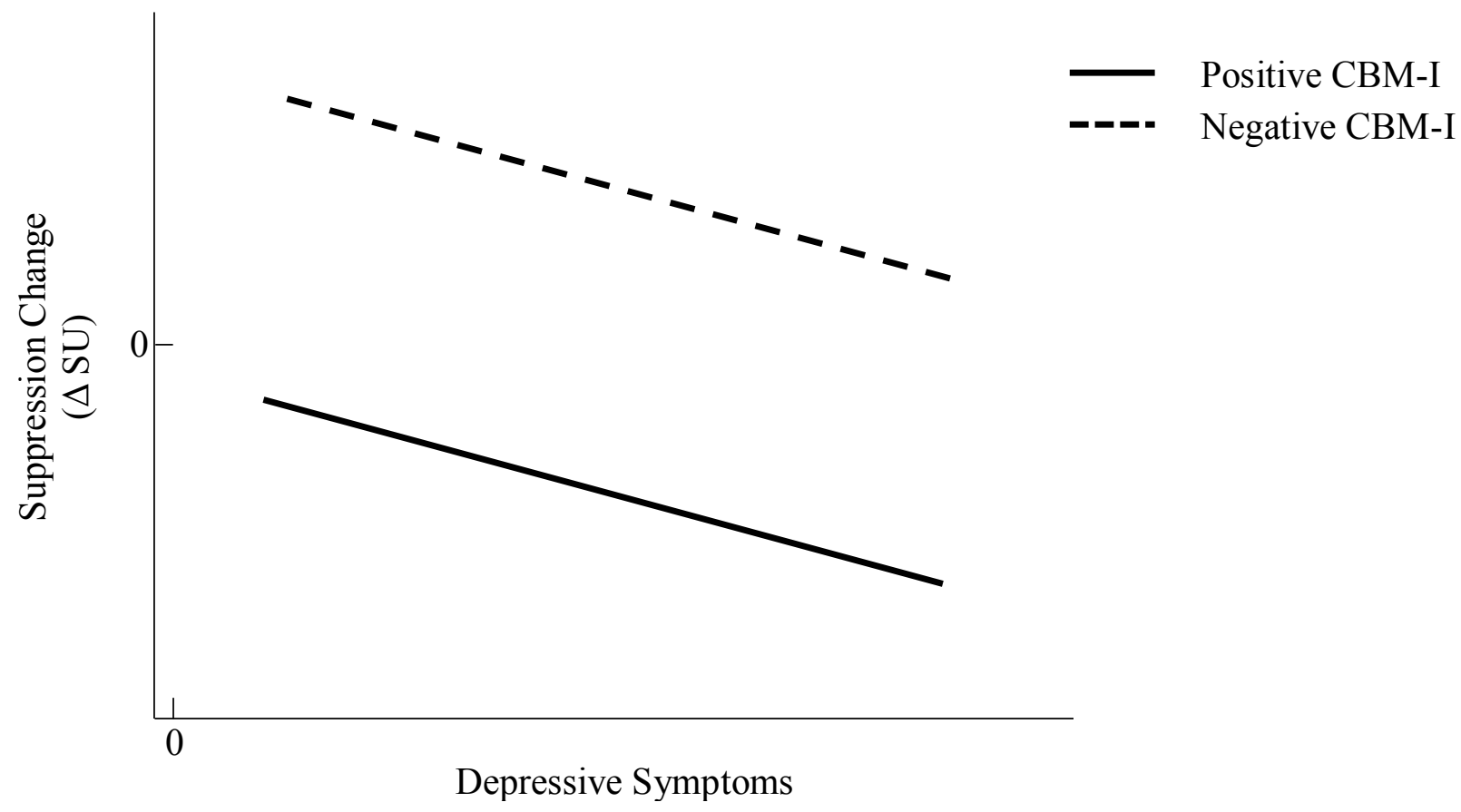

Figure 5. Depressive symptoms (DASS-D) moderate the relationship between CBM-I training group and suppression change (SERQ-M-SU scores posttraining - scores pretraining). $\Delta \mathrm{SU}$ scores closer to 0 indicate less change; positive $\Delta \mathrm{SU}$ scores indicate an increase occurred in rumination use, while negative $\Delta \mathrm{SE}$ scores indicate a decrease occurred in rumination use. 


\section{ROLE OF COGNITIVE BIAS IN EMOTION REGULATION}

emotion regulation strategy questionnaire in a Canadian undergraduate population, (d) provide validity data for the use of the emotion induction used in the present study in research assessing spontaneous emotion regulation, and (e) determine whether attentional control moderates the relationship between CBM-I training and interpretation bias change.

\section{Method}

\section{Participants}

The minimum sample size for each group (alpha set at .05, power at .80) was identified as 28 , following a power calculation using a within-group effect size of $d=0.74$ calculated from data published by Rohrbacher and colleagues (2014). The study on which the power analysis estimates were derived compared a single session of positive imagery-based bias training with a control group that was presented with the first part of the same ambiguous scenarios with no resolution. As such, 60 undergraduate students were recruited and randomized using simple randomization in Microsoft Excel to either a positive or negative bias training group. Due to technical difficulties with E-Prime, 5 participants could not complete all study components and an additional 5 participants were recruited for a total of 32 in the positive group and 33 in the negative group.

All participants were recruited through SONA. SONA is an online recruitment system for undergraduate psychology students at Ryerson University to receive course credit. Students aged 18-65 years with self-reported normal hearing were included in the study. Because depressive symptoms were a moderator, participants in the sample were intended to have varying levels of symptoms. The transition to university is accompanied by the introduction of several stressors that can precipitate or exacerbate mood issues (Kadison, 2004). Therefore this environment allows for variance in the development of depressive symptoms: with some students 


\section{ROLE OF COGNITIVE BIAS IN EMOTION REGULATION}

experiencing no symptoms, others experiencing mild to moderate dysphoria, and approximately 15.6\% experiencing clinically significant depression or anxiety (Eisenberg, Gollust, Golderstein, \& Hefner, 2007). Therefore, undergraduate students were recruited to ensure variance of depressive symptoms in the sample. In keeping with past experiments involving a negative CBM-I training condition (Mackintosh, Mathews, Yiend, Ridgeway, \& Cook, 2006; Telman, Holmes, \& Lau, 2013; Yiend et al., 2005), to be sensitive to the issue of inducing a negative interpretation bias in those with a known history of psychological disorders — as well minimizing the likelihood of a possible ceiling effect in those with high depression symptoms_-participants were asked if they had a current or past diagnosis of a mood or anxiety disorder or another serious mental illness, with those responding in the affirmative being excluded from the present study.

\section{Measures}

Visual Analogue Scale. To perform manipulation checks for the emotion inductions and assess whether the filler task helped return participants back to baseline following bias training, emotion was measured before and after tasks with a visual analogue scale (VAS). Participants were asked to rate their "mood" on a bipolar scale 100mm in length with the anchors "Extremely positive" and "Extremely negative". VASs are brief, easy to administer, and unlike with Likert scales which are prone to response bias (Böckenholt, 2016), it is highly unlikely a participant can select the same response to the millimeter on a VAS, minimizing risk of response bias.

Depression and Anxiety Stress Scales. The Depression and Anxiety Stress Scales (DASS) measure depression, anxiety, and stress symptoms (Lovibond \& Lovibond, 1995). Given the role of both clinical depression and dysphoria in cognitive biases and emotion regulation, severity of depressive symptoms were analyzed as a moderator in the present study. Unlike past 


\section{ROLE OF COGNITIVE BIAS IN EMOTION REGULATION}

research which has artificially grouped participants based on cutoff scores, in the present study depressive symptoms were measured on a continuum. Participants completed the DASS-21 to assess for presence of stress, and depression and anxiety symptoms over the past week. An example question from the depression subscale (DASS-D) is "I felt that life was meaningless". Participants rated the frequency or severity of their symptom on a 4-point Likert-type scale from 0 (does not apply) to 3 (applies very much, or most of the time). Cronbach's alpha values for all three subscales of the DASS-21 are excellent ( $\alpha=0.94$ for depression, $\alpha=.87$ for anxiety, and $\alpha$ $=.91$ for stress), and it is a valid measure of anxious and depressive symptomatology: with appropriate subscales strongly related to the Beck Depression Inventory $(r=0.77)$, the Beck Anxiety Inventory $(r=.85)$, and the State-Trait Anxiety Inventory $(r=.55)$ (Antony, Bieling, Cox, Enns, \& Swinson, 1998).

Attentional Control Scale. The Attentional Control Scale (ACS) is a self-report measure of individual differences in attentional control ability (Derryberry \& Reid, 2002). Attentional control is an aspect of cognitive control that commands the voluntary focusing and shifting of

attention, with individuals with superior attentional control showing less attention bias (Ólafsson, Smári, Guðmundsdóttir, Ólafsdóttir, Harðardóttir, Einarsson, 2011). An example item is "When I need to concentrate and solve a problem, I have trouble focusing my attention", and is rated on a scale from 1 (almost never) to 4 (always; see Appendix A). Factor analysis supports a two factor structure of the 20-item ACS with shifting and focusing subscales, and correlations between the subscales and several cognitive control self-report measures, as well as performance on attentional tasks, support the validity of the ACS as a measure of attentional control (Judah, Grant, Mills, \& Lechner, 2014). Moreover, the focusing subscale correlates with trait anxiety $(r$ $=-.35)$, and the shifting subscale correlates with trait depression $(r=-.40$; Judah et al., 2014). It 


\section{ROLE OF COGNITIVE BIAS IN EMOTION REGULATION}

should be noted that the Focusing subscale is comprised of 7 items, while the Shifting subscale is comprised of 5 items: therefore, some items from the total score are not included in the subscales (Judah et al., 2014). Given the influential role of attention bias on interpretation bias (Everaert et al., 2016), total attentional control, attentional focusing, and attentional shifting were assessed as moderators of interpretation bias change.

Ambiguous Scenarios Test. The Ambiguous Scenarios Test for depression (AST-D) is a measure of depressotypic interpretation bias (Berna, Lang, Goodwin, \& Holmes, 2011). Rohrbacher and Reinecke (2014) developed and validated parallel forms A and B of the AST-D (see Appendix B) to measure interpretation bias change. It consists of ambiguous scenarios that are vividly imagined and then rated based on pleasantness. The scenarios reflect three content areas based on Beck's cognitive triad: negative interpretations about future situations, past experiences, and one's own skills and performance in situations. An example scenario is "You give a speech at your friend's wedding. When you have finished, you observe the audience's reaction". Each form consists of 15 questions rated on an 11-point scale from -5 (very unpleasant) to +5 (very pleasant), which allows for a maximum score of +75 and a minimum score of -75 , indicating a very negative bias. However, for the present study, total scores were centered at $75($ maximum $=150$, minimum $=0)$ in order to eliminate negative scores for data analysis. Therefore, higher scores indicated a more positive interpretation bias and lower scores indicated a more negative interpretation bias. By having participants rate pleasantness, they do not have to explicitly state how they interpret the situation and therefore the AST-D is less likely to be subject to demand characteristics than an open ended measure of interpretation bias (Schoth \& Liossi, 2017). Both A and B forms have an acceptable internal consistency $(\alpha=0.77$ 


\section{ROLE OF COGNITIVE BIAS IN EMOTION REGULATION}

and 0.78 respectively; Rohrbacher \& Reinecke, 2014). Each form took approximately 5 minutes to complete.

Cognitive Bias Modification for Interpretation Bias. CBM-I is a training paradigm developed to train a positive interpretation bias; however, it can be used to train a negative interpretation bias as well (Koster, Fox, \& MacLeod, 2009). Imagery CBM-I has been shown to have the most robust effects (Holmes, Mathews, Dalgleish, \& Mackintosh, 2006). The aim of imagery-based bias training is to train an individual to automatically imagine positive resolutions of ambiguous situations, and is accomplished through repeated practice in generating such positive resolutions through the use of mental imagery (Blackwell et al., 2015). The participant is played audio recordings of everyday scenarios, approximately 10 seconds in length, and instructed to vividly imagine themselves in the situation by taking a first-person perspective. The scenario remains ambiguous until the end, at which point the resolution is either positive or negative. Before presentation of each scenario the screen reads "Shut your eyes. Imagine" for 1 second, followed by the audio recording of a voice reading the scenario. A positive training example would be "It's your birthday, and your partner reaches over to you with a present. You open it and feel incredibly happy". The resolution is in italics and an alternative negative resolution to the same scenario would be "feel disappointed". The same scenarios were used for both training groups, with the positive training group imagining only positive resolutions and the negative training group imagining only negative resolutions. Following the scenario, a beep signaled for participants to open their eyes and rate "How vividly could you imagine the scenario described?" on a scale from 1 (not at all vivid) to 5 (extremely vivid) in order to focus participants on generating mental imagery. 


\section{ROLE OF COGNITIVE BIAS IN EMOTION REGULATION}

Previous research using single-session bias modification has found it to be successful with 50 training scenarios (Rohrbacher, Blackwell, Holmes, \& Reinecke, 2014). As such 50 training scenarios were randomly selected using a random number generator from the 208 scenarios that have both a positive and negative resolution option used by Blackwell and colleagues (2015). Scenarios were randomized for each participant in E-Prime 2.0 software (Psychology Software Tools, Pittsburgh, PA) into 5 blocks of 10 scenarios, with short breaks allowed between blocks with a repetition of instructions. The whole CBM-I procedure, including instructions, took between 30-45 minutes to complete.

Filler Task. As done in past studies (Rohrbacher et al., 2014), all participants were presented with the same classical music extract following bias training for 5 minutes in order to equalize emotion levels between the two groups. The present study used the first 5 minutes of "Piano Sonata No. 8 in A minor, K310 - Mozart" played by Randolph Hokanson, and taken from Youtube.com (Just Instrumental Music, 2017).

Autobiographical Emotion Induction. Research looking to assess spontaneous emotion regulation does so by inducing negative emotions and then assessing to what extent participants used certain strategies in response to the presentation of negative material (Quigley \& Dobson, 2014). In order to test whether negative interpretation bias interferes with the use of reappraisal, the emotion induction must simulate a situation which induces participants to emotionally regulate while also having the potential to invoke interpretation bias. Therefore, the situation must be self-referential (Hertel \& El-Messidi, 2006), give rise to negative emotions (Volokhov \& Demaree, 2010), and be objectively ambiguous. To achieve this, the current study employed a modified version the Autobiographical Emotion Regulation Task (AERT) developed by Speed and colleagues (2017). 


\section{ROLE OF COGNITIVE BIAS IN EMOTION REGULATION}

The AERT is a computerized word-viewing task that can induce negative emotion with idiographic stimuli. In the first part, participants were asked to recall two recent autobiographical situations that resulted in intense negative emotions, but which may have had an alternative explanation (e.g., being turned down for a job). As per the example, people often do not know exactly why they were turned down for a job but still make assumptions such as "I am unqualified", "I did really badly in the interview", or "someone else was better qualified". Following identification of two situations, participants rated the emotional intensity of each memory using a Likert-scale from 1 (not negative) to 5 (extremely negative). If participants rated the memory 1 or 2 , they were asked to select a more negative memory. Following the rating, participants wrote down 10 keywords they view as tightly linked to the situation.

During the emotion induction portion of the AERT, participants were presented with the 10 keywords related to one of the memories randomized through E-Prime with the following instructions: "We will now be showing you keywords you identified earlier, please read them carefully". As the emotion regulation in response to the emotion induction is meant to be spontaneous, no other instructions were provided. Past research has employed the AERT to study instructed emotion regulation (Speed et al., 2017); however, spontaneous emotion regulation has yet to be assessed through the use of idiographic stimuli. Therefore, the present study was the first to employ this novel paradigm as an emotion induction to elicit spontaneous emotion regulation. To validate the use of this methodology, participants were asked to complete VASs before and after the emotion induction portion. Additionally, they completed a post-induction questionnaire asking "Did viewing the words make you sad?" on a scale of 1 (yes), 2 (somewhat), or 3 (no); "Did viewing the words make you think about the associated memory?", 


\section{ROLE OF COGNITIVE BIAS IN EMOTION REGULATION}

on a scale of 1 (yes), 2 (somewhat), or 3 (no); and "How vividly did you remember the situation?" on a scale of 1 (very vividly), 2 (somewhat vividly), or 3 (not at all vividly).

State Emotion Regulation Questionnaire. The State Emotion Regulation Questionnaire (SERQ) was developed by Quigley and Dobson (2014) based on the Emotion Regulation

Questionnaire (ERQ), a well-established measure of habitual suppression and reappraisal (Gross \& John, 2003); in order to determine the degree to which participants used suppression, reappraisal, rumination, and distraction in response to a negative emotion induction. As the present study used the AERT to induce negative emotions rather than a film clip, the SERQ was reworded accordingly. This modified SERQ (SERQ-M, see Appendix C) also included an extra item about reappraisal taken from the ERQ. The SERQ-M consisted of 13 items divided into four subscales with 3 items assessing for suppression, rumination, and distraction, and 4 for reappraisal, rated on a 7-point scale from 1 (strongly disagree) to 7 (strongly agree). The SERQ$\mathrm{M}$ also included a final item "other" for participants to describe any alternative strategies they may have used. The authors of the SERQ did not report reliability for the distraction subscale; however, the reliability was good for suppression $(\alpha=0.83)$, adequate for reappraisal $(\alpha=0.79)$ and poor/fair for rumination ( $\alpha=0.66$, Quigley \& Dobson, 2014). As the SERQ was developed based on the ERQ for assessing spontaneous emotion regulation, no validity testing has been conducted on it to date. Therefore, a minor objective of the present study was to corroborate evidence with past findings by assessing and reporting the reliability of the SERQ-M subscales.

State Difficulties in Emotion Regulation Scale. The State Difficulties in Emotion Regulation Scale (SDERS; Lavender, Tull, DiLillo, Messman-Moore, \& Gratz, 2017) is a 21item measure assessing state emotion dysregulation adapted from the Difficulties in Emotion Regulation Scale (Gratz \& Roemer, 2004), that assesses multiple aspects of trait emotion 


\section{ROLE OF COGNITIVE BIAS IN EMOTION REGULATION}

dysregulation. Exploratory factor analysis supports a four factor structure to the SDERS. The four subscales assess nonacceptance of current emotions (Nonacceptance), difficulties modulating emotional and behavioural responses in the moment (Modulate), limited awareness of current emotions (Awareness), and limited clarity about current emotions (Clarity). Example questions are "I feel embarrassed for feeling this way" and "My emotions feel overwhelming", and are rated on a 5-point scale from 1 (not at all) to 5 (completely). The SDERS total score has good internal consistency $(\alpha=.86)$, and is significantly positively associated with several trait measures of emotion dysregulation and negatively associated with mindfulness and the ability to modulate negative emotional states: thereby providing preliminary support for its reliability and validity (Lavender et al., 2017). The SDERS was correlated with the SERQ-M to establish convergent and discriminant validity.

\section{Procedure}

Participants were recruited online through the SONA System for student recruitment within the Ryerson psychology program. At recruitment, participants received information regarding their involvement in the study, responded whether they had a known history of a psychological disorder (and were excluded if they respond affirmatively), and selected a time to complete the study in the laboratory. Randomization to the negative and positive training groups was done through simple randomization in the Microsoft Excel participant tracking database and took place upon recruitment.

Upon arrival to the Sleep and Depression Laboratory, participants received more information about their participation in the study before providing written informed consent.

First, participants completed a number of questionnaires: providing information on demographic background, depressive symptoms (DASS-21), attentional control (ACS), and the first 


\section{ROLE OF COGNITIVE BIAS IN EMOTION REGULATION}

interpretation bias form (AST-D). The order for presentation of AST-D forms A and B was assigned through simple randomization for each participant in the Excel tracking database. Participants then completed the first portion of the emotion induction task by identifying two negative memories and providing 10 keywords related to each, after which a study assistant inputted the keywords into text files linked to E-Prime for randomization and presentation.

Next, participants underwent the first emotion induction, where 10 keywords were presented to participants on the computer screen. Immediately before and after presentation of the keywords, participants rated their emotions on a VAS, followed by completion of the postinduction questionnaire. As there were two memories included in the task, the order of which memory would be presented for which emotion induction was assigned through simple randomization in the Excel tracking database. Following the first emotion induction, participants completed the SERQ-M to determine to what extent they used each emotion regulation strategy while viewing the keywords, and then the SDERS to assess their emotional dysregulation.

Upon completion of the first emotion induction, the investigator or study assistant explained mental imagery in detail and went through four examples with the participant to verify they understood how to generate mental imagery, using visual props to explain the difference between field and observer perspective (for specific instructions contact Blackwell et al., 2015). Once the participant was able to successfully complete the four examples, they completed a VAS and electronic presentation of the bias training scenarios began. Between each block, participants were allowed a short break and continued when they pressed the space bar. When the scenarios finished, participants completed a brief manipulation check form to determine their competence in performing the imagery-based bias training as instructed (see Appendix D). 


\section{ROLE OF COGNITIVE BIAS IN EMOTION REGULATION}

Following training, participants again rated their emotions on the VAS before and after completing the filler task of listening to classical music for 5 minutes. There was no filler task before training because the instructions and examples of mental imagery took approximately 15 minutes to complete and acted as a neutral task to return emotion to baseline following the first emotion induction. After the filler task, participants completed the second interpretation bias form and the second set of emotion induction procedures exactly as outlined above.

Finally, participants were shown funny clips to counteract the negative emotions induced. Participants completed a VAS after presentation of the clips, and the investigator sought out verbal feedback from participants to ensure their emotions were sufficiently repaired before leaving the study. Participants were also debriefed with regards to the purpose of the study and provided with a list of counselling resources. In total, all study procedures took approximately 75-90 minutes to complete for each participant (see Figure 6 for outline of procedures).

All study procedure were approved by the Ryerson Research Ethics Board. All analyses, unless otherwise specified, were completed using IBM SPSS Statistics v25.

\section{Results}

\section{Missing Cases}

Decisions to address missing cases were determined a-priori. For two cases, all data was missing for the posttraining SERQ-M, SDERS, and post-induction VAS due to technical difficulties with E-Prime. For one case, all data on the ACS was missing because the participant was not aware there was a back side to the questionnaire. Finally, due to experimenter error, five participants were missing data on one of their VAS scales. All of these missing cases were therefore viewed to be missing completely at random (MCAR), and as such, listwise deletion was used for analyses (Soley-Bori, 2013). 


\begin{tabular}{|c|c|}
\hline Arrive In-Lab & $\begin{array}{ll}\text { - } & \text { Signed informed consent } \\
\text { - } & \text { Demographics } \\
\text { - } & \text { DASS-21 } \\
\text { - } & \text { ACS } \\
\text { - } & \text { Part } 1 \text { of AERT (identify keywords) }\end{array}$ \\
\hline & - AST-D \\
\hline Emotion Induction & $\begin{array}{ll}\text { - } & \text { VAS } \\
\text { - } & \text { Part } 2 \text { of AERT } \\
\text { - } & \text { VAS } \\
\text { - } & \text { Post-Induction Questionnaire } \\
\text { - } & \text { SERQ-M } \\
\text { - } & \text { S-DERS }\end{array}$ \\
\hline CBM-I & $\begin{array}{ll}\text { - } & \text { Instructions \& } 4 \text { examples } \\
\text { - } & \text { VAS } \\
\text { - } & \text { Present Scenarios } \\
\text { - } & \text { Manipulation Check } \\
\text { - } & \text { VAS } \\
\text { - } & \text { Filler } \\
\text { - } & \text { VAS }\end{array}$ \\
\hline & - AST-D \\
\hline $\begin{array}{l}\text { Emotion } \\
\text { Induction }\end{array}$ & $\begin{array}{ll}\text { - } & \text { VAS } \\
\text { - } & \text { Part } 2 \text { of AERT (view keywords) } \\
\text { - } & \text { VAS } \\
\text { - } & \text { Post-Induction Questionnaire } \\
\text { - } & \text { SERQ-M } \\
\text { - } & \text { S-DERS }\end{array}$ \\
\hline Finishing & $\begin{array}{ll}\text { - } & \text { Funny film clips } \\
\text { - } & \text { VAS } \\
\text { - } & \text { Debrief }\end{array}$ \\
\hline
\end{tabular}

Figure 6. Outline of procedure design. 


\section{ROLE OF COGNITIVE BIAS IN EMOTION REGULATION}

Some participants had missing items on various questionnaires that were thus not MCAR.

Multiple imputation methods could not be used because the PROCESS macro (Hayes, 2014)

does not accommodate such methods. According to Shrive and colleagues (2006), multiple imputation and individual mean imputation have been found to be equally accurate for dealing with missing data on a multi-item depression scale. Therefore, individual mean imputation was used to calculate item scores for missing items on all questionnaires, which were subsequently used to calculate questionnaire subscale and total scores.

\section{Group Differences}

To test for initial group differences, chi-square tests of independence were planned to test differences for categorical variables and independent samples t-tests were planned for continuous variables, when assumptions were violated non-parametric alternatives were used.

Normality of age, depression (DASS-D), anxiety (DASS-A), stress (DASS-S), pretraining emotion regulation (each SERQ-M subscale), emotion dysregulation (SDERS total score), pretraining interpretation bias (AST-D total score), and attentional control (ACS total score), attentional focusing (ACS focusing subscale), and attentional shifting (ACS shifting subscale), was assessed using the Shapiro-Wilk test and outliers were evaluated through an examination of Z-scores, with scores $> \pm 3$ considered outliers. Based on examination of Z-scores and Shapiro-Wilk test there were no outliers and data was normally distributed for attentional focusing $(p=.29)$, attentional shifting $(p=.11)$, total attentional control $(p=.90)$, pretraining interpretation bias $(p=.97)$, and pretraining reappraisal $(p=.45)$; thus, independent samples ttests were used to assess group differences. All other data was not normal on the Shapiro-Wilk test, all $p<.05$, and a visual examination of the data revealed it was either positively or negatively skewed. Bootstrapping is one approach to deal with violations of normality, it allows 


\section{ROLE OF COGNITIVE BIAS IN EMOTION REGULATION}

variables to be kept in their original non-transformed units making the results more intuitively interpretable and allows for calculations of effect sizes (Sainani, 2012); thus, 5000 sample BCa bootstrapping was used for all analyses when the assumption of normality was violated.

The assumption of homogeneity of variance was assessed using Levene's Test for Equality of Variances and was met for age $(F=.004, p=.95)$, depression $(F=2.02, p=.16)$, stress $(F=.54, p=.47)$, reappraisal $(F=.10, p=.76)$, distraction $(F=.32, p=.57)$, attentional $\operatorname{control}(F=1.25, p=.27)$, attentional focusing $(F=.01, p=.94)$, attentional shifting $(F=3.60$, $p=.06)$, interpretation bias $(F=.66, p=.42)$, and emotion dysregulation $(F=1.72, p=.19)$. The assumption was violated for anxiety $(F=5.66, p=.02)$, rumination $(F=4.60, p=.04)$, and suppression $(F=8.21, p=.01)$, so results are reported for output under "equal variances not assumed".

For both gender and ethnicity, more than $20 \%$ of contingency cells had expected values less than 5; thus, Fisher's exact test was used to assess for group differences.

At pre-manipulation, the groups were statistically equivalent on all variables with the exception of ethnicity, attentional shifting, and depression (see Table 1 for results and breakdown of ethnicity by percentage). The positive training group was significantly less depressed than the negative training group, was significantly better at shifting attention, and had significantly better total attentional control.

\section{Manipulation Checks}

Vividness ratings. To assess whether both groups imagined scenarios equally vividly, an independent samples t-test was planned. A mean vividness rating score, on a Likert-type scale from 1 (not at all vivid) to 5 (extremely vivid), was averaged from all 50 ratings for each participant to be used as the independent variable. Based on a visual examination of the data and 
ROLE OF COGNITIVE BIAS IN EMOTION REGULATION

Table 1

Pretraining Group Differences

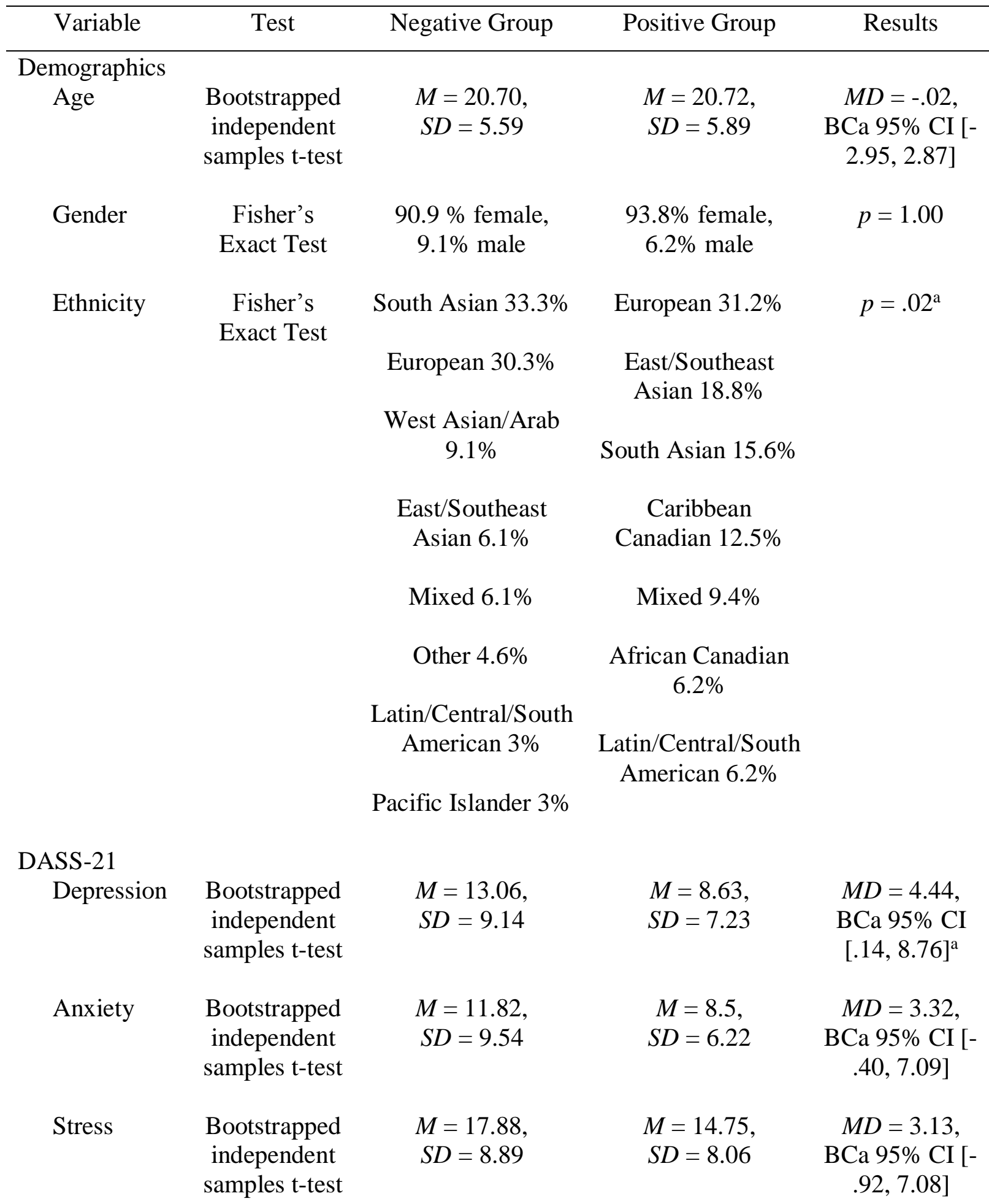

SERQ 


\begin{tabular}{|c|c|c|c|c|}
\hline Reappraisal & $\begin{array}{c}\text { Independent } \\
\text { samples t-test }\end{array}$ & $\begin{array}{c}M=16.51 \\
S D=5.93\end{array}$ & $\begin{array}{c}M=15.25 \\
S D=5.82\end{array}$ & $\begin{array}{c}t(63)=.86 \\
p=.39\end{array}$ \\
\hline Suppression & $\begin{array}{l}\text { Bootstrapped } \\
\text { independent } \\
\text { samples t-test }\end{array}$ & $\begin{array}{c}M=15.03 \\
S D=3.89\end{array}$ & $\begin{array}{c}M=13.72 \\
S D=5.75\end{array}$ & $\begin{array}{c}M D=1.31, \\
\text { BCa 95\% CI [- } \\
1.03,3.69]\end{array}$ \\
\hline Rumination & $\begin{array}{l}\text { Bootstrapped } \\
\text { independent } \\
\text { samples t-test }\end{array}$ & $\begin{array}{c}M=15.88 \\
S D=2.66\end{array}$ & $\begin{array}{c}M=15.41 \\
S D=4.32\end{array}$ & $\begin{array}{c}M D=.47, \\
\text { BCa } 95 \% \text { CI }[- \\
1.19,2.17]\end{array}$ \\
\hline Distraction & $\begin{array}{l}\text { Bootstrapped } \\
\text { independent } \\
\text { samples t-test }\end{array}$ & $\begin{array}{c}M=11.24 \\
S D=4.71\end{array}$ & $\begin{array}{l}M=9.66 \\
S D=4.99\end{array}$ & $\begin{array}{c}M D=1.59 \\
\text { BCa } 95 \% \text { CI }[- \\
.69,3.84]\end{array}$ \\
\hline \multicolumn{5}{|l|}{$\mathrm{CS}$} \\
\hline Total score & $\begin{array}{l}\text { Independent } \\
\text { samples t-test }\end{array}$ & $\begin{array}{c}M=46.72 \\
S D=7.95\end{array}$ & $\begin{array}{c}M=51.63 \\
S D=9.62\end{array}$ & $\begin{array}{c}t(62)=-2.23 \\
p=.03^{\mathrm{a}}\end{array}$ \\
\hline Focusing & $\begin{array}{l}\text { Independent } \\
\text { samples t-test }\end{array}$ & $\begin{array}{c}M=16.53 \\
S D=4.33\end{array}$ & $\begin{array}{c}M=18.69 \\
S D=4.37\end{array}$ & $\begin{array}{c}t(62)=-1.98 \\
p=.052\end{array}$ \\
\hline Shifting & $\begin{array}{l}\text { Independent } \\
\text { samples t-test }\end{array}$ & $\begin{array}{c}M=11.50 \\
S D=2.06\end{array}$ & $\begin{array}{c}M=12.92 \\
S D=2.99\end{array}$ & $\begin{array}{c}t(62)=-2.20 \\
p=.03^{\mathrm{a}}\end{array}$ \\
\hline
\end{tabular}

AST-D

Total score

Independent $\quad M=89.67$,

$M=93.00$,

$t(62)=-.78$, samples t-test

$S D=15.78$

$S D=18.56$

$p=.44$

\section{SDERS}

Total score

Independent
samples t-test

$M=42.25$,
$S D=10.44$

$M=38.38$,

$M D=3.88$, $S D=13.66$

Note. $M D=$ mean difference; DASS-21 = Depression and Anxiety Stress Scales; SERQ = State Emotion Regulation Questionnaire; ACS = Attentional Control Scale; AST-D = Ambiguous Scenarios Test; SDERS = State Difficulties in Emotion Regulation Scale. Group differences reported at pretraining. $N=65$ for all analyses with the exception of attentional control, attentional focusing, and interpretation bias; $N=64$. Bootstrapped tests used 5000 sample BCa bootstrapping.

${ }^{a}$ Significant at .05 level. 


\section{ROLE OF COGNITIVE BIAS IN EMOTION REGULATION}

the Shapiro-Wilk test $(p=.05)$, the data violated the assumption of normality and a 5000 sample BCa bootstrapping method was used for the independent samples t-test. Based on Levene's Test for Equality of Variances, the assumption of homogeneity of variance was met $(F=.22, p=.64)$.

On average, participants in the negative bias training group $(M=3.86, S D=.09)$ and participants in the positive training group $(M=3.86, S D=.10)$ did not differ on how vividly they could imagine the training scenarios, $t(63)<.001, p=1.00$ : as the difference was less than -.001 , BCa $95 \%$ CI $[-.26, .25]$. A mean score of 3.86 indicates they were able to imagine scenarios on average between "somewhat" and "very" vividly.

CBM-I manipulation check. An independent samples t-test was planned to assess whether both groups responded similarly to the manipulation check questionnaire following bias training, which assessed the extent to which participants were able to adhere to the CBM-I instructions of actively imagining the scenarios from a first person perspective without verbally analyzing the images. The total score of the 8 items of the manipulation check questionnaire was calculated for each participant to be used as the independent variable (minimum score 8 , maximum score 72). Based on a visual examination of the data and the Shapiro-Wilk test $(p=$ .12), the data were normally distributed. Based on Levene's Test for Equality of Variances, the assumption of homogeneity of variance was met $(F=3.31, p=.07)$.

On average, participants in the negative bias training group $(M=48.97, S D=6.98)$ were better able to follow the CBM-I instructions than participants in the positive training group $(M=$ 45.00, $S D=4.93), t(63)=2.64, p=.01$ : indicative of a medium sized effect; $d=.65$.

Negative memory intensity ratings. To determine whether randomization of memories was successful in making the memories equally negative between groups and emotion inductions, two chi-square tests of independence were planned to compare emotional intensity 


\section{ROLE OF COGNITIVE BIAS IN EMOTION REGULATION}

ratings of memories (i.e., neutral, negative, extremely negative) at each emotion induction between the negative and positive groups. Emotional intensity ratings were also compared between the first and second emotion inductions for the whole sample using a McNemar-Bowker test. For memories presented at both the first and second emotion induction, more than $20 \%$ of contingency cells had expected values less than 5; thus, Fisher's exact test was used.

Two-sided Fisher's exact tests revealed no significant differences between groups' intensities of memory ratings during the first $(p=.88)$ and second emotion inductions $(p=.17)$. The two-sided McNemar-Bowker test revealed no significant differences in symmetry of proportions of memory intensity ratings between the first and second emotion inductions ( $p=$ .99) for the whole sample.

Emotion inductions. To determine whether the negative emotion inductions were effective, two separate $2 \times 2$ mixed analyses of variance (ANOVAs) were planned for each emotion induction: with group as the between-group factor, time as the within-group factor, and emotion ratings on the $100 \mathrm{~mm}$ visual analog scale (VAS), ranging from 0 (extremely negative) to 100 (extremely positive), as the dependent variable.

First emotion induction. An examination of Z-scores revealed no outliers in either the between-group or the within-group factors. Normality of the distribution of emotion scores was assessed for both between-group and within-group factors using the Shapiro-Wilk test; the assumption of normality was met in all cases $(p<.05)$, with the exception of the distribution of emotion scores following the emotion induction for the positive group $(p=.04)$. However, given that the mixed-ANOVA is robust to violations of normality when sample size is sufficiently large and equal between groups, and a visual inspection of the Q-Q plots indicated only a slight deviation from normality, it was decided to carry out the planned analysis without transforming 


\section{ROLE OF COGNITIVE BIAS IN EMOTION REGULATION}

the data. When sample sizes are equal and relatively large $(n=32)$ it is recommended to not rely on Levene's Test for Equality of Variances as it is susceptible to Type I error, and instead use the variance ratio, or Harley's $F_{\max }\left(\right.$ Field, 2013). The calculated $F_{\max }=1.9$ was smaller than the expected $F_{\max }=2.61$, and therefore the variance was homogeneous and the assumption was not violated.

The mixed-ANOVA revealed main effects of both time, $F(1,62)=68.63, p<.001$, large effect size of $\eta_{\mathrm{p}}^{2}=.53$; and group, $F(1,62)=4.21, p=.04$, medium effect size of $\eta_{\mathrm{p}}^{2}=.06$. Emotion was overall higher in the positive group than the negative group and decreased in both groups following the emotion induction (see Figure 7).

Finally, an independent samples t-test was also used to compare groups' responses on the emotion induction manipulation check questionnaire (total score), which assessed the extent to which participants were able to experience negative emotion, think of the negative memory, and imagine it vividly during the emotion induction. The assumption of normality was not met based on the Shapiro-Wilk test, $p<.001$, and 5000 sample BCa bootstrapping was used for the analysis. The assumption of homogeneity of variance was assessed using Levene's Test for Equality of Variances and was met $(F=.11, p=.74)$. The negative $(M=4.36, S D=1.45)$ and positive $(M=4.97, S D=1.64)$ bias training groups had a mean difference of $-.61, \mathrm{BCa} 95 \% \mathrm{CI}$ $[-1.34, .11]$, which was not a significant difference, $t(63)=-1.58, p=.12$.

Second emotion induction. An examination of Z-scores revealed no outliers in either the between-group or the within-group factors. Normality of the distribution of emotion scores was assessed for both between-group and within-group factors using the Shapiro-Wilk test, and the assumption of normality was met in all cases $(p<.05)$. The calculated $F_{\max }=2.33$ was found to 


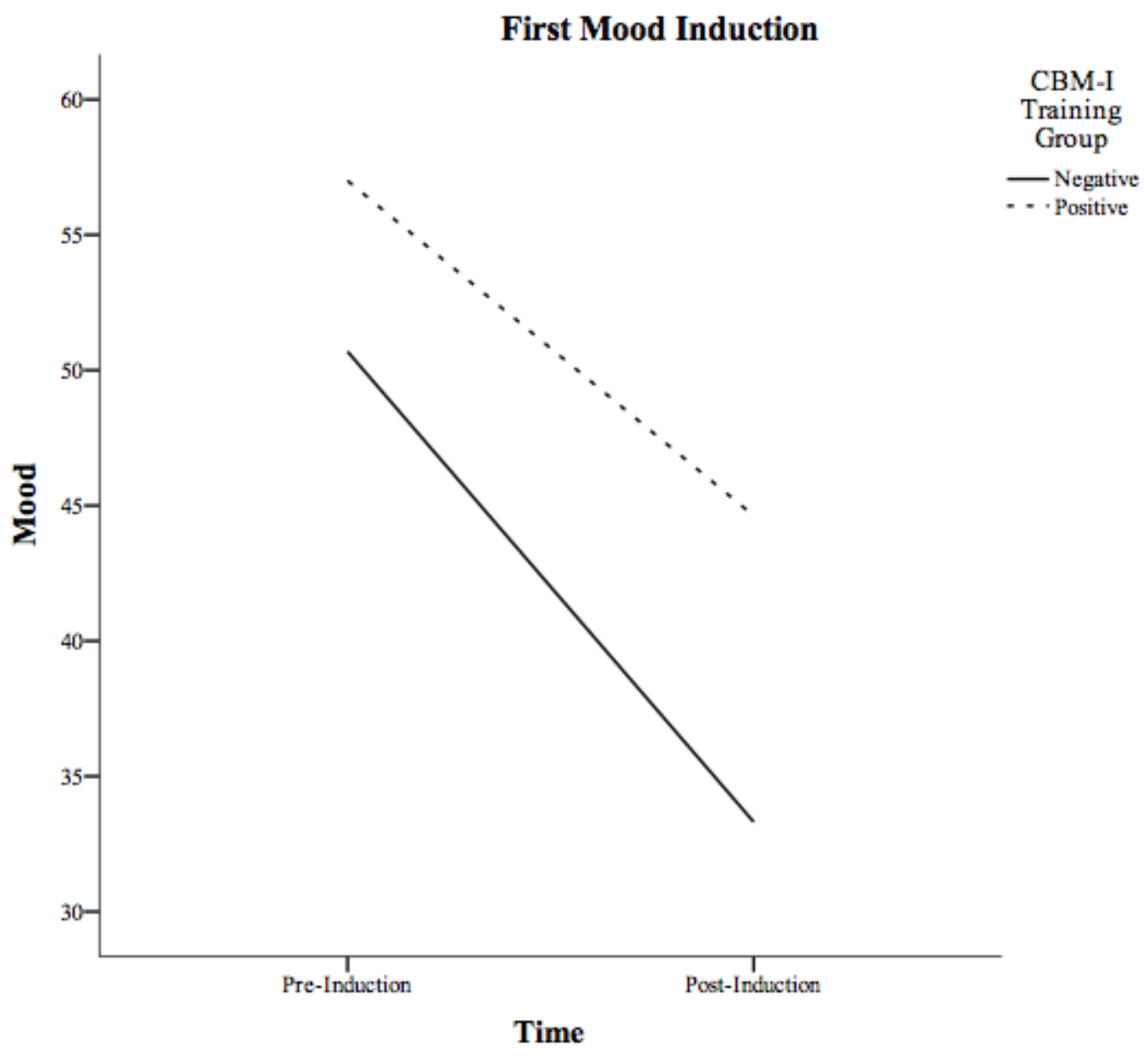

Figure 7. Significant main effects of group and time for emotion (VAS score) during the first emotion induction, with $N=64$. A score of 0 on the $100 \mathrm{~mm}$ VAS indicates emotion is "extremely negative" and a score of 100 indicates emotion is "extremely positive". 


\section{ROLE OF COGNITIVE BIAS IN EMOTION REGULATION}

be smaller than the expected $F_{\max }=2.61$, and therefore the variance was homogeneous and the assumption was not violated.

The mixed-ANOVA revealed a main effect of time, $F(1,59)=36.48, p<.001$, large effect size of $\eta_{\mathrm{p}}^{2}=.38$. There was no significant main effect of group, $F(1,59)=1.65, p=.20$, and no significant interaction identified, $F(1,59)=.002, p=.97$. Emotion decreased in both groups following the emotion induction (see Figure 8).

An independent samples t-test was also used to compare groups' responses on the emotion induction manipulation check questionnaire (total score), which assessed the extent to which participants were able to experience negative emotion, think of the negative memory, and imagine it vividly during the emotion induction. The assumption of normality was not met based on the Shapiro-Wilk test, $p<.001$, and 5000 sample BCa bootstrapping was used for the analysis. The assumption of homogeneity of variance was assessed using Levene's Test for Equality of Variances and was met $(F=.85, p=.36)$. The negative $(M=4.91, S D=1.55)$ and positive $(M=4.81, S D=1.89)$ bias training groups had a mean difference of .10, BCa $95 \%$ CI [$.75, .91]$, which was not a significant difference, $t(61)=.23, p=.82$.

Filler task. To determine whether the filler task was effective in returning emotion to baseline and equalizing emotion between groups posttraining, a 2x3 mixed-ANOVA was planned: with group as the between-group factor, time (pretraining, posttraining, and post-filler) as the within-group factor, and emotion ratings (VAS score; 0 being extremely negative, 100 being extremely positive) as the dependent variable.

An examination of $Z$-scores revealed one outlier with a $Z$-score $> \pm 3$ in the positive group prior to training, which was removed from the following analyses. Normality of the distribution of emotion scores was assessed for both between-group and within-group factors 


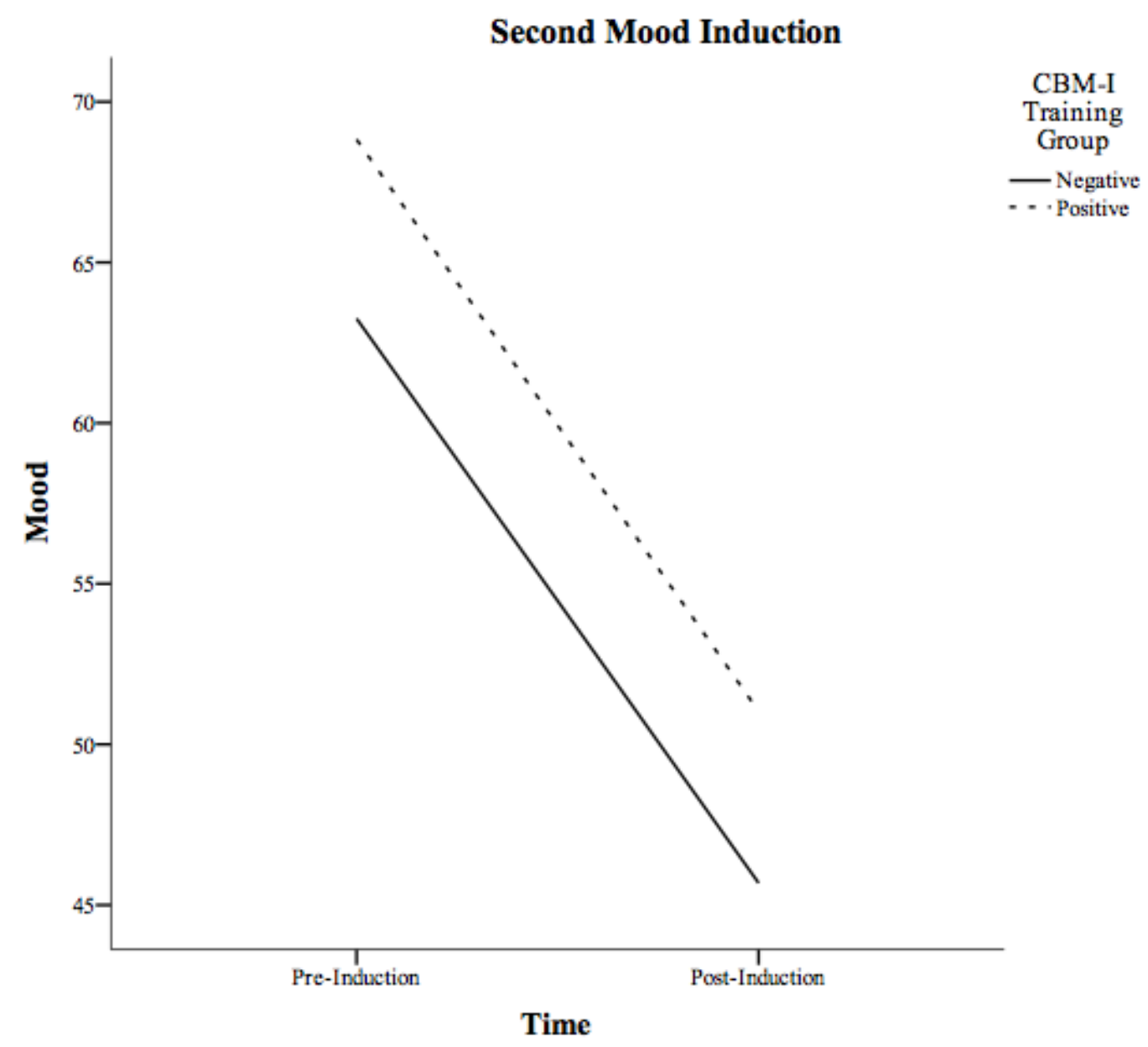

Figure 8. Significant main effect of time for emotion (VAS score) during the second emotion induction, with $N=61$. A score of 0 on the $100 \mathrm{~mm}$ VAS indicates emotion is "extremely negative" and a score of 100 indicates emotion is "extremely positive". 


\section{ROLE OF COGNITIVE BIAS IN EMOTION REGULATION}

using the Shapiro-Wilk test. The assumption of normality was met in all cases $(p<.05)$, with the exceptions of the distributions of emotion scores after the filler task for the whole sample $(p=$ $.03)$, after training for the positive group $(p=.03)$, and following the filler task for the positive group ( $p=.04)$. No skewness statistic divided by its standard error was greater than \pm 1.96 , and a visual inspection of the Q-Q plots indicated only a slight deviation from normality. Given that the mixed-ANOVA is robust to violations of normality when sample size is sufficiently large and equal between groups, it was decided to carry out the planned analysis without transforming the data. Mauchly's Test of Sphericity indicated the assumption of sphericity was not violated ( $p$ $=.12$ ) and Levene's Test of Equality of Error Variances indicated the assumption of homogeneity of variance was also met before and after training, and following the filler task $(p=$ $.95, p=.62$, and $p=.78$ respectively).

The mixed-ANOVA revealed a main effect of time, $F(2,122)=5.30, p=.006$, medium effect size of $\eta_{\mathrm{p}}^{2}=.08$, and a significant group $\mathrm{x}$ time interaction $F(2,122)=5.86, p=.004$, medium effect size of $\eta_{\mathrm{p}}{ }^{2}=.09$. There was no main effect of group, $F(1,61)=2.15, p=.15$. Throughout the training procedures and filler task, emotion remained unchanged in the positive group, while in the negative group emotion decreased posttraining and increased following the

filler task (see Figure 9). Planned contrast analyses revealed that participants' emotion before training did not differ from emotion following the filler task (mean difference $=.61, p=1.00$ ).

\section{Psychometric Properties of AST-D and SERQ-M}

In order to assess the psychometric properties of the State Emotion Regulation Questionnaire modified for the purposes of this study (SERQ-M) and the Ambiguous Scenarios Test (AST-D) in this sample: analyses to determine the internal consistency, convergent and 


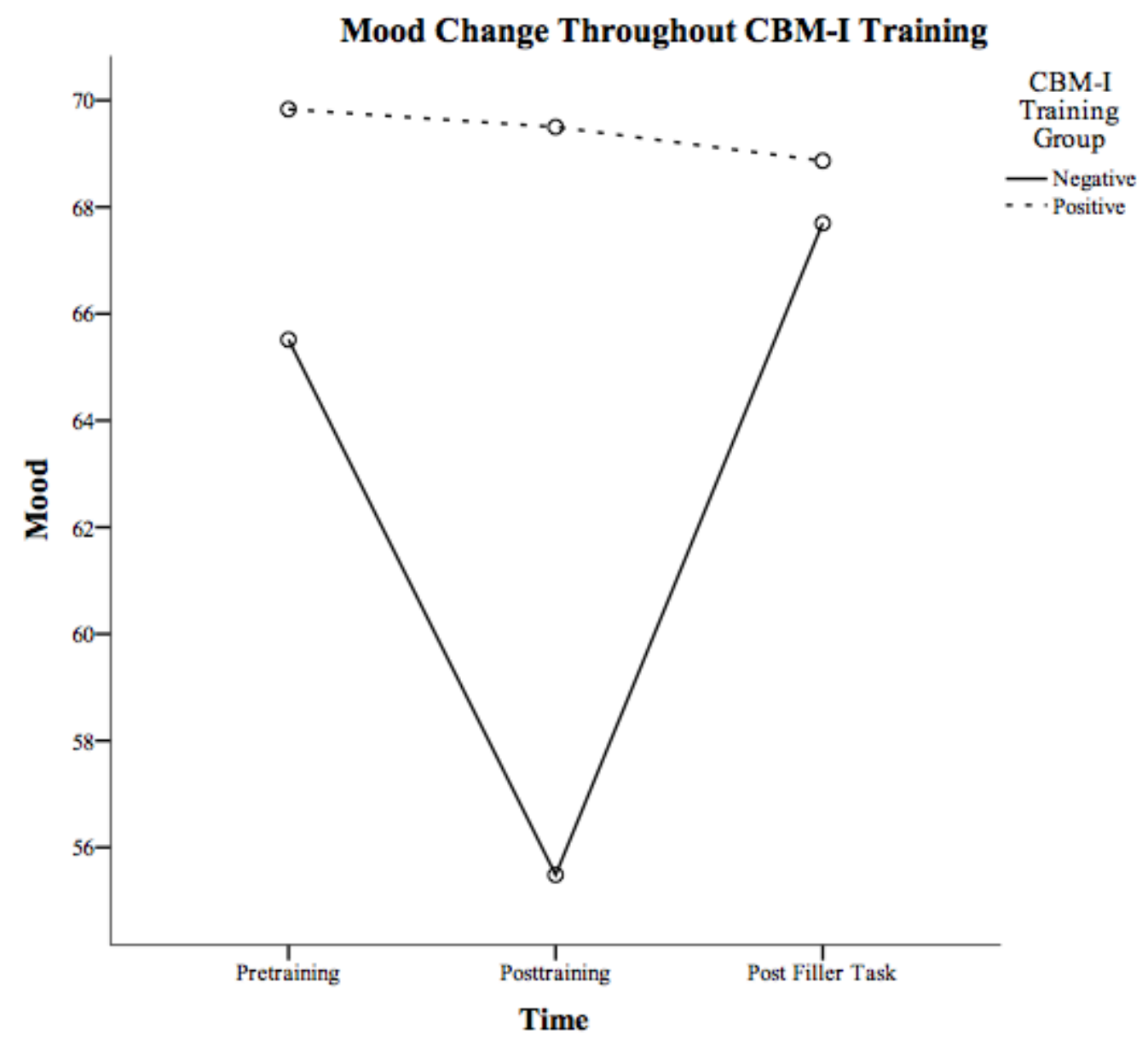

Figure 9. Significant main effect of time and significant group $\mathrm{x}$ time interaction for emotion (VAS score) over the course of CBM-I training and the filler task, with $N=63$. A score of 0 on the 100mm VAS indicates emotion is "extremely negative" and a score of 100 indicates emotion is "extremely positive". 


\section{ROLE OF COGNITIVE BIAS IN EMOTION REGULATION}

discriminant validities, and structural validity of both questionnaires were conducted (De Souza, Alexandre, \& Guirardello, 2017).

Internal consistency. Internal consistency for the AST-D was evaluated using Cronbach alpha values for forms A and B overall (see Table 2). Internal consistency was assessed for the SERQ-M for both pre and posttraining (see Table 3). Alpha values if an item was deleted were assessed to determine whether removing certain items would increase internal consistency. Removing items for the suppression, reappraisal, or distraction subscales did not greatly improve overall internal consistency of the scale. The addition of item 13 to the original SERQ, creating the SERQ-M, neither decreased nor increased the subscales internal consistency. Results indicated that removing either item 8 or 12 from the rumination subscale would improve the internal consistency; however, it should be noted there are only three items in this scale.

Convergent and discriminant validity. Construct validity of the SERQ-M and the ASTD (both completed prior to training) was evaluated through assessing convergent and discriminant validities. Specifically, 1000 BCa bootstrapped bivariate correlation analysis was used to determine the correlations between each of the SERQ-M subscales and each of the SDERS subscales (i.e. Awareness, Nonacceptance, Modulate, Clarity, and the Total Emotion Dysregulation Score); and the correlation between the total AST-D score pretraining and the DASS depression and anxiety subscales, and the ACS total and subscale scores.

Interpretation bias as measured by the AST-D total score was significantly negatively correlated with both depression and anxiety (see Table 4). In addition, it was also significantly positively correlated with attentional shifting and overall attentional control (ACS total score).

Of the SDERS subscales, reappraisal was only significantly correlated with awareness of current emotions, with a small to medium effect size (see Table 5). Rumination was negatively 
ROLE OF COGNITIVE BIAS IN EMOTION REGULATION

Table 2

AST-D Reliability Psychometrics

\begin{tabular}{|c|c|c|c|c|}
\hline Scale & $M$ & $S D$ & $\begin{array}{c}\text { Mean Inter-Item } \\
\text { Correlation }\end{array}$ & $\alpha$ \\
\hline $\begin{array}{l}\text { Form A } \\
\text { AST-D (A) total }\end{array}$ & 1.3 & .97 & .11 & .63 \\
\hline AST-D (A) "future" & .51 & 1.2 & .04 & .19 \\
\hline AST-D (A) "self" & 1.2 & 1.3 & .20 & .58 \\
\hline AST-D (A) "experience" & 2.4 & 1.6 & .17 & .47 \\
\hline $\begin{array}{l}\text { Form B } \\
\text { AST-D (B) total }\end{array}$ & 1.3 & 1.2 & .18 & .77 \\
\hline AST-D (B) "future" & 1.0 & 1.6 & .24 & .60 \\
\hline AST-D (B) "self" & 1.4 & 1.4 & .18 & .56 \\
\hline AST-D (B) "experience" & 1.4 & 1.8 & .24 & .54 \\
\hline
\end{tabular}

Note. AST-D = Ambiguous Scenarios Test; $\alpha=$ Cronbach's alpha value. Form A and Form B reported for whole sample $(N=63)$ regardless of whether the questionnaire was completed before or after training. 
ROLE OF COGNITIVE BIAS IN EMOTION REGULATION

Table 3

SERQ-M Reliability Psychometrics

\begin{tabular}{lcccc}
\hline Scale & $M$ & $S D$ & Inter-Item Correlation & $\alpha$ \\
\hline $\begin{array}{l}\text { SERQ-M pretraining } \\
\text { Suppression }\end{array}$ & 14.39 & 4.90 & .72 & .88 \\
Rumination & 15.65 & 3.55 & .31 & .56 \\
Reappraisal & 15.89 & 5.86 & .46 & .77 \\
Distraction & 10.46 & 4.88 & .48 & .74 \\
SERQ-M posttraining & & & & .90 \\
Suppression & 12.41 & 5.87 & .76 & .39 \\
Rumination & 15.51 & 3.61 & .20 & .62 \\
Reappraisal & 15.24 & 5.33 & .29 & .82 \\
Distraction & 9.43 & 5.03 & .60 &
\end{tabular}

Note. SERQ-M = Modified State Emotion Regulation Questionnaire. $\alpha=$ Cronbach's alpha value. $N=65$ for all pretraining analyses, for posttraining $N=63$ ( $n=31$ for positive group; $n$ $=32$ for negative group) 
ROLE OF COGNITIVE BIAS IN EMOTION REGULATION

Table 4

Correlations between AST-D and other measures

\begin{tabular}{lcc}
\hline & \multicolumn{2}{c}{ Interpretation Bias (AST-D) } \\
\cline { 2 - 3 } & $r$ & BCa 95\% CI \\
\hline Depression (DASS-D) & $-.45^{\mathrm{a}}$ & {$[-.62,-.25]$} \\
Anxiety (DASS-A) & $-.28^{\mathrm{a}}$ & {$[-.46,-.08]$} \\
Attentional Focusing (ACS Focusing) & .26 & {$[-.02, .52]$} \\
Attentional Shifting (ACS Shifting) & $.40^{\mathrm{a}}$ & {$[.12, .61]$} \\
Attentional Control (ACS Total) & $.36^{\mathrm{a}}$ & {$[.08, .58]$} \\
\end{tabular}

Note. AST-D = Ambiguous Scenarios Test; ACS = Attentional Control Scale; DASS =

Depression and Anxiety Stress Scales. Pretraining interpretation bias as measured by the ASTD total score centered at $75 . \mathrm{BCa} 95 \% \mathrm{CI}=$ Bias corrected and accelerated $95 \%$ confidence intervals. $N=63$.

${ }^{a}$ significant at .05 level. 
ROLE OF COGNITIVE BIAS IN EMOTION REGULATION

Table 5

Correlations between SERQ subscales and SDERS subscales

\begin{tabular}{lcccc}
\hline & $\begin{array}{c}\text { Reappraisal } \\
(r, \mathrm{BCa} 95 \% \mathrm{CI})\end{array}$ & $\begin{array}{c}\text { Suppression } \\
(r, \mathrm{BCa} 95 \% \mathrm{CI})\end{array}$ & $\begin{array}{c}\text { Rumination } \\
(r, \mathrm{BCa} 95 \% \mathrm{CI})\end{array}$ & $\begin{array}{c}\text { Distraction } \\
(r, \mathrm{BCa} 95 \% \mathrm{CI})\end{array}$ \\
\hline Awareness & $.20^{\mathrm{a}},[.01, .39]$ & $.03,[-.22, .25]$ & $-.39^{\mathrm{a}},[-.59,-.19]$ & $.29^{\mathrm{a}},[.08, .50]$ \\
Nonacceptance & $.10,[-.14, .36]$ & $.33^{\mathrm{a}},[.16, .48]$ & $.22^{\mathrm{a}},[.02, .41]$ & $.25^{\mathrm{a}},[.002, .50]$ \\
Modulate & $-.02,[-.27, .25]$ & $.39^{\mathrm{a}},[.20, .52]$ & $.15,[-.05, .35]$ & $.24^{\mathrm{a}},[.01, .47]$ \\
Clarity & $.16,[-.10, .38]$ & $-.04,[-.35, .23]$ & $.01,[-.26, .25]$ & $.22,[-.05, .46]$ \\
SDERS Total & $.13,[-.12, .36]$ & $.35^{\mathrm{a}},[.16, .51]$ & $.06,[-.17, .29]$ & $.37^{\mathrm{a}},[.14, .57]$
\end{tabular}

Note. SERQ = State Emotion Regulation Questionnaire; SDERS = State Difficulties in

Emotion Regulation Scale. BCa 95\% CI = Bias corrected and accelerated 95\% confidence intervals. $N=65$.

a significant at .05 level. 


\section{ROLE OF COGNITIVE BIAS IN EMOTION REGULATION}

correlated with awareness of one's emotions and positively correlated with nonacceptance of emotions. Suppression was significantly positively correlated with nonacceptance, difficulties modulating emotional responses, and the SDERS total score ( $r$ ranging from .33 to .39); while distraction was significantly correlated with awareness, nonacceptance, difficulties modulating responses ( $r$ ranging from .24 to .29), as well as the SDERS total score $(r=.37)$.

Structural and factorial validity. To evaluate the factorial and structural validity of the AST-D and the SERQ-M, confirmatory factor analysis (CFA) was conducted using the R software package (R Core Team, 2016). When conducting the CFA for form A of the AST-D, the software was unable to provide fit measures because the model did not converge and produced warnings that "lavaan did not converge after 701 iterations" and "estimates are most likely unreliable". As such, the measures of model fit are not reported here. Standardized factor loadings for items in each subscale are provided in Figure 10; however, given the errors resulting from nonconvergence, the software could not produce $p$-values or $95 \%$ confidence intervals for any loading.

When conducting the CFA for form $\mathrm{B}$, model fit statistics were as follows: RMSEA = $.11 ; \mathrm{TLI}=.62 ; \mathrm{CFI}=.68$. Figure 11 shows the model and standardized factor loadings for ASTD form B for the entire sample $(N=65)$, regardless of whether the form was completed before or after training. Factor loadings for items 4 and 5 on the Self subscale; items 3, 7, and 9 on the Future subscale; and items 10 and 13 on the Experiences subscale were found to be significant at the $p=.05$ level.

The CFA for the SERQ-M completed prior to training provided these measures of model fit: $\mathrm{RMSEA}=.10 ; \mathrm{TLI}=.83 ; \mathrm{CFI}=.87$. Figure 12 shows the model and standardized factor 


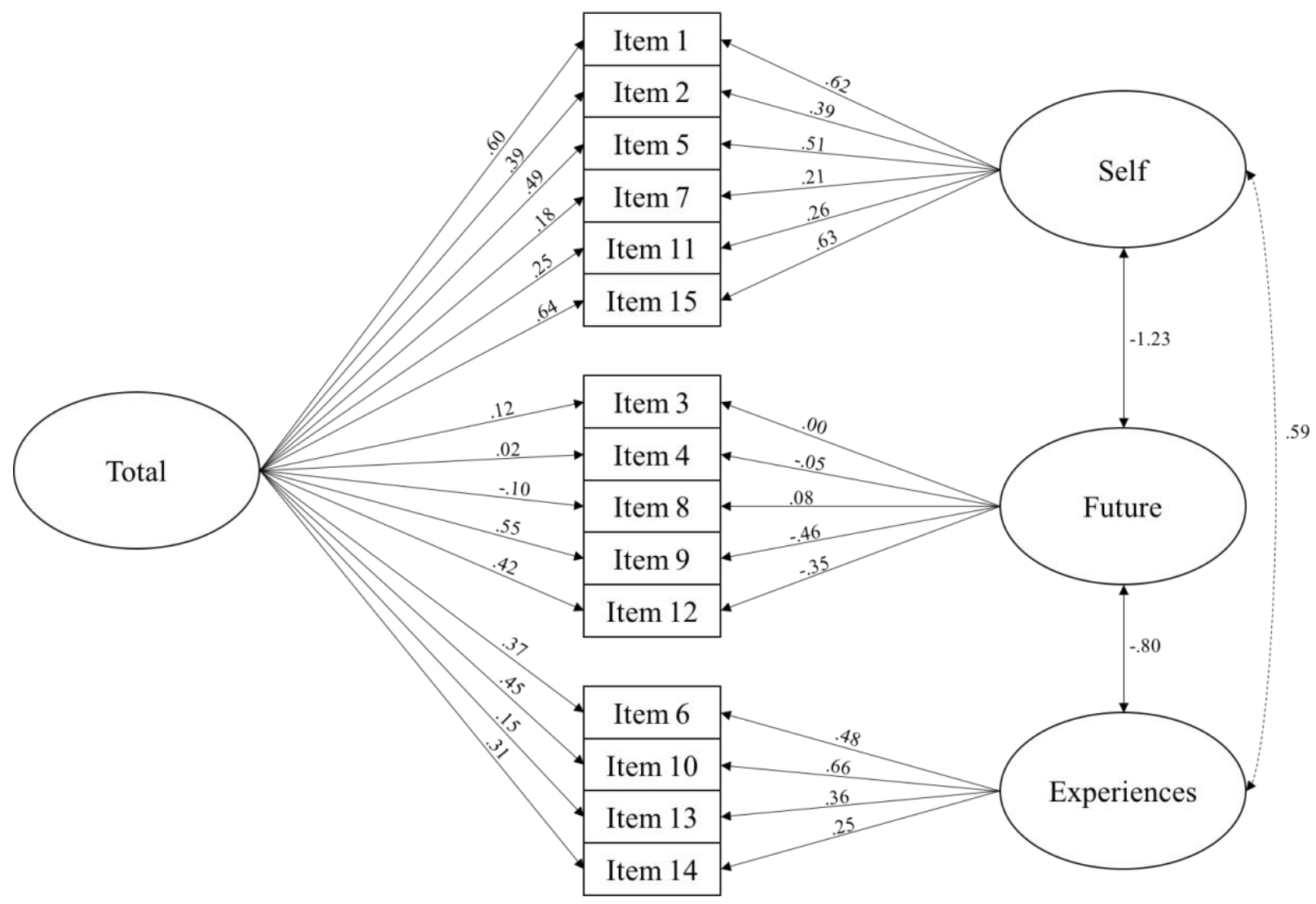

Figure 10. Structural equation modeling for the Ambiguous Scenarios Test (AST-D) Form A. 


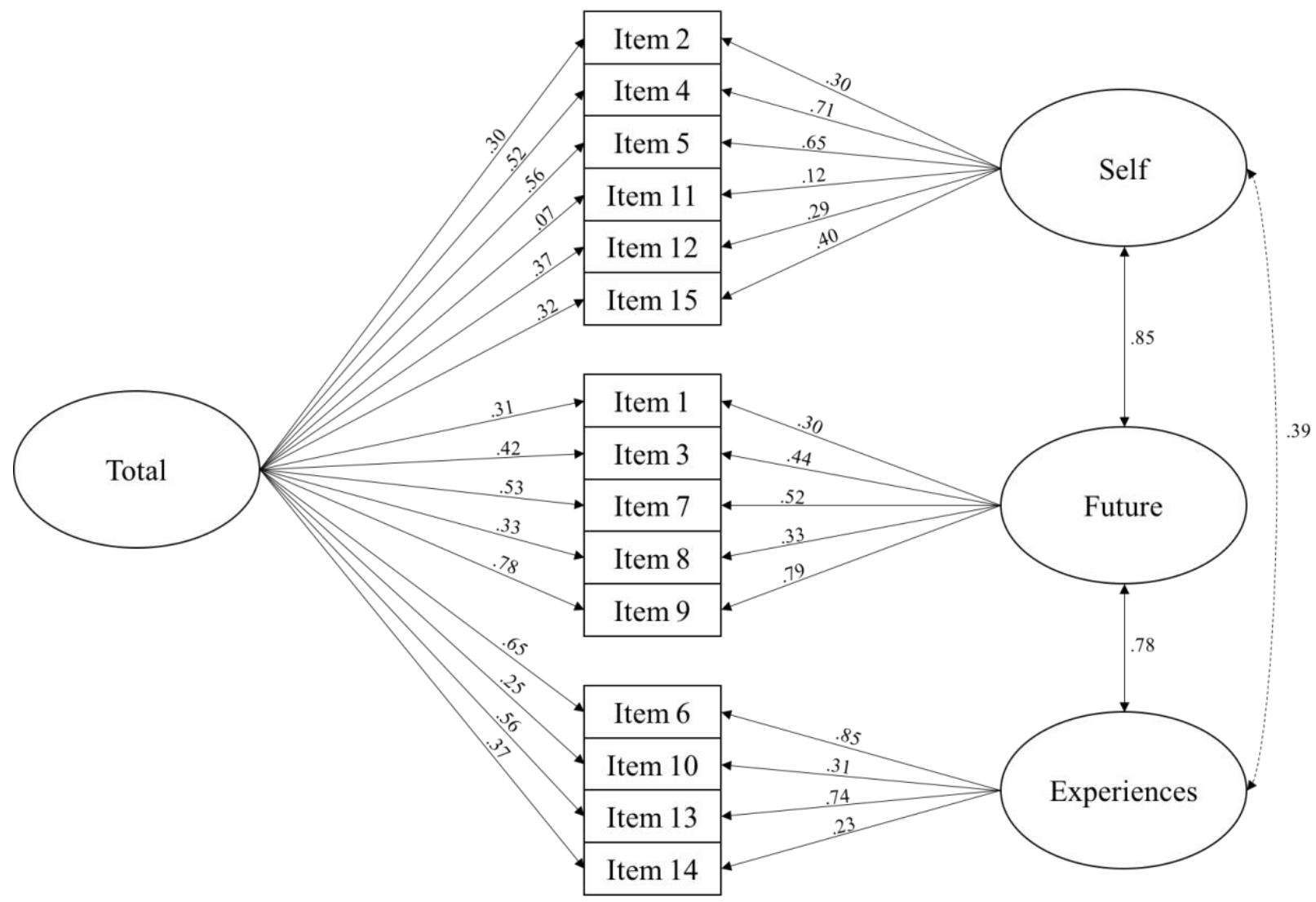

Figure 11. Structural equation modeling for the Ambiguous Scenarios Test (AST-D) Form B. 
ROLE OF COGNITIVE BIAS IN EMOTION REGULATION

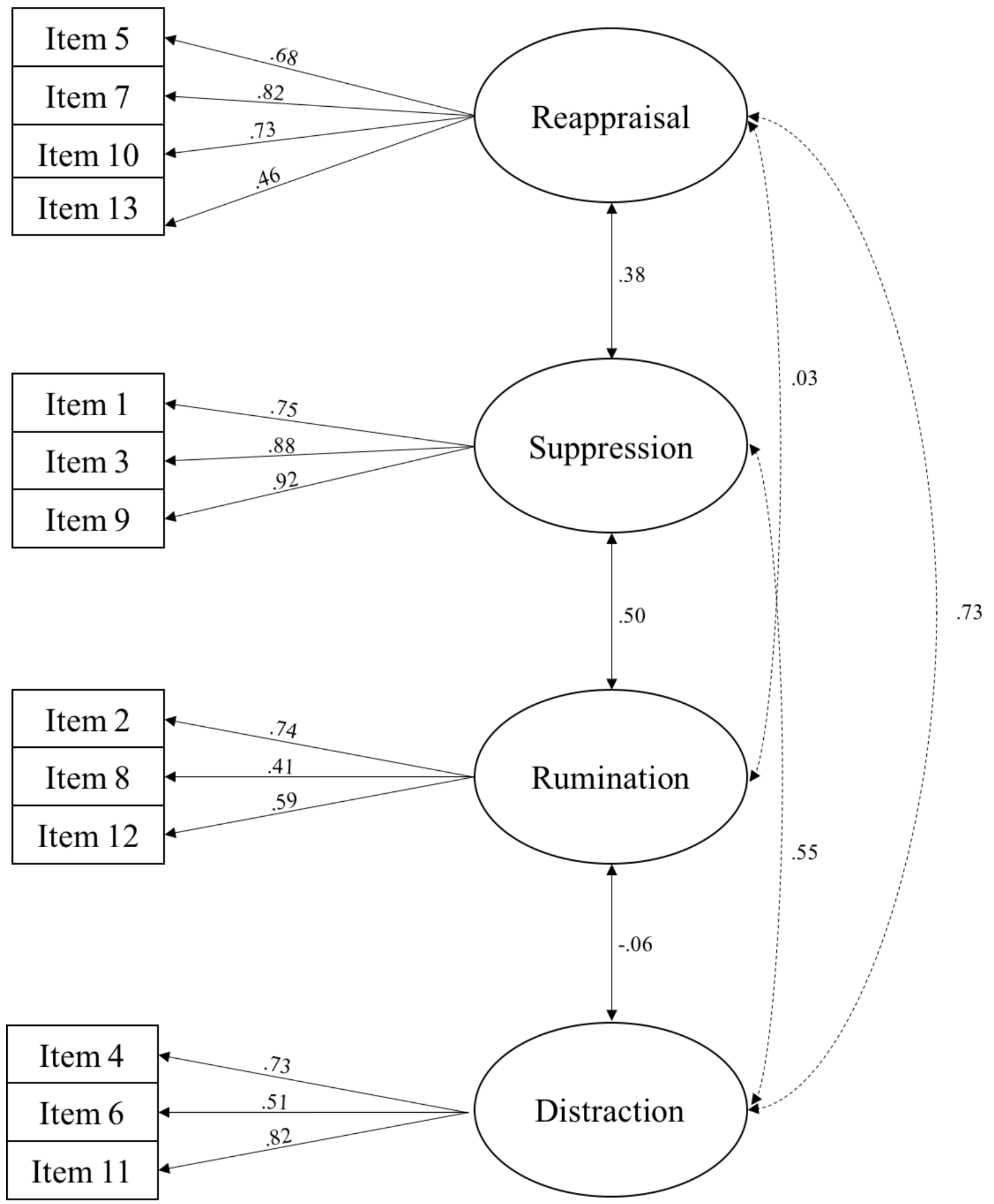

Figure 12. Structural equation modeling for the State Emotion Regulation Questionnaire (SERQ) completed pretraining. 


\section{ROLE OF COGNITIVE BIAS IN EMOTION REGULATION}

loadings for the SERQ-M pretraining for the entire sample $(N=65)$. Factor loadings for all items were found to be significant at the $p=.05$ level.

\section{Main Analyses}

Primary aim: was CBM-I training effective? The primary aim of this study was to determine whether the imagery-based interpretation bias training was effective in altering interpretation bias. A 2x2 mixed-ANOVA was planned, with group as the between-group factor, time as the within-group factor, and interpretation bias (AST-D total score centered at 75 to eliminate negative values) as the dependent variable.

An examination of Z-scores revealed no outliers in either the between-group or the within-group factors. Normality of the distribution of emotion scores was assessed for both between-group and within-group factors using the Shapiro-Wilk test, the assumption of normality was met in all cases $(p<.05)$. The calculated $F_{\max }=1.6$ was smaller than the expected $F_{\max }=2.61$, and therefore the variance was homogeneous and the assumption was not violated.

A mixed-ANOVA revealed a main effect of time, $F(1,62)=8.53, p=.005$, medium effect size of $\eta_{\mathrm{p}}^{2}=.12$. There was no main effect of group, $F(1,62)=1.91, p=.17$, and no significant interaction, $F(1,62)=.78, p=.38$. In the sample as a whole, interpretation bias increased following the training. The groups did not differ in their amount of interpretation bias

overall, and the change in interpretation bias was not significantly different between the negative and positive groups (see Figure 13).

Secondary aims: Model testing. The secondary aim of this study was to test for the hypothesis that interpretation bias change would mediate the relationship between group and emotion regulation strategy change, and that depressive symptoms would moderate the a and c paths in this model. A separate moderated mediation analysis was run for each emotion 


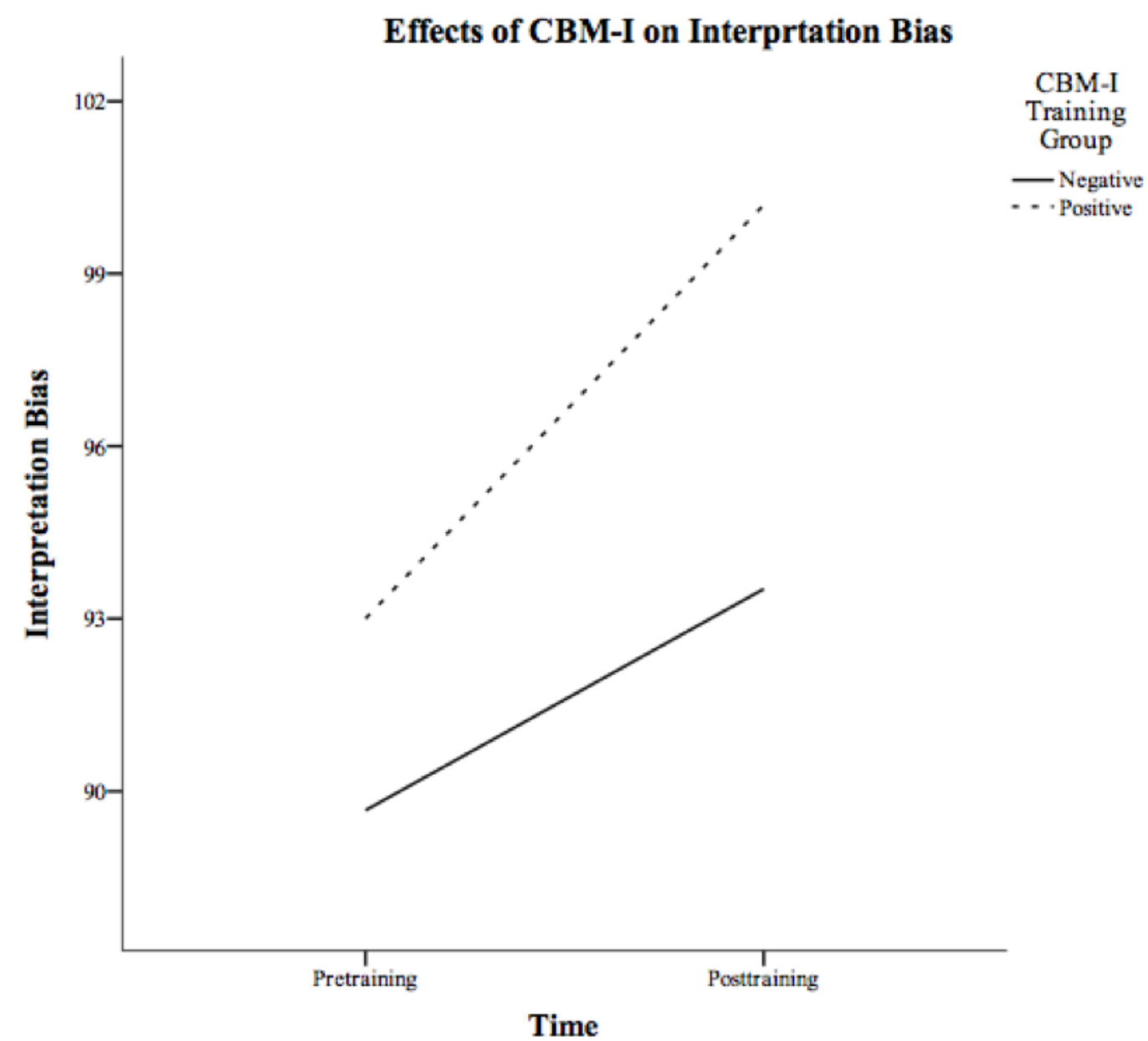

Figure 13. Significant main effect of time for interpretation bias (AST-D total score centered at 75) during CBM-I training, with $N=64$. A score of 0 on the AST-D indicates a high negative interpretation bias, a score of 150 indicates a high positive interpretation bias, and a score of 75 indicates no bias; therefore, higher scores on the AST-D indicate a more positive interpretation bias. 


\section{ROLE OF COGNITIVE BIAS IN EMOTION REGULATION}

regulation strategy (i.e., reappraisal, suppression, rumination, distraction; see Figure 14 for an example). Model 8 of Hayes PROCESS macro (2014) was used to test these hypotheses.

Multicollinearity between the independent variable, the moderator, and the interaction terms was assessed for all models using VIF scores. All VIF values were below 2, and therefore, the assumptions of multicollinearity were met. The option for heteroscedasticity-consistent standard errors was used in the analyses.

Depressive symptoms were not a significant moderator in any model and there were no direct or indirect effects of interpretation bias change on emotion regulation strategy change in any model. There were also no differences in emotion regulation change between the negative and positive groups, as group was not a significant predictor of emotion regulation strategy change in any model (see Tables 6 and 7 for reappraisal and rumination, and Figure 15 for suppression).

\section{Minor Objectives}

Is depression correlated with emotion regulation strategies? To replicate past findings that depression is positively correlated with rumination and suppression and negatively correlated with reappraisal, Pearson's product moment correlation analyses were planned between depression (DASS-D scores) and emotion regulation strategy use during the emotion induction prior to any training (SERQ-M subscale scores). Given that depression, rumination, and suppression were not normally distributed, 5000 sample BCa bootstrapping was used for all analyses.

The analyses revealed that none of the emotion regulation subscales were significantly correlated with depression (suppression BCa 95\% CI $[-.15, .35]$; rumination BCa 95\% CI [-.33, $.20]$; reappraisal BCa $95 \%$ CI $[-.25, .28])$. 
ROLE OF COGNITIVE BIAS IN EMOTION REGULATION

Table 6

Results of Moderated Mediation Model for Reappraisal Change

\begin{tabular}{lccc}
\hline & $B$ & $S E$ & $p$ \\
\hline Predictors of Interpretation Bias $\Delta$ & .60 & 5.81 & .92 \\
$\quad$ Group & -.28 & .62 & .65 \\
Depression & .38 & .48 & .43 \\
$\quad$ Group X Depression & & & \\
Predictors of Reappraisal $\Delta$ & .07 & .03 & $.03^{\mathrm{a}}$ \\
$\quad$ Interpretation Bias $\Delta$ & -.16 & 2.40 & .95 \\
Group & -.02 & .27 & .93 \\
Depression & -.07 & .18 & .71 \\
Group x Depression &
\end{tabular}

Note. $\mathrm{CI}=$ confidence interval; $\mathrm{SE}=$ standard error; $\Delta=$ change. For $N=62$, the indirect effect of the highest order product, with interpretation bias $\Delta$ as the mediator, was .03, $S E=.05$, BC 95\% CI $[-.03, .16]$.

a significant at .05 level. 


\section{ROLE OF COGNITIVE BIAS IN EMOTION REGULATION}

\section{Table 7}

Results of Moderated Mediation Model for Rumination Change

\begin{tabular}{lccc}
\hline \multicolumn{1}{c}{ Predictors of Rumination $\Delta$} & $B$ & $S E$ & $p$ \\
\hline Interpretation Bias $\Delta$ & .08 & .04 & $.03^{\mathrm{a}}$ \\
Group & 1.03 & 1.63 & .53 \\
Depression & .07 & .23 & .76 \\
Group x Depression & $<.001$ & .15 & 1.00 \\
\hline
\end{tabular}

Note. $\mathrm{CI}=$ confidence interval; $\mathrm{SE}=$ standard error; $\Delta=$ change. For $N=62$, the indirect effect of the highest order product, with interpretation bias $\Delta$ as the mediator, was .03, $S E=.05, \mathrm{BC} 95 \% \mathrm{CI}[-.03, .17]$. For predictors of Interpretation Bias $\Delta$ see Table 6.

${ }^{a}$ significant at .05 level. 
ROLE OF COGNITIVE BIAS IN EMOTION REGULATION

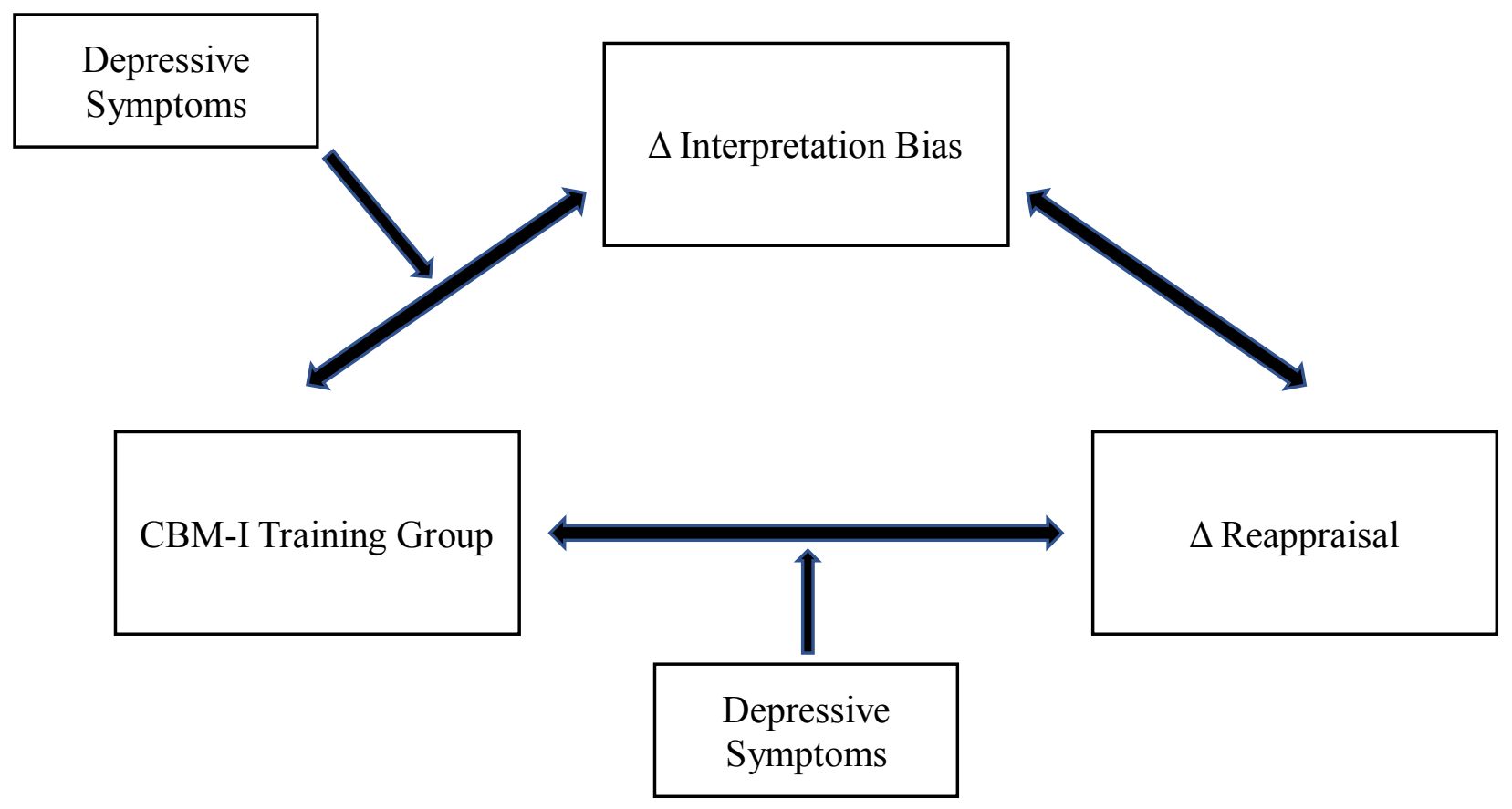

Figure 14. Example mediated moderation and moderated mediation within the same model with reappraisal change as the dependent variable. 
ROLE OF COGNITIVE BIAS IN EMOTION REGULATION

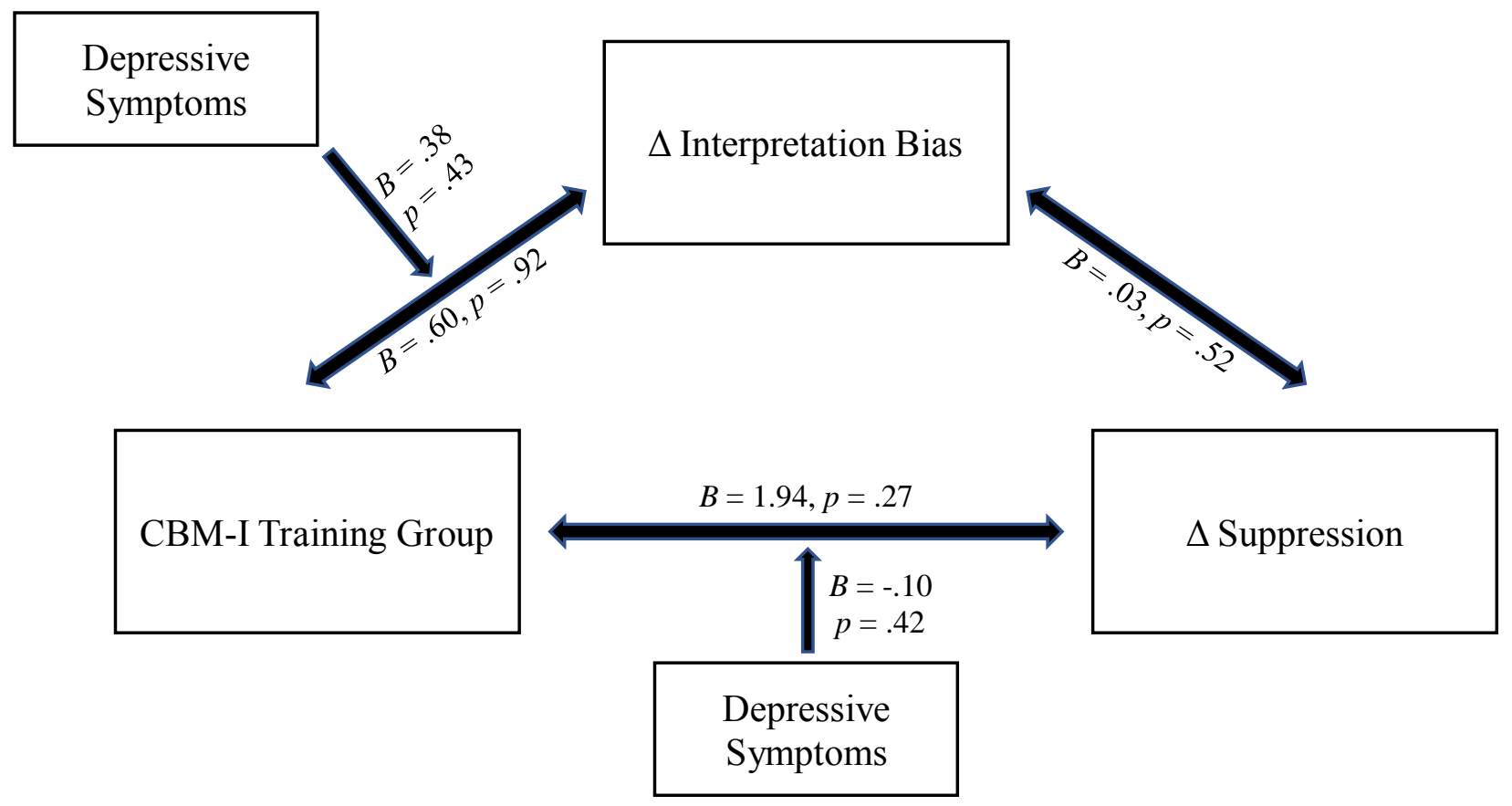

Figure 15. No path is significant. Indirect effect of highest order product of the mediator is .01, $S E=.04, \mathrm{BC} 95 \% \mathrm{CI}[-.03, .14]$ 


\section{ROLE OF COGNITIVE BIAS IN EMOTION REGULATION}

Is attentional control a moderator? To assess whether attentional control moderated the relationship between group and interpretation bias change, three moderated regression analyses were planned using the Hayes PROCESS marco model 1 (Hayes, 2014): with interpretation bias change as the dependent variable, group as the independent variable, and attentional control (ACS total score), attentional focusing (ACS focusing subscale), and attentional shifting (ACS shifting subscale) as moderators in each model. The assumptions of multicollinearity were met based on an examination of VIF scores (i.e., no VIF values were greater than 2). The option for heteroscedasticity-consistent standard errors was used in all analyses.

The test of the model revealed that attentional focusing significantly moderated the relationship between group and interpretation bias change, and attentional focusing was a significant predictor of interpretation bias change (see Table 8). Though the regression model was not significant, $F(3,59)=2.47, p=.07, R^{2}=.09$, the addition of the interaction term explained an additional $5 \%$ of the variance in the model $(p=.05)$. For individuals with above average attentional focusing ability (1 standard deviation above the mean), group was significantly related to interpretation bias change, $B=11.37, S E=5.21, p=.03$ (see Figure 16). In the positive group interpretation bias became more positive following training regardless of attentional focusing ability: whereas in the negative group interpretation bias became more positive following training for those individuals with below average attentional focusing ability, and slightly more negative following training only for those individuals with above average attentional focusing ability. 
ROLE OF COGNITIVE BIAS IN EMOTION REGULATION

Table 8

Results of Moderated Model for Interpretation Bias Change

\begin{tabular}{lllll}
\hline \multicolumn{1}{c}{ Predictors of Interpretation Bias $\Delta$} & $B$ & $S E$ & $p$ \\
\hline Attentional Focusing & -2.92 & 1.24 & $.02^{\mathrm{a}}$ & \\
Group & -23.63 & 14.18 & .10 & \\
Group X Attentional Focusing & 1.58 & .79 & $.05^{\mathrm{a}}$ & \\
\hline
\end{tabular}

Note. $\mathrm{SE}=$ standard error; $\Delta=$ change. $N=63$

${ }^{a}$ significant at .05 level. 


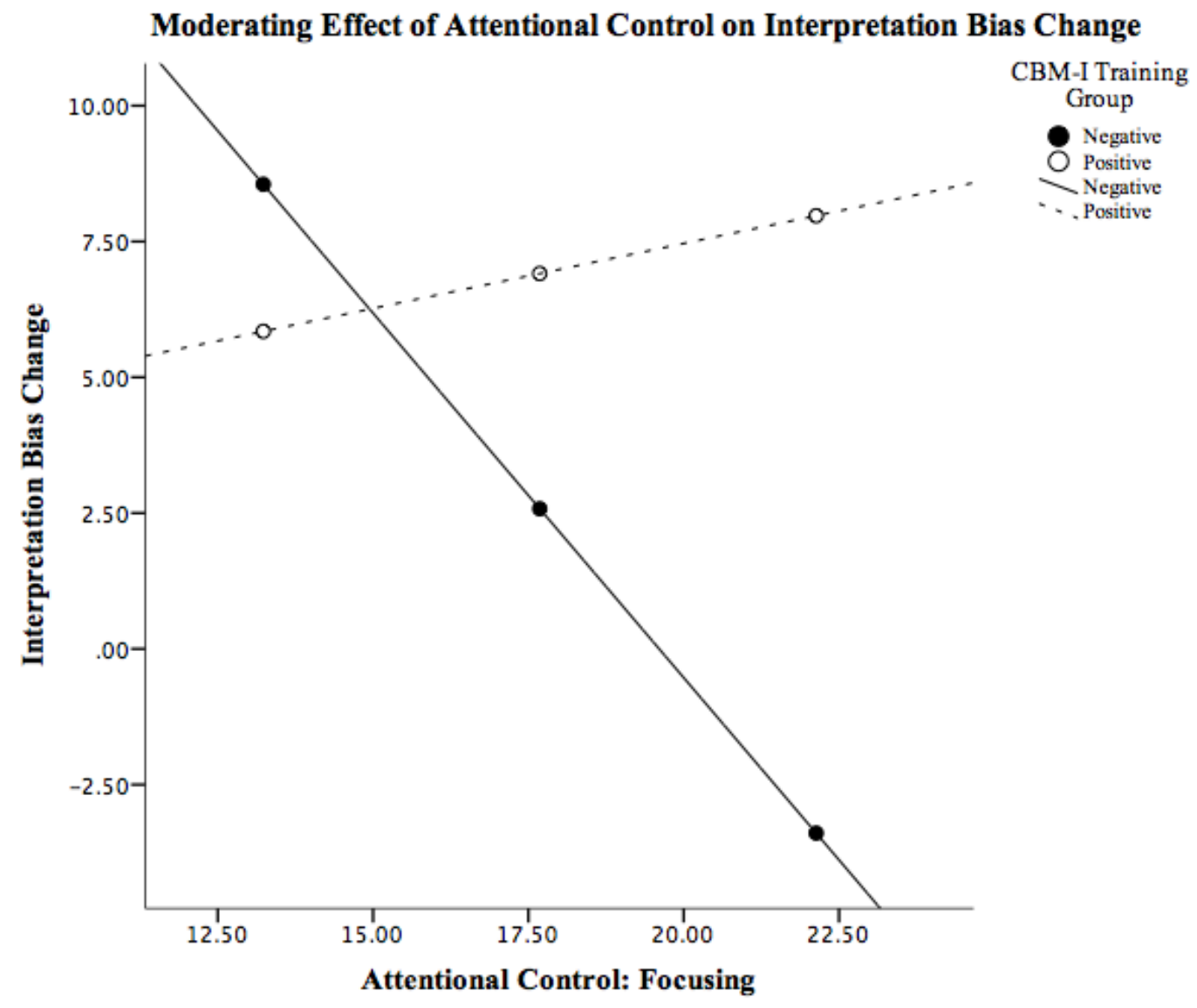

Figure 16. Significant main effects of group and attentional focusing (ACS focusing subscale), and significant group $\mathrm{x}$ attentional focusing interaction for interpretation bias change (AST-D total score centered at 75 posttraining - score pretraining), with $N=63$. 


\section{ROLE OF COGNITIVE BIAS IN EMOTION REGULATION}

Tests of the model revealed that neither total attentional control nor attentional shifting significantly moderated the relationship between group and interpretation bias change (see Figures 17 and 18).

\section{Post Hoc Analyses}

First emotion induction post hoc. The group $\mathrm{x}$ time mixed-ANOVA assessing change in emotion during the first emotion induction revealed a significant main effect of group in addition to a main effect of time. The correlation between depression (DASS-D) and emotion prior to the first emotion induction (VAS score) was assessed to determine whether pre-existing group differences in depression may have accounted for the main effect of group. The correlation was found to be significant, $r=-.44, p<.01$.

To determine whether the amount of emotion change experienced by the negative and positive groups differed, an independent samples t-test was conducted, with amount of emotion change (VAS score pre emotion induction - VAS score post emotion induction) as the dependent variable. The assumption of normality was not met based on the Shapiro-Wilk test $(p=.04)$, so 5000 sample BCa bootstrapping was used for the analysis. The assumption of homogeneity of variance was assessed using Levene's Test for Equality of Variances and was met $(F=.52, p=$ .47). The negative bias training group $(M=17.38, S D=13.61)$ and positive training group $(M=$ $12.38, S D=15.08)$ had a mean difference of $5(\mathrm{BCa} 95 \% \mathrm{CI}[-1.86,11.79])$, which was not a significantly different amount of emotion change on the $100 \mathrm{~mm}$ VAS, $t(62)=1.39, p=.17$.

CBM-I training effectiveness post hoc. The finding that there was no significant group $\mathrm{x}$ time interaction effect of bias training on interpretation bias required further exploration, given that the purpose of the training was different and opposite for each group. Therefore, two separate research questions that required post-hoc investigation were: 1) did the CBM-I training 
ROLE OF COGNITIVE BIAS IN EMOTION REGULATION

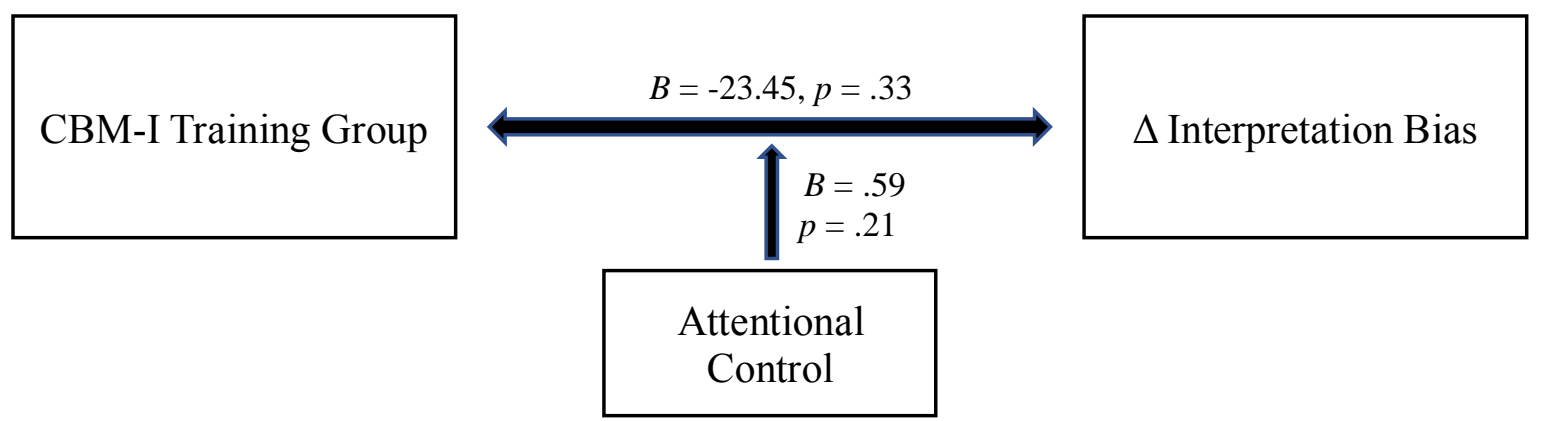

Figure 17. Moderated regression model for interpretation bias change with attentional control (ACS total score) as the moderator. No path is significant. 
ROLE OF COGNITIVE BIAS IN EMOTION REGULATION

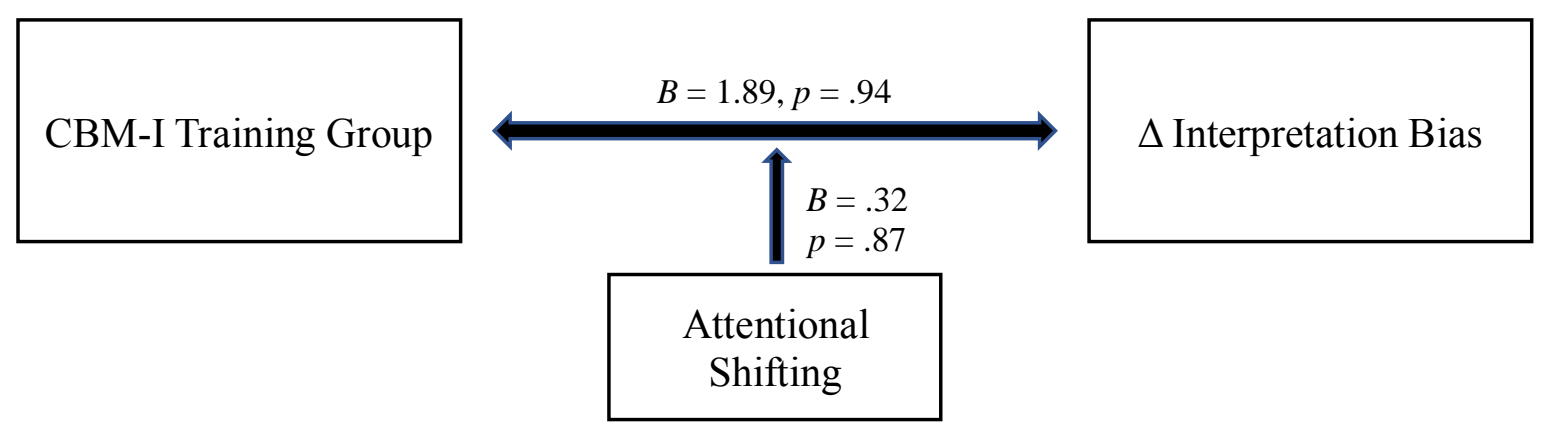

Figure 18. Moderated regression model for interpretation bias change with attentional shifting (ACS shifting subscale) as the moderator. No path is significant. 


\section{ROLE OF COGNITIVE BIAS IN EMOTION REGULATION}

have the intended effect in the positive group (i.e., was the level of bias different before and after training for the positive group), and 2) did the CBM-I training have the intended effect in the negative group (i.e. was the level of bias different before and after training for the negative group).

As such, two separate paired samples t-tests were used to assess whether the bias training worked in making interpretation bias (AST-D scores) more positive following training for the positive group and more negative for the negative group. Based on the Shapiro-Wilk test, the assumption of normality of differences was met for both the negative $(p=.12)$ and positive $(p=$ .16) groups, and a visual examination of box-plots revealed one outlier in the negative group which was excluded from the analyses. For the positive group, the paired samples t-test revealed a significant difference in interpretation bias before $(M=93.00, S D=18.56)$ and after $(M=$ $100.19, S D=14.68)$ the training, $t(30)=-2.33, p=.03$. For the negative group, the paired samples t-test revealed no significant difference in interpretation bias before $(M=90.19, S D=$ 15.74) and after $(M=92.81, S D=15.82)$ the training, $t(31)=-1.36, p=.18$.

\section{Discussion}

\section{Primary Aim: Effectiveness of CBM-I}

This study tested whether interpretation bias interferes with the use of helpful emotion regulation strategies by experimentally manipulating the bias in a positive or negative direction; the interpretation bias training succeeded in inducing bias change only for the positive training group. It was hypothesized that participants in the negative group would be trained to have more negative interpretations and the positive training would result in more positive interpretations. Given that this was true for only one group (i.e., as revealed in post hoc analyses), we focus our discussion on the potential explanations herein. 


\section{ROLE OF COGNITIVE BIAS IN EMOTION REGULATION}

There are several plausible explanations for why the training did not have the desired effect for the negative group. First, it is possible one session of imagery-based bias training was insufficient to induce a negative bias in this population. Most of the literature on the effectiveness of CBM-I focuses specifically on training a more positive bias (Holmes et al., 2006; Rohrbacher et al., 2014), often over multiple sessions (Blackwell et al., 2015; Bowler et al., 2012; Williams et al., 2013). To date, no experiments that compare a negative and positive training group have used an imagery-based paradigm like the one in the present study. Rather, visual training paradigms that lack an imagery component have typically been used (MenneLothman et al., 2014). Moreover, while some studies have found group differences in interpretation bias posttraining, these studies only had one assessment point for interpretation bias, thereby preventing examination of any within group effects of training (Mackintosh et al., 2006; Telman et al., 2013; Yiend et al., 2005). Standage and colleagues (2010) improved upon this limitation by examining within-group differences in interpretation bias as measured by the Scrambled Sentences Task (SST). Though they found the training effective for both groups when interpretation bias was tested under a cognitive load, all sentences on the SST were relevant to social anxiety, whereas the interpretation bias measure in this study assessed depressotypic interpretations (Rohrbacher \& Reinecke, 2014). No previous literature has employed the same methodology as the present study. As such, it is possible single-session imagery-based bias training may not be enough to make interpretations more negative in a normative student population. To better understand why this would be the case for negative bias training, but not positive training, several other studies are discussed.

Three studies employing single-session visual bias training with two assessment points had findings similar to those of the present study. All three found no interpretation style changes 


\section{ROLE OF COGNITIVE BIAS IN EMOTION REGULATION}

in the negative groups, whereas the positive groups made either faster or more adaptive interpretations posttraining (AlMoghrabi, Huijding, \& Franken, 2018; Möbius et al., 2015;

Peters, Constans, \& Mathews, 2011). Möbius and colleagues argued that negative bias training may contrast the natural interpretation tendencies of healthy individuals and provoke reactance (2015). Reactance is a human response to perceived threat to one's freedoms that leads to motivation to restore that freedom (Brehm, 1966). Within psychological experiments, this can lead to the opposite of the manipulation's intended effect and occurs automatically when participants become aware of the circumstances of the experiment (Fulcher \& Hammerl, 2005). Similarly, AlMoghrabi and colleagues (2018) examined the number of training errors made by each group and postulated that some participants in the negative group were actively choosing benign interpretations and resisting training. In the present study, participants were healthy nondepressed individuals and had benign interpretation tendencies at the outset of the experiment (see Table 1 for mean AST-D scores). Therefore, unlike participants in the positive group who were susceptible to the training because imagining positive scenarios did not threaten their positive appraisal style, participants in the negative group may have found continuously generating negative mental imagery inconsistent with their intrinsic benign interpretation style and automatically perceived this as a threat to their freedoms, thereby triggering reactance that would account for the lack of interpretation bias change in the negative group. Interestingly, participants in the negative group had higher self-reported ratings of their ability to follow the instructions for generation of mental imagery, which is consistent with an unconscious and automatic reactance effect. Additionally, our results revealed that participants in the negative group who were less able to maintain attention on their desired focal point experienced a positive change in interpretation bias akin to that in the positive training group, while those with above 


\section{ROLE OF COGNITIVE BIAS IN EMOTION REGULATION}

average attentional ability experienced a very small negative effect of training, as was originally expected (see Figure 16). Given this, some participants in the negative group may have experienced reactance and unconsciously resisted the effects of a training toward an interpretation style that is incongruent with their own - whereas participants with above average attentional focusing abilities were able to maintain their attention on the training and experienced some expected negative training effects.

Another possibility is that negative interpretation bias can only be detected when assessed under cognitive load. While the interpretation bias measure used in the present study (AST-D) was developed to assess for self-reported interpretation bias outside of a cognitive load condition, Rude and colleagues (2003) found that negative interpretation bias could only be assessed by the SST (i.e., an implicit measure of interpretation bias) when under cognitive load. This finding is consistent with Wenzlaff and Bates' (1998) assertion that individuals with remitted depression actively suppress their negative interpretations through effortful cognitive control. Conceivably, interpretation bias changed following negative training but was being actively suppressed by the healthy individuals who did not have initial negative biases, and thus would have emerged only if assessed under cognitive load. As this was not part of the procedures in the present study, it cannot be ruled out and should be assessed in future research.

Finally, it is unlikely that the change in interpretation bias that occurred in the positive group was due solely to a change in emotion, as emotion in the positive group did not change following training (see Figure 9).

Finding no demonstrable training effect in the negative group was unexpected. While the planned analysis found an effect of time and no group by time interaction effect, post hoc analyses revealed an effect of time for the positive group only. One likely explanation for this 


\section{ROLE OF COGNITIVE BIAS IN EMOTION REGULATION}

discrepancy was that the test of the interaction was underpowered (Keppel \& Wickens, 2004). To support this proposition, $\mathrm{G}^{*}$ Power was used to compute the achieved power for the interaction effect $(1-\beta=.38)$. This is much lower than Cohen's suggested $80 \%(1988)$, and it is therefore likely that the mixed-ANOVA did not have enough power to detect the difference in interpretation bias change between the positive and negative groups. The "poor" to "questionable" internal consistencies (George \& Mallery, 2003) of the different subscales and forms making up the measure of interpretation bias were also a concern. Internal consistency assesses the extent to which all items of the scale measure the same underlying construct. Given that the measure of interpretation bias did not demonstrate superior internal consistency in the present sample, it may have inadequately measured participants' depressotypic interpretation tendencies, thus limiting the confidence in the results. After considering the low achieved power of the interaction, substandard psychometric properties of the bias measure, and the contextualization of the present study within past literature's predominant focus solely on positive interpretation bias training, the decision was made to interpret the post hoc analyses and concentrate the discussion on possible explanations for why the bias training had the intended effect for the positive group only.

\section{Secondary Aims: Mediation and Moderation Effects}

The exploration of mediation and moderation discovered no effects between bias change and change in any of the emotion regulation strategies (i.e., reappraisal, rumination, suppression), or between group and emotion regulation. As there was no bias change in the negative group and no significant effect of training on emotion regulation strategies overall, it is not surprising that interpretation bias change did not mediate change in emotion regulation. 


\section{ROLE OF COGNITIVE BIAS IN EMOTION REGULATION}

Three explanations that account for the lack of mediation effects include: 1) the change in interpretation bias in the positive group was not large enough to alter emotion regulation; 2) the emotion induction used in the present study was not the appropriate task to test emotion regulation strategy use; and 3) interpretation bias change does not truly lead to emotion regulation changes.

First, the interpretation bias increase in the positive group only had a small to medium effect $(d=-.44)$ based on Cohen's interpretation (1988). This may not be a large enough change in interpretation bias to elicit subsequent changes in emotion regulation responding.

The second possibility is that the emotion induction task (i.e., Autobiographical Emotion Regulation Task-AERT) was not able to spontaneously elicit emotion regulation in a manner that interpretation bias would affect. The goal of the modified emotion induction task was to induce negative emotion by having participants remember an ambiguous negative memory. However, the issue lies in a memory being both negative and ambiguous. As this has never been done in previous research, it is possible participants were either unable to think of such a memory or were overly focused on their original negative interpretation of the situation. Interestingly, a meta-analysis found that bias training paradigms do not decrease reactivity to stressors (Menne-Lothman et al., 2014). By examining the variety of stress induction methods employed in various studies (e.g., videos of accidents, unsolvable anagrams, negative mood inductions), the authors concluded "emotional challenges currently employed [are] arguably not the most suitable for assessment of the more subtle effects of interpretation biases on negative mood-reactivity as the reaction to these stressors are not under the direct influence of interpretation biases" (Menne-Lothman et al., 2014, p.21). Although the present study attempted to circumvent this issue by deliberately creating an ambiguous and self-referent negative 


\section{ROLE OF COGNITIVE BIAS IN EMOTION REGULATION}

emotion induction so as to elicit spontaneous emotion regulation, it may have failed in artificially creating a situation that was under the purview of interpretation bias.

Finally, interpretation bias may have no role in emotion regulation. However, given the cross-sectional research suggesting interpretation bias predicts use of reappraisal and rumination (Everaert et al., 2017), in addition to the integration of emotion and cognitive theories outlined earlier, the two preceding explanations are more parsimonious.

\section{Minor Aims}

This study also explored a number of minor aims, namely: 1) replicating past findings that depressive symptoms are positively correlated with rumination and suppression and negatively correlated with reappraisal; 2) providing validity data for the use of the emotion induction in the present study (AERT) in research assessing spontaneous emotion regulation; 3) determining whether attentional control moderates the relationship between bias training group and interpretation bias change; and 4) evaluating the psychometric properties of the measure of interpretation bias (AST-D) and emotion regulation strategy questionnaire (SERQ-M) in a Canadian undergraduate population.

Past findings that depressive symptoms positively correlate with various emotion regulation strategies (Joormann \& Stanton, 2016) could not be replicated. The AERT appears to be an appropriate tool for negative emotion induction as it elicited spontaneous emotion regulation and led to an emotion decrease in both groups; however, it is unclear whether it is an appropriate paradigm to assess emotion regulation changes under the influence of interpretation bias. Attentional focusing moderated the relationship between group and interpretation bias change, whereby the negative training had the opposite of the intended effect for participants who were worse at selectively focusing attention. Finally, psychometric properties of the 


\section{ROLE OF COGNITIVE BIAS IN EMOTION REGULATION}

interpretation bias and emotion regulation strategy measures were assessed. Internal consistencies of the parallel forms of the bias measure were "questionable" to "acceptable". The three-factor structure was not supported due to reliabilities ranging from "poor" to “questionable" and the CFA indicating poor fit (De Souza et al., 2017). Nonetheless, interpretation bias correlated most with depressive symptoms, less with anxious symptoms, and did not correlate with stress: as expected given the role of interpretation bias as a factor in both depression and anxiety (Mathews \& Mackintosh, 2000; Wisco \& Nolen-Hoeksema, 2010). Interpretation bias also correlated with attentional shifting, a finding consistent with the combined cognitive bias hypothesis (Everaert et al., 2014). Internal consistency for the emotion regulation measure was good for suppression and distraction, adequate for reappraisal, and poor for rumination. The 4-subscale structure had adequate to good fit, with all factor loadings greater than .3 (De Souza et al., 2017). Adaptive strategies (i.e., reappraisal and distraction) correlated with adaptive facets of emotion regulation (i.e., awareness of emotions), and unhelpful strategies (i.e., suppression and rumination) correlated with emotion dysregulation (i.e., non-acceptance of emotions, difficulties modulating responses, overall emotion dysregulation; see Table 4), consistent with previous research (Joormann \& D’Avanzato, 2010).

\section{Limitations and Future Directions}

Some potential limitations can be identified for the present study. First, since post hoc analyses showed the interaction effect lacked power, it is possible the sample size was also too small to find mediation effects of interpretation bias change. Second, results indicated that random assignment to groups failed in ensuring group equivalence for depressive symptoms, attentional shifting ability, and total attentional control, making it is possible that because the positive group was less depressed and had better attentional control, this impacted how they 


\section{ROLE OF COGNITIVE BIAS IN EMOTION REGULATION}

responded to the bias training and accounted for some of the results. Nonetheless, Strube (1991) argued it is unlikely for nonequivalence of groups to lead to faulty inferences about the efficacy of an intervention as 1) the difference between groups would have to be quite large, and 2) low power (a limitation in the present study) prevents detection of small to moderate false treatment effects. This study also did not have a neutral control group, which could have helped determine whether the negative training was ineffective or whether participants in the negative group were resisting it in some way, while also helping to rule out maturation and testing effects. In addition, issues arose with regard to difficulties understanding the instructions for selecting negative memories and generating imagery for some participants. The psychometric findings could relate to a lack of motivation in the present population, or a fault with the task descriptions. Moreover, the present study did not have measures of trait emotion regulation or attention bias, both of which could have helped to further explore the present findings. Finally, the low reliabilities of the interpretation bias and emotion regulation measures indicate variability in participants' answers, leaving a certain level of doubt about whether the underlying constructs of reappraisal, rumination, and interpretation bias were accurately captured.

There are several suggestions for future research that stem from the limitations in the present study. Since the autobiographical emotion induction task was uniquely modified for the present study, the instructions should be validated in future research and its utility for measuring emotion regulation under the influence of interpretation bias evaluated, by comparing it against a simulated ambiguous confederate situation. Based on the findings of this study, further psychometric work is necessary to improve the interpretation bias measure and the emotion regulation questionnaire's rumination subscale. 


\section{ROLE OF COGNITIVE BIAS IN EMOTION REGULATION}

Another important step to progress the state of the research would involve an examination of changes in trait emotion regulation following a longer period of interpretation bias training. It is proposed that future studies compare a positive bias training to a neutral control group over the span of one week. One recent meta-analysis found significant positive change in emotion in the neutral condition, indicating that it was not truly a control condition like a no-training condition (Menne-Lothman et al., 2014). Indeed, Krahé and colleagues (2016) noted that several past studies of multisession bias training found reductions in negative interpretation bias following both positive and neutral training (50\% positive, $50 \%$ negative scenarios), and proposed an alternative active control condition involving generation of imagery without resolution of ambiguity. Similarly, we propose that future research should include a neutral control group that imagines scenarios beginning ambiguously without any conclusion, either negative or positive. Depressive symptoms should also be assessed throughout the week to be able to determine whether subsequent changes in emotion regulation strategy use result from changes in interpretation bias or depressive symptoms. Additionally, depressive symptoms should be analyzed as a moderator, due to possible ceiling effects of emotion regulation strategy change in those with a benign interpretation bias at the outset of the study. This research would build upon the present study by allowing stronger inferences to be made about the application of cognitive-emotional theory to emotion regulation in everyday life. Moreover, multiple sessions of bias training would allow for participants to practice their novel positive interpretations between sessions to further consolidate learning, potentially leading to stronger changes in interpretation bias (Mobini, Reynolds, \& Mackintosh, 2013). Under these conditions, greater change in interpretation bias would likely lead to greater changes in emotion regulation. 


\section{ROLE OF COGNITIVE BIAS IN EMOTION REGULATION}

In sum, this study found evidence for training a positive interpretation bias only, in single-session imagery-based bias training. The present study was the first to show that automatic interpretation biases can be made more benign in students with a range of depressive symptoms after only one session of imagery-based training. There were several explanations for the failure to find a similar result for the negative group. As such, future studies should address these methodological issues to explore the relationship between bias and emotion regulation. Building upon the present study through the additive effects of a week-long interpretation bias training would shed light on the underlying mechanisms of problematic emotion regulation strategy selection in individuals with depressive symptoms. It would also have the benefit of evaluating the effectiveness of interpretation bias training on depressive symptoms in a nondepressed population, thus helping to optimize this approach for future clinical use as an adjunct intervention. 


\title{
ROLE OF COGNITIVE BIAS IN EMOTION REGULATION
}

\author{
Appendix A \\ Attentional Control Scale
}

Please rate the following questions on a scale from 1 (almost never), 2 (sometimes), 3 (often), and 4 (always).

1. It's very hard for me to concentrate on a difficult task when there are noises around

2. When I need to concentrate and solve a problem, I have trouble focusing my attention

3. When I am working hard on something, I still get distracted by events around me

4. My concentration is good even if there is music in the room around me

5. When concentrating, I can focus my attention so that I become unaware of what's going on in the room around me

6. When I am reading or studying, I am easily distracted if there are people talking in the same room

7. When trying to focus my attention on something, I have difficulty blocking out distracting thoughts

8. I have a hard time concentrating when I'm excited about something

9. When concentrating I ignore feelings of hunger or thirst

10. I can quickly switch from one task to another

11. It takes me a while to get really involved in a new task

12. It is difficult for me to co-ordinate my attention between the listening and writing required when taking notes during lectures

13. I can become interested in a new topic very quickly when I need to

14. It is easy for me to read or write while I'm also talking on the phone

15. I have trouble carrying on two conversations at once 


\section{ROLE OF COGNITIVE BIAS IN EMOTION REGULATION}

16. I have a hard time coming up with new ideas quickly

17. After being interrupted or distracted, I can easily shift my attention back to what I was doing before

18. When a distracting thought comes to mind, it is easy for me to shift my attention away from it

19. It is easy for me to alternate between two different tasks

20. It is hard for me to break from one way of thinking about something and look at it from another point of view

Reverse code items: 1, 2, 3, 6, 7, 8, 11, 12, 15, 16, and 20.

Focusing: 1, 2, 3, 6, 7, 8, 12.

Shifting: 10, 13, 17, 18, 19. 


\section{ROLE OF COGNITIVE BIAS IN EMOTION REGULATION}

\section{Appendix B}

\section{Ambiguous Scenarios Test}

Participants are asked to indicate their answers using an 11-point scale anchored from (-5) very unpleasant to $(+5)$ very pleasant.

1. As you enter the room, the commission welcomes you and begins with the oral examination. After just a few minutes you know intuitively how the examination will go.

2. At the company you are working for there have been big cut-backs. One day you are called in to see your boss. When you enter the room, the boss' face is tired.

3. You are interested in a job, but think you might be under-qualified and so ask for details. When you speak to the people, you realize what your chances are to get the job.

4. You are camping in a forest and are very cold. You decide to light a fire. The flames grow in intensity much faster than you imagined.

5. You are going to see a very good friend at the station. You have not seen them for years. You feel emotional, thinking about how much they might have changed.

6. You are hosting a dinner party for 10 people and got pretty stressed out while preparing the food. You can tell from the initial reaction of the guests how they like the food.

7. It is an overcast day and you are sitting on the beach. You look up to notice the weather really beginning to change.

8. Your partner asks you to buy a present for his/her sister's birthday as he/she is busy. When the sister opens it, her face shows you how she feels.

9. On a rainy Sunday, you let your thoughts wander freely. Many memories come back...

10. Your best friend convinces you to go on a blind date and as you sit in the bar waiting to meet your date, you think about how it will go. 


\section{ROLE OF COGNITIVE BIAS IN EMOTION REGULATION}

11. You give a speech at your friend's wedding. When you have finished, you observe the audience's reaction.

12. Some important people are visiting the office and you are asked at the last minute to present a project to them. Afterwards, you get feedback on your performance.

13. You are in a reflective mood and think back at past achievements and disappointments that you have experienced during your life. Overall, your main feelings about your life so far emerge.

14. You are going to see your sister in her school play. You have left it to the last minute to get there. As you drive up to the school and see the parking bays you anticipate the time it will take you to arrive.

15. You go to a wedding where you know very few other guests. After the party, you reflect on how the other guests behaved.

16. You are starting a new job that you very much want. You think about what it will be like.

17. Your next birthday is approaching soon. You reflect about your life so far.

18. Your friend is very keen on skating and persuades you to try it out. At the rink you put on the skates and step on the ice. You glide forward, slowly at first, then faster.

19. As you walk into the interview room, the panel of interviewers welcomes you and proceeds to ask some tough questions. By the end of the interview, you know what the outcome is.

20. You are a passionate hobby photographer and wonder, if you could publish a photo book. A friend of yours, who works for a publishing company, tells you what she thinks about this idea.

21. You go to a place you visited as a child. Walking around makes you feel emotional.

22. The probation period at your new job is almost over. You get invited to your boss and 


\section{ROLE OF COGNITIVE BIAS IN EMOTION REGULATION}

receive feedback on how you have done so far.

23. You would love to join a choir and go to an audition. The next day the director of the choir calls you on the phone to tell you if you can join the choir.

24. You want to refresh your Italian language skills und enrol for an advanced-level language course. The teacher, however, would like to give a placement test first.

25. It is the end of December. You reflect upon the year behind of you.

26. You got invited to a class reunion. That makes you remember your school days...

27. When you clean up the attic, you find some of your old photo albums you have not looked at in a while. You begin to browse...

28. Your colleague just came back from the holidays and tells you enthusiastically about her experiences. While you listen to her, you think of your last vacation.

29. You are organizing the annual office party on a small budget. On the night of the party, you look around to see if people are enjoying themselves.

30. You buy a new outfit for a party. You can tell if you made the right choice by the reaction of the other people.

AST-D-II (A) comprises the items 1, 3, 8, 10, 20, 29 (factor “self"), 9, 17, 27, 28 (factor “experiences") and 4, 5, 14, 15, 22 (factor "future").

AST-D-II (B) comprises the items 6, 11, 12, 23, 24, 30 (factor "self”), 13, 21, 25, 26 (factor “experiences”) and 2, 7, 16, 18, 19 (factor “future”). 


\section{ROLE OF COGNITIVE BIAS IN EMOTION REGULATION}

\section{Appendix C}

\section{State Emotion Regulation Questionnaire}

Instructions: We are interested in how you experience and manage emotions. Below is a list of things that people might think or do when they are reminded of an emotional memory. Using the rating scale below, please indicate the extent to which you agree with the following statements about your experience while viewing the words. Please write the number that corresponds to your response in the blank area to the left of each statement.

\begin{tabular}{|c|c|c|c|c|c|c|}
\hline 1 & 2 & 3 & 4 & 5 & 6 & 7 \\
\hline $\begin{array}{l}\text { Strongly } \\
\text { disagree }\end{array}$ & Neutral & $\begin{array}{r}\text { Strongly } \\
\text { agree }\end{array}$
\end{tabular}

1. I tried not to let my feelings show (SU)

2. I thought about how the words/memory made me feel (RU)

3. I tried to suppress my emotions (SU)

4. I tried to distract myself from the words or emotions of the memory (DI)

5. I thought about the words/memory in a way that helps me to experience less emotion (RE)

6. I thought about something unrelated to the words/memory (DI)

7. I tried to adopt an unemotional attitude towards the words/memory (RE)

8. I thought about how the content of the memory is related to my current life (RU)

9. I tried to keep my emotions to myself (SU)

10. I thought about the words/memory in a way that made me feel neutral (RE)

11. I tried not to think about how the words/memory made me feel (DI)

12. I focused on the emotions I felt at the time of the memory (RU)

13. I changed the way I was thinking about the memory (RE)

14. Other: 
ROLE OF COGNITIVE BIAS IN EMOTION REGULATION

\section{Appendix D}

Manipulation Check Questionnaire

During the last task (listening to scenarios):

1) How difficult or easy did you find your task of listening to the scenarios?

\begin{tabular}{|l|l|l|l|l|l|l|l|l|}
\hline 1 & 2 & 3 & 4 & 5 & 6 & 7 & 8 & 9 \\
\hline
\end{tabular}

Extremely

difficult
Neither easy nor difficult
Extremely easy

2) How much did you find yourself thinking in IMAGES (i.e. in mental pictures and sensory impressions) as you were listening to the scenarios?

\begin{tabular}{|l|l|l|l|l|l|l|l|l|}
\hline 1 & 2 & 3 & 4 & 5 & 6 & 7 & 8 & 9 \\
\hline
\end{tabular}

Not at all

Half the time

All the time

3) How much did you find yourself COMPARING the scenarios with how you are in reality as you were listening to the scenarios?

\begin{tabular}{|l|l|l|l|l|l|l|l|l|}
\hline 1 & 2 & 3 & 4 & 5 & 6 & 7 & 8 & 9 \\
\hline
\end{tabular}

Not at all

Half the time

All the time

4) How much did you find yourself VERBALLY ANALYSING THE MEANING of the scenarios as you were listening to them?

\begin{tabular}{|l|l|l|l|l|l|l|l|l|}
\hline 1 & 2 & 3 & 4 & 5 & 6 & 7 & 8 & 9 \\
\hline
\end{tabular}

Not at all

Half the time

All the time 


\section{ROLE OF COGNITIVE BIAS IN EMOTION REGULATION}

5) How much were you imagining the situation from a BYSTANDER'S POINT OF VIEW (i.e. watching the situation happening to yourself, from the outside) as you were listening to the sentences?

\begin{tabular}{|l|l|l|l|l|l|l|l|l|}
\hline 1 & 2 & 3 & 4 & 5 & 6 & 7 & 8 & 9 \\
\hline
\end{tabular}

Not at all

Half the time

All the time

6) How much were you imagining the situations from THROUGH YOUR OWN EYES, AS IF ACTIVELY INVOLVED (i.e. from a personal point of view) as you were listening to the scenarios?

\begin{tabular}{|l|l|l|l|l|l|l|l|l|}
\hline 1 & 2 & 3 & 4 & 5 & 6 & 7 & 8 & 9 \\
\hline
\end{tabular}

Not at all

Half the time

All the time

7) How much of the time did you find it difficult to focus on your task, i.e. your attention wandered and you found it difficult to concentrate?

\begin{tabular}{|l|l|l|l|l|l|l|l|l|}
\hline 1 & 2 & 3 & 4 & 5 & 6 & 7 & 8 & 9 \\
\hline
\end{tabular}

Not at all

Half the time

All the time

8) How personally relevant were the scenarios you listened to?

\begin{tabular}{|l|l|l|l|l|l|l|l|l|}
\hline 1 & 2 & 3 & 4 & 5 & 6 & 7 & 8 & 9 \\
\hline
\end{tabular}

Not at all

Half the time

All the time 


\section{ROLE OF COGNITIVE BIAS IN EMOTION REGULATION}

\section{References}

Ahearn, E. P. (1997). The use of visual analog scales in mood disorders: A critical review. Journal of Psychiatric Research, 31, 569-579. doi:10.1016/S0022-3956(97)00029-0

Allison, P. D. (1990). Change scores as dependent variables in regression analysis. Sociological Methodology, 20, 93-114.

Alloy, L. B. (1991). Depression and anxiety: Disorders of emotion or cognition? Psychological Inquiry, 2, 72-74. doi:10.1207/s15327965pli0201_16

AlMoghrabi, N., Huijding, J., \& Franken, I. H. A. (2018). The effects of a novel hostile interpretation bias modification paradigm on hostile interpretations, mood, and aggressive behavior. Journal of Behavior Therapy and Experimental Psychiatry, 58, 3642.

American Psychiatric Association. (2013). Diagnostic and statistical manual of mental disorders (5th ed.). Arlington, VA: American Psychiatric Association.

Antony, M. M., Bieling, P. J., Cox, B. J., Enns, M. W., \& Swinson, R. P. (1998). Psychometric properties of the 42-item and 21-item versions of the depression anxiety stress scales in clinical groups and a community sample. Psychological Assessment, 10, 176-181. doi:10.1037/1040-3590.10.2.176

Beck, A. T. (1963). Thinking and depression: I. Idiosyncratic content and cognitive distortions. Archives of General Psychiatry, 9, 324-333.

Beck, A. T. (1964). Thinking and depression: II. Theory and therapy. Archives of General Psychiatry, 10, 561-571.

Beck, A. T. (1967). Depression: Causes and treatment. Philadelphia, PA: University of Pennsylvania Press. 


\section{ROLE OF COGNITIVE BIAS IN EMOTION REGULATION}

Beck, A. T., Rush, A. J., Shaw, B. F., \& Emery, G. (1979). Cognitive therapy for depression. New York, NY: The Guilford Press.

Beevers, C. G. (2005). Cognitive vulnerability to depression: A dual process model. Clinical Psychology Review, 25, 975-1002. doi:10.1016/j.cpr.2005.03.003

Berna, C., Lang, T. J., Goodwin, G. M., \& Holmes, E. A. (2011). Developing a measure of interpretation bias for depressed mood: An ambiguous scenarios test. Personality and Individual Differences, 51, 349- 354. doi:10.1016/j.paid.2011.04.005

Blackwell, S. E., Browning, M., Mathews, A., Pictet, A., Welch, J., Davies, J., . . Holmes, E. A. (2015). Positive imagery-based cognitive bias modification as a web-based treatment tool for depressed adults: A randomized controlled trial. Clinical Psychological Science, 3, 91-111. doi:10.1177/2167702614560746

Blackwell, S. E., \& Holmes, E. A. (2010). Modifying interpretation and imagination in clinical depression: A single case series using cognitive bias modification. Applied Cognitive Psychology, 24, 338-350. doi: 10.1002/acp.1680

Böckenholt, U. (2016). Measuring response styles in Likert items. Psychological Methods, 22, 69-83. doi:10.1037/met0000106

Bowler, J. O., Mackintosh, B., Dunn, B. D., Mathews, A., Dalgleish, T., \& Hoppitt, L. (2012). A comparison of cognitive bias modification for interpretation and computerized cognitive behavior therapy: Effects on anxiety, depression, attentional control, and interpretive bias. Journal of Consulting and Clinical Psychology, 80, 1021-1033.

doi:10.1037/a0029932 


\section{ROLE OF COGNITIVE BIAS IN EMOTION REGULATION}

Bredemeier, K., Berenbaum, H., Brockmole, J. R., Boot, W. R., Simons, D. J., \& Most, S. B. (2012). A load on my mind: Evidence that anhedonic depression is like multi-tasking. Acta Psychologica, 139, 137-145. doi:10.1016/j.actpsy.2011.11.007

Brehm, J. W. 1966). A theory of psychological reactance. New York: Academic Press.

Butler, G., \& Mathews, A. (1983). Cognitive processes in anxiety. Advances in Behaviour Research and Therapy, 5, 51-62. doi:10.1016/0146-6402(83)90015-2

Cohen J. (1988). Statistical Power Analysis for the Behavioral Sciences. New York, NY: Routledge Academic.

Cowden Hindash, A. H., \& Amir, N. (2012). Negative interpretation bias in individuals with depressive symptoms. Cognitive Therapy and Research, 36, 502-511. doi:10.1007/s10608-011-9397-4

Cowden Hindash, A. H., \& Rottenberg, J. (2017). Turning quickly on myself: Automatic interpretation biases in dysphoria are self-referent. Cognition and Emotion, 31, 395-402. doi:10.1080/02699931.2015.1105792

De Souza, A.C., Alexandre, N.M., \& Guirardello, E. (2017). Psychometric properties in instruments evaluation of reliability and validity. Epidemiologia e Serviços de Saúde, 26, 649-659.

Derryberry, D., \& Reed, M. A. (2002). Anxiety-related attentional biases and their regulation by attentional control. Journal of Abnormal Psychology, 111, 225-236. doi:10.1037//0021843X.111.2.225

Diamond, A. (2013). Executive functions. Annual Review of Psychology, 64, 135-168. doi:10.1146/annurev-psych-113011-143750 


\section{ROLE OF COGNITIVE BIAS IN EMOTION REGULATION}

Egloff, B., Schmukle, S. C., Burns, L. R., \& Schwerdtfeger, A. (2006). Spontaneous emotion regulation during evaluated speaking tasks: Associations with negative affect, anxiety expression, memory, and physiological responding. Emotion, 6, 356-366. doi:10.1037/1528-3542.6.3.356

Ehring, T., Tuschen-Caffier, B., Schnülle, J., Fischer, S., \& Gross, J. J. (2010). Emotion regulation and vulnerability to depression: Spontaneous versus instructed use of emotion suppression and reappraisal. Emotion, 10, 563-572. doi:10.1037/a0019010

Eisenberg, D., Gollust, S. E., Golberstein, E., \& Hefner, J. L. (2007). Prevalence and correlates of depression, anxiety, and suicidality among university students. American Journal of Orthopsychiatry, 77, 534-542. doi:10.1037/0002-9432.77.4.534

Ellis, H. C., Ottaway, S. A., Varner, L. J., Becker, A. S., \& Moore, B. A. (1997). Emotion, motivation, and text comprehension: The detection of contradictions in passages. Journal of Experimental Psychology: General, 126, 131-146. doi:10.1037/0096-3445.126.2.131

Everaert, J., Duyck, W., \& Koster, E. H. W. (2014). Attention, interpretation, and memory biases in subclinical depression: A proof-of-principle test of the combined cognitive biases hypothesis. Emotion, 14, 331-340. doi:10.1037/a0035250

Everaert, J., Grahek, I., Duyck, W., Buelens, J., Van den Bergh, N., \& Koster, E. H. W. (2017). Mapping the interplay among cognitive biases, emotion regulation, and depressive symptoms. Cognition and Emotion, 31, 726-735. doi:10.1080/02699931.2016.1144561

Field, A. P. (2013). Discovering statistics using IBM SPSS statistics: And sex and drugs and rock 'n' roll, $4^{\text {th }}$ edition. Los Angeles, CA: SAGE. 


\section{ROLE OF COGNITIVE BIAS IN EMOTION REGULATION}

Fulcher, E. P., \& Hammerl, M. (2005). Reactance in affective-evaluative learning: Outside of conscious control? Cognition and Emotion, 19, 197-216. doi:10.1080/02699930441000283

George, D., \& Mallery, P. (2003). SPSS for Windows step by step: A simple guide and reference. 11.0 update (4th ed.). Boston: Allyn \& Bacon.

Gotlib, I. H., \& Joormann, J. (2010). Cognition and depression: Current status and future directions. Annual Review of Clinical Psychology, 6, 285-312. doi:10.1146/annurev.clinpsy.121208.131305

Gratz, K. L., \& Roemer, L. (2004). Multidimensional assessment of emotion regulation and dysregulation: Development, factor structure, and initial validation of the difficulties in emotion regulation scale. Journal of Psychopathology and Behavioral Assessment, 26, 41-54. doi:10.1023/B:JOBA.0000007455.08539.94

Gross, J. J., \& John, O. P. (2003). Individual differences in two emotion regulation processes: Implications for affect, relationships, and well-being. Journal of Personality and Social Psychology, 85, 348-362. doi:10.1037/0022-3514.85.2.348

Gross, J. J., \& Thompson, R. A. (2007). Emotion regulation: Conceptual foundations. In J. J. Gross (Ed.), Handbook of emotion regulation (pp. 3-24). New York, NY: Guilford Press.

Gross, J.J. (2010). Emotion Regulation. In M. Lewis, J.M. Haviland-Jones, \& L.F. Barrett (Eds.), Handbook of emotions (pp. 497-512). New York, NY: The Guilford Press.

Hayes, A. F. (2014). Introduction to mediation, moderation, and conditional process analysis: a regression-based approach. Retrieved from http://ebookcentral.proquest.com.ezproxy.lib.ryerson.ca 


\section{ROLE OF COGNITIVE BIAS IN EMOTION REGULATION}

Hedlund, S., \& Rude, S.S. (1995). Evidence of latent depressive schemas in formerly depressed individuals. Journal of Abnormal Psychology, 104, 517-525. doi:10.1037/0021843X.104.3.517

Hertel, P. T., \& El-Messidi, L. (2006). Am I blue? depressed mood and the consequences of selffocus for the interpretation and recall of ambiguous words. Behavior Therapy, 37, 259268. doi:10.1016/j.beth.2006.01.003

Holmes, E. A., Mathews, A., Dalgleish, T., \& Mackintosh, B. (2006). Positive interpretation training: Effects of mental imagery versus verbal training on positive mood. Behavior Therapy, 37, 237-247. doi:10.1016/j.beth.2006.02.002

Hume, D. (2008). Emotions and moods. In S.P. Robbins \& T.A. Judge (Eds.), Organizational behavior (258-297). Upper Saddle River, NJ: Prentice Hall.

Joormann, J., \& D'Avanzato, C. (2010). Emotion regulation in depression: Examining the role of cognitive processes: Cognition \& emotion lecture at the 2009 ISRE meeting. Cognition and Emotion, 24, 913-939. doi:10.1080/02699931003784939

Joormann, J., \& Siemer, M. (2011). Affective processing and emotion regulation in dysphoria and depression: Cognitive biases and deficits in cognitive control. Social and Personality Psychology Compass, 5, 13-28. doi:10.1111/j.1751-9004.2010.00335.x

Joormann, J., \& Stanton, C. H. (2016). Examining emotion regulation in depression: A review and future directions. Behaviour Research and Therapy, 86, 35-49. doi:10.1016/j.brat.2016.07.007

Judah, M. R., Grant, D. M., Mills, A. C., \& Lechner, W. V. (2014). Factor structure and validation of the attentional control scale. Cognition and Emotion, 28, 433-451. doi:10.1080/02699931.2013.835254 


\section{ROLE OF COGNITIVE BIAS IN EMOTION REGULATION}

Just Instrumental Music (2017, Oct 9). Mozart Classical Music for Studying, Concentration, Relaxation | Study Music | Piano Instrumental. [Video file]. Retreived from https://www.youtube.com/watch?v=VB6SIK18Md0\&t=233s

Kadison, R.D. (2004). The mental-health crisis: What colleges must do. The Chronicle of Higher Education, 51(16), B.20.

Keppel, G., \& Wickens, T.D. (2004). Main effects and simple effects. In Design \& analysis: a researcher's handbook, $4^{\text {th }}$ edition. (pp. 242-264). Upper Saddle River, NJ: Pearson Education, Inc.

Koster, E. H. W., Fox, E., \& MacLeod, C. (2009). Introduction to the special section on cognitive bias modification in emotional disorders. Journal of Abnormal Psychology, 118, 1-4. doi:10.1037/a0014379

Koster, E. H., \& Hoorelbeke, K. (2015). Cognitive bias modification for depression. Current Opinion in Psychology, 4, 119-123. doi:10.1016/j.copsyc.2014.11.012

Krahé, C., Mathews, A., Whyte, J., \& Hirsch, C. R. (2016). Cognitive bias modification for interpretation with and without prior repetitive negative thinking to reduce worry and rumination in generalised anxiety disorder and depression: Protocol for a multisession experimental study with an active control condition. BMJ Open, 6, e013404. doi:10.1136/bmjopen-2016-013404

Lavender, J. M., Tull, M. T., DiLillo, D., Messman-Moore, T., \& Gratz, K. L. (2017). Development and validation of a state-based measure of emotion dysregulation: The state difficulties in emotion regulation scale (S-DERS). Assessment, 24, 197-209. doi:10.1177/1073191115601218 


\section{ROLE OF COGNITIVE BIAS IN EMOTION REGULATION}

Lawson, C., MacLeod, C., \& Hammond, G. (2002). Interpretation revealed in the blink of an eye: Depressive bias in the resolution of ambiguity. Journal of Abnormal Psychology, 111, 321-328. doi:10.1037//0021-843X.111.2.321

Lovibond, S.H. \& Lovibond, P.F. (1995). Manual for the Depression Anxiety Stress Scales. $\left(2^{\text {nd }}\right.$. Ed.) Sydney: Psychology Foundation.

Mackintosh, B., Mathews, A., Yiend, J., Ridgeway, V., \& Cook, E. (2006). Induced biases in emotional interpretation influence stress vulnerability and endure despite changes in context. Behavior Therapy, 37, 209-222. doi:10.1016/j.beth.2006.03.001

MacLeod, C., \& Grafton, B. (2016). Anxiety-linked attentional bias and its modification: Illustrating the importance of distinguishing processes and procedures in experimental psychopathology research. Behaviour Research and Therapy, 86, 68-86. doi:10.1016/j.brat.2016.07.005

Mathews, A., \& Mackintosh, B. (2000). Induced emotional interpretation bias and anxiety. Journal of Abnormal Psychology, 109, 602-615. doi:10.1037/0021-843X.109.4.602

Mauss, I. B., Levenson, R. W., McCarter, L., Wilhelm, F. H., \& Gross, J. J. (2005). The tie that binds? coherence among emotion experience, behavior, and physiology. Emotion, 5, 175190. doi:10.1037/1528-3542.5.2.175

Menne-Lothmann, C., Viechtbauer, W., Hohn, P., Kasanova, Z., Haller, S. P., kker, M., .. . Lau, J. Y. F. (2014). How to boost positive interpretations? A meta-analysis of the effectiveness of cognitive bias modification for interpretation. PLoS One, 9, e100925. doi:10.1371/journal.pone.0100925 


\section{ROLE OF COGNITIVE BIAS IN EMOTION REGULATION}

Mobini, S., Reynolds, S., \& Mackintosh, B. (2013). Clinical implications of cognitive bias modification for interpretative biases in social anxiety: An integrative literature review. Cognitive Therapy and Research, 37, 173-182. doi:10.1007/s10608-012-9445-8

Möbius, M., Tendolkar, I., Lohner, V., Baltussen, M. M. N., \& Becker, E. S. (2015). Refilling the half-empty glass - investigating the potential role of the interpretation modification paradigm for depression (IMP-D). Journal of Behavior Therapy and Experimental Psychiatry, 49, 37-43. doi:10.1016/j.jbtep.2015.03.002

Nolen-Hoeksema, S., Wisco, B. E., \& Lyubomirsky, S. (2008). Rethinking rumination. Perspectives on Psychological Science, 3, 400-424. doi:10.1111/j.17456924.2008.00088.x

North, C. S., Yutzy, S. H., \& Goodwin, D. W. (2010). Goodwin and Guze's psychiatric diagnosis: Carol S. North, Sean H. Yutzy (6th ed.). Oxford; New York: Oxford University Press.

Ólafsson, R. P., Smári, J., Guðmundsdóttir, F., Ólafsdóttir, G., Harðardóttir, H. L., \& Einarsson, S. M. (2011). Self-reported attentional control with the attentional control scale: Factor structure and relationship with symptoms of anxiety and depression. Journal of Anxiety Disorders, 25, 777-782. doi:10.1016/j.janxdis.2011.03.013

Peters, K. D., Constans, J. I., \& Mathews, A. (2011). Experimental modification of attribution processes. Journal of Abnormal Psychology, 120, 168-173. doi:10.1037/a0021899

Pictet, A., Coughtrey, A. E., Mathews, A., \& Holmes, E. A. (2011). Fishing for happiness: The effects of generating positive imagery on mood and behaviour. Behaviour Research and Therapy, 49, 885-891. doi:10.1016/j.brat.2011.10.003 


\section{ROLE OF COGNITIVE BIAS IN EMOTION REGULATION}

Pictet, A., Jermann, F., \& Ceschi, G. (2016). When less could be more: Investigating the effects of a brief internet-based imagery cognitive bias modification intervention in depression. Behaviour Research and Therapy, 84, 45-51. doi:10.1016/j.brat.2016.07.008

Power, M. J., \& Dalgleish, T. (2016). Cognition and emotion: From order to disorder ( $3^{\text {rd }}$ ed.) New York, NY: Psychology Press.

Psychology Software Tools, Inc. [E-Prime 2.0]. (2012). Retrieved from http://www.pstnet.com.

Quigley, L., \& Dobson, K. S. (2014). An examination of trait, spontaneous and instructed emotion regulation in dysphoria. Cognition and Emotion, 28, 622-635. doi:10.1080/02699931.2013.848786

R Core Team (2016). R: A language and environment for statistical computing. R Foundation for Statistical Computing, Vienna, Austria. URL https://www.R-project.org/

Ray, R. D., Wilhelm, F. H., \& Gross, J. J. (2008). All in the mind's eye? anger rumination and reappraisal. Journal of Personality and Social Psychology, 94, 133-145. doi:10.1037/0022-3514.94.1.133

Richards, J. M., \& Gross, J. J. (2000). Emotion regulation and memory: The cognitive costs of keeping one's cool. Journal of Personality and Social Psychology, 79, 410-424. doi:10.1037/0022-3514.79.3.410

Rohrbacher, H., \& Reinecke, A. (2014). Measuring change in depression-related interpretation bias: Development and validation of a parallel ambiguous scenarios test. Cognitive Behaviour Therapy, 43, 239-250. doi:10.1080/16506073.2014.919605

Rohrbacher, H., Blackwell, S. E., Holmes, E. A., \& Reinecke, A. (2014). Optimizing the ingredients for imagery-based interpretation bias modification for depressed mood: Is 


\section{ROLE OF COGNITIVE BIAS IN EMOTION REGULATION}

self-generation more effective than imagination alone? Journal of Affective Disorders, 152-154, 212-218. doi:10.1016/j.jad.2013.09.013

Rude, S. S., Valdez, C. R., Odom, S., \& Ebrahimi, A. (2003). Negative cognitive biases predict subsequent depression. Cognitive Therapy and Research, 27, 415-429. doi:10.1023/A:1025472413805

Rude, S. S., Wenzlaff, R. M., Gibbs, B., Vane, J., \& Whitney, T. (2002). Negative processing biases predict subsequent depressive symptoms. Cognition and Emotion, 16, 423-440. doi:10.1080/02699930143000554

Sainani, K.L. (2012). Dealing with non-normal data. $P M \& R, 4,1001-1005$. doi:10.1016/j.pmrj.2012.10.013

Sanchez, A., Everaert, J., \& Koster, E. H. W. (2016). Attention training through gaze-contingent feedback: Effects on reappraisal and negative emotions. Emotion, 16, 1074-1085. doi:10.1037/emo0000198

Scherer, K. R., \& Shorr, A., \& Johnstone, T. (Ed.). (2001). Appraisal processes in emotion: theory, methods, research. Canary, NC: Oxford University Press.

Schneider, W., \& Chein, J. M. (2003). Controlled \& automatic processing: Behavior, theory, and biological mechanisms. Cognitive Science, 27, 525-559. doi:10.1016/S03640213(03)00011-9

Schoth, D. E., \& Liossi, C. (2017). A systematic review of experimental paradigms for exploring biased interpretation of ambiguous information with emotional and neutral associations. Frontiers in Psychology, 8, 171. doi:10.3389/fpsyg.2017.00171 


\section{ROLE OF COGNITIVE BIAS IN EMOTION REGULATION}

Shrive, F. M., Stuart, H., Quan, H., \& Ghali, W. A. (2006). Dealing with missing data in a multiquestion depression scale: A comparison of imputation methods. BMC Medical Research Methodology, 6, 57-57. doi:10.1186/1471-2288-6-57

Soley-Bori, M. (2013). Dealing with missing data: Key assumptions and methods for applied analysis. (Report No. 4). Boson: Boston University.

Speed, B. C., Levinson, A. R., Gross, J. J., Kiosses, D. N., \& Hajcak, G. (2017). Emotion regulation to idiographic stimuli: Testing the autobiographical emotion regulation task. Neuropsychologia, doi:10.1016/j.neuropsychologia.2017.04.032

Standage, H., Ashwin, C., \& Fox, E. (2010). Is manipulation of mood a critical component of cognitive bias modification procedures? Behaviour Research and Therapy, 48, 4-10. doi:10.1016/j.brat.2009.08.005

Standage, H., Harris, J., \& Fox, E. (2014). The influence of social comparison on cognitive bias modification and emotional vulnerability. Emotion, 14, 170-179. doi:10.1037/a0034226

Strube, M. J. (1991). Small sample failure of random assignment: A further examination. Journal of Consulting and Clinical Psychology, 59, 346-350. doi:10.1037/0022006X.59.2.346

Telman, M. D., Holmes, E. A., \& Lau, J. Y. F. (2013). Modifying adolescent interpretation biases through cognitive training: Effects on negative affect and stress appraisals. Child Psychiatry \& Human Development, 44, 602-611. doi:10.1007/s10578-013-0386-6

Tran, T. B., Hertel, P. T., \& Joormann, J. (2011). Cognitive bias modification: Induced interpretive biases affect memory. Emotion, 11, 145-152. doi:10.1037/a0021754

Volokhov, R. N., \& Demaree, H. A. (2010). Spontaneous emotion regulation to positive and negative stimuli. Brain and Cognition, 73, 1-6. doi:10.1016/j.bandc.2009.10.015 


\section{ROLE OF COGNITIVE BIAS IN EMOTION REGULATION}

Wenzlaff, R. M., \& Bates, D. E. (1998). Unmasking a cognitive vulnerability to depression: How lapses in mental control reveal depressive thinking. Journal of Personality and Social Psychology, 75, 1559-1571. doi:10.1037/0022-3514.75.6.1559

Williams, A. D., Blackwell, S. E., Mackenzie, A., Holmes, E. A., \& Andrews, G. (2013). Combining imagination and reason in the treatment of depression: A randomized controlled trial of internet-based cognitive-bias modification and internet-CBT for depression. Journal of Consulting and Clinical Psychology, 81, 793-799. doi: $10.1037 / \mathrm{a} 0033247$

Williams, J. M. Watts, F. N., Macleod, C., \& Mathews, A. (1988). Cognitive psychology and emotional disorders. New York, NY: John Wiley \& Sons Ltd.

Wisco, B. E. (2009). Depressive cognition: Self-reference and depth of processing. Clinical Psychology Review, 29, 382-392. doi:10.1016/j.cpr.2009.03.003

Wisco, B. E., \& Nolen-Hoeksema, S. (2010). Interpretation bias and depressive symptoms: The role of self-relevance. Behaviour Research and Therapy, 48, 1113-1122. doi:10.1016/j.brat.2010.08.004

World Health Organization. (2008). The global burden of disease: 2004 update. Geneva: Author.

Yiend, J., Mackintosh, B., \& Mathews, A. (2005). Enduring consequences of experimentally induced biases in interpretation. Behaviour Research and Therapy, 43, 779-797. doi:10.1016/j.brat.2004.06.007

Zhang, X., Yu, H. W., \& Barrett, L. F. (2014). How does this make you feel? A comparison of four affect induction procedures. Frontiers in Psychology, 5, 689. doi:10.3389/fpsyg.2014.00689 